\section{Motherhood at Early Bronze Age Unterhautzenthal, Lower Austria}

\author{
Katharina Rebay-Salisbury \\ Doris Pany-Kucera \\ Michaela Spannagl-Steiner \\ Fabian Kanz \\ Patrik Galeta \\ Maria Teschler-Nicola \\ Roderick B. Salisbury
}

\begin{abstract}
This article utilises skeletal evidence $(n=57)$ from settlement features and graves at Unterhautzenthal, Lower Austria, to outline our methodological approach to researching motherhood in prehistory. Unterhautzenthal includes the grave of a pregnant teenager, a triple burial of a woman with two children and a family grave of a man, woman and baby; additional women's graves include remains of neonates and young children. Comparing archaeological context information with osteobiographical data allows us to draw inferences about the social status of women and the ways Bronze Age motherhood was conceptualised. The archaeological approach includes a gender and age analysis of material culture and Social Index calculations. The osteological analyses include age at death, sex, body height, health indicators, and pathologies, with an emphasis on pelvic changes. Physical traces that may relate to strain through pregnancy and childbirth were explored in detail. In addition to morphological assessment of the entire skeletal collection, we applied tooth cementum annulation analysis, ${ }^{14} \mathrm{C}$ dating, and $\delta^{13} \mathrm{C} / \delta^{15} \mathrm{~N}$ isotope analysis to selected individuals. These data, in conjunction with demographic modelling, enable us to draw conclusions about women's age at first pregnancy and the average number of children per woman, as well as the cultural and social context of motherhood.
\end{abstract}

\section{Keywords}

Motherhood, women, sex, gender, Early Bronze Age, Austria, Unterhautzenthal.

Zusammenfassung - Mutterschaft im frübbronzezeitlichen Unterhautzenthal, Niederösterreich

Dieser Artikel stellt unseren methodischen Ansatz zur Erforschung von Mutterschaft in der Urgeschichte anhand von Skelettresten $(\mathrm{n}=57)$ aus Siedlungs- und Grabbefunden von Unterhautzenthal, Niederösterreich, vor. Die Individuen umfassen unter anderem eine schwangere Jugendliche, eine Frau mit zwei Kindern und eine Frau, die mit einem Baby und einem Mann in einem Familiengrab bestattet wurde. In weiteren Frauengräbern wurden Reste von Neugeborenen und Kleinkindern gefunden. Der Vergleich archäologischer Kontextinformationen mit osteobiografischen Daten erlaubt es, Schlussfolgerungen über den sozialen Status von Frauen zu ziehen und darüber, wie Mutterschaft in der Bronzezeit konzipiert war. Der archäologische Ansatz schließt eine Gender- und Altersanalyse der materiellen Kultur und Sozialindexberechnungen mit ein. Die osteologische Analyse umfasst Sterbealter, Geschlecht, Körpergröße, Gesundheitsindikatoren und Pathologien, mit einem Schwerpunkt auf Beckenmerkmalen. Körperliche Spuren, die sich möglicherweise auf die Belastung durch Schwangerschaft und Geburt beziehen, wurden im Detail erforscht. Neben der morphologischen Beurteilung aller Individuen wenden wir Zahnzementanalysen, ${ }^{14} \mathrm{C}$-Datierungen und die Analyse von $\delta^{13} \mathrm{C} / \delta^{15} \mathrm{~N}$-Isotopenverhältnissen bei ausgewählten Individuen an. In Verbindung mit demografischen Modellen ermöglichen diese Daten Rückschlüsse auf das Alter der Frauen bei der ersten Schwangerschaft, die durchschnittliche Kinderzahl sowie den kulturellen und sozialen Kontext von Mutterschaft.

\section{Schlüsselbegriffe}

Mutterschaft, Frauen, biologisches Geschlecht, soziales Geschlecht, Frühbronzezeit, Österreich, Unterhautzenthal.

\section{Introduction}

Motherhood and early child rearing are among the most important, and yet underexplored, building blocks of Bronze Age societies. Since they are often interpreted as natural, normal, and inevitable parts of women's lives instead of sets of cultural practices, there is little information available on how motherhood was conceptualised in prehistoric societies. This includes bio-anthropological data such as the women's age at first pregnancy, the typical time gap between births, and the average number of children a woman had, as 
well as the cultural and social context of motherhood derived from archaeological data.

Social responses to pregnancy, birth and early child rearing, as well as the link between women's reproductive status and social status are explored in a series of case studies investigated within the framework of the project The Social Status of Motherhood in Bronze Age Europe. The project explores whether and how the social status of women changed as they became mothers and how reproduction was culturally embedded in Bronze Age central Europe.

This article utilises the cemetery of Unterhautzenthal as a pilot study to outline our methodological approach to researching motherhood in prehistory. This approach is still being formulated and refined as more and more case studies are added to generate a comprehensive picture of Bronze Age motherhood. Crucial to this investigation is the seamless integration of archaeological, anthropological, forensic, and demographic approaches, supplemented by genetic and isotopic data, building on good-quality published settlement and cemetery excavations. Unterhautzenthal is very suitable for this pilot study, as settlement and cemetery features have been recently excavated and published from an archaeological point of view; drawings and catalogues of finds, plans and maps are accessible thanks to the work of Ernst Lauermann. ${ }^{1}$ So far, however, only a preliminary age-at-death and sex assessment has been available, which made further analysis of the skeletal remains of paramount importance.

\section{Early Bronze Age Eastern Austria}

Early Bronze $\mathrm{Age}^{2}$ eastern Austria is characterised by small-scale communities that inhabited settlements of a few houses and practiced farming and animal husbandry. ${ }^{3}$ Bronze objects such as jewellery, weapons, and tools had an established place in society and enabled wealth to be accumulated and stored as well as displayed and distributed. Lower Austria, north of the Danube, is part of the large, central European cultural complex of the Únětice Culture, ${ }^{4}$ distributed from Thuringia and Saxony over Bohemia and Moravia to Silesia, Slovakia and Lower Austria. Heavy, cast bronze objects were preferred in this area, and the presence of some princely graves ${ }^{5}$ suggests a complex social order.

The majority of the dead were buried in small groups of graves near the settlements. About 150 cemetery sites are known in Lower Austria north of the Danube, but only about ten encompass more than ten graves. ${ }^{6}$ For a

\footnotetext{
1 Lauermann 1991a. - Lauermann 1991b. - Lauermann 1995.

2 About 2150-1700 BC: cf. Stockhammer et al. 2015.

3 Neugebauer 1994.

4 Lauermann 2003.

5 E.g. KienLin 2008.

6 Lauermann 2003, 500.
}

representative sample of the Austrian Únětice complex, we selected the well-preserved skeletal material from Fels am Wagram, ${ }^{7}$ Schleinbach, ${ }^{8}$ Unterhautzenthal ${ }^{9}$ and Zwingendorf $^{10}$ to analyse within the framework of our project.

Bodies were usually interred in flexed positions in single graves. In contrast to the area south of the Danube in Lower Austria, where a strict gendered placement of bodies was practiced (e.g. at Franzhausen, Pottenbrunn, and Gemeinlebarn), ${ }^{11}$ both men and women in the Únětice group were usually buried on their right side with their heads towards the south. Some variation in the positioning of bodies is observed and the presence of double and multiple graves allows insights into family relationships. ${ }^{12}$ The secondary re-opening of graves in the Moravian-Austrian area of the Únětice Culture was more common than in other areas, ${ }^{13}$ but still not quite as widespread as was the case south of the Danube. ${ }^{14}$

\section{Unterhautzenthal and Its Human Remains}

The site of Unterhautzenthal, situated approximately $30 \mathrm{~km}$ north-west of Vienna, was discovered in 1985, and excavated by the Lower Austrian County Museum MAMUZ Schloss Asparn under the directorship of Ernst Lauermann in the years 1987 and 1989-1994. ${ }^{15}$ The first eight individuals were discovered in the course of settlement excavations; some bodies were deposited in re-used storage pits, whereas others were found in rectangular, south-north oriented grave pits. ${ }^{16}$ Magnetometry revealed a small cemetery towards

7 ENGELHARDT 1973.

8 RETTENBACHER 2004.

9 LAUERMANN 1991b. - LaUermanN 1995.

10 WEWERKA 1982.

11 Bertemes 1989. - Neugebauer 1991. - Neugebauer, NeugeBAUER 1997. - BLESL 2006.

12 Cf. Rebay-Salisbury in press.

13 STUChlík 1990, 165.

14 Cf. SPREnger 1999.

15 Lauermann 1991a. - Teschler-Nicola, Berner 1991. - LaUERMANN 1992. - LAUERMANn 1993. - LaUermann 1995. - LaUeRmann 1997. - Lauermann, Pucher, Schmitzberger 2001. - LauERMANN 2003.

16 LAUERMANN 1991b. - In the original excavation documentation, all recorded features were called 'Verfärbung' (literally: discolouration) and given a continuous number. In this article, we translate 'Verfärbung' as feature and use it as 'Verfärbung' was used; an overarching term that encompasses graves, settlement pits with burials, and contexts that could not be more clearly defined. The term grave is reserved for physical structures that appear to have been specifically built for burials, i.e. the deposition of one or more dead bodies. We aim to preserve the original numbering system and retain one single number for features, graves, and the individuals found in them. For the most part, two or more individuals in a feature were differentiated by adding the letters A, B and C. However, this system was initiated during the course of excavation and has been applied inconsistently (hence Feature $95=$ Grave 95 contains the three individuals 90, 90A and $90 \mathrm{~B}$, whereas Feature $122=$ Grave 122 contains the individuals 122A, 122B and 122C). 
Table 1. Radiocarbon dates of five individuals from Unterhautzenthal.

\begin{tabular}{|c|c|c|c|c|c|}
\hline Beta no. & Individual & Sex & Age & Conventional age & Calendar calibration (probability) \\
\hline 469622 & $27 \mathrm{~B}$ & - & 6 years & $3550+/-30 \mathrm{BP}$ & $1976-1861 \mathrm{cal} \mathrm{BC}(67.7 \%) ; 1853-1772 \mathrm{cal} \mathrm{BC}(26.9 \%)$ \\
\hline 469618 & 95 & female & $35-45$ years & $3580+/-30 \mathrm{BP}$ & $2028-1878 \mathrm{cal} \mathrm{BC}(94.2 \%) ; 1839-1828 \mathrm{cal} \mathrm{BC}(1.2 \%)$ \\
\hline 469619 & $95 \mathrm{~A}$ & - & $3-4$ years & $3540+/-30 \mathrm{BP}$ & $1955-1767 \mathrm{cal} \mathrm{BC}(95.4 \%)$ \\
\hline 469620 & 105 & - & $2-3$ years & $3530+/-30 \mathrm{BP}$ & $1943-1763 \mathrm{cal} \mathrm{BC}(95.4 \%)$ \\
\hline 469621 & $122 \mathrm{~B}$ & female & $17-20$ years & $3580+/-30 \mathrm{BP}$ & $2028-1878 \mathrm{cal} \mathrm{BC}(94.2 \%) ; 1839-1828 \mathrm{cal} \mathrm{BC}(1.2 \%)$ \\
\hline
\end{tabular}

the east of the settlement features, which was subsequently fully excavated. Although some later settlement activities disturbed the area, the boundaries of the cemeteries were identified and the cemetery originally seems to have comprised about 40 to 50 graves. ${ }^{17}$

AMS Radiocarbon dates taken from five individuals (Table 1) suggest that the cemetery was likely not used for more than a century and that the western and eastern parts were roughly contemporaneous. ${ }^{18}$ All dates overlap between 1943 cal BC and 1878 cal BC, with an overall range of 2028-1763 cal BC. The combined dates of individuals 95 and $95 \mathrm{~A}$, which were probably deposited during one funerary event, range between 1935 and 1885 BC.

Within the typo-chronological framework, the earliest graves date to Bronze Age A1b, the latest to Bronze Age A2a. ${ }^{19}$ Two of the radiocarbon-dated skeletons were buried with typo-chronologically significant dress pins: a Scbleifenkopfnadel was found in Grave 95, dated to 2028-1878 cal BC or Bz A1b, and a Hülsenkopfnadel in Grave 105, dated to 1943-1763 cal BC or Bz A2a. These two data points thus correspond to the conventional sequence of pin development, but they do not exclude the simultaneous use of the two pin types. ${ }^{20}$

The results of an initial sex and age assessment as well as the physical characterisation of the individuals carried out by Maria Teschler-Nicola and Margit Berner in the 1990s

17 LaUermann 1995, 5.

18 AMS radiocarbon dating was performed at Beta Analytic on bone collagen extracted with alkali. Conventional radiocarbon ages (BP) were corrected for natural and laboratory induced total isotopic fractionation effects and calibrated with BetaCal3.21 using the INTCAL 2013 atmospheric reservoir database. - See Reimer et al. 2013.

19 LAUERMANN 2003, 619.

20 Ruckdeschel 1978. - StOckhammer et al. 2015, 8. were included in the original site publications. ${ }^{21}$ Building on these studies, the anthropological re-analysis of the skeletal remains for the purpose of understanding motherhood was undertaken by Doris Pany-Kucera and Michaela Spannagl-Steiner and focussed specifically on pelvic features, which may relate to birth events, as well as selected palaeopathological changes, which provide insights into health, disease, and living conditions in the early Bronze Age more generally (Appendices 1-2).

In the course of this work, the sex of the individual from Grave 108 was corrected to an adolescent male individual and the individual from Grave 123 was corrected to a mature female individual. ${ }^{22}$ The age of nine individuals was corrected: the child from Feature 105 was probably only 2-3 years

21 Teschler-Nicola, Berner 1991. - Lauermann 1995. - The skeletal remains from Unterhautzenthal are curated by the Anthropological Department of the Natural History Museum in Vienna, except for the two children from Feature 27, which are exhibited at the Museum MAMUZ Schloss Asparn.

22 Methods of sexing adapted from Todd 1920. - Wolff-HeIdegGER 1954. - ACsÁdi, NeMESKÉRI 1970. - SzILVÁSsY 1978. - Ubelaker 1978. - Ferembach, Schwidetzky, Stloukal 1979. - Lovejoy et al. 1985a. - Lovejoy et al. 1985b. - MeIndL, Lovejoy 1985. - SzilvÁsSy 1988. - Brooks, Suchey 1990. - BuiKstra, UbeLAKER 1994. - BrŮŽEK 2002. - White, Black, Folkens 2012 include a macroscopic assessment of the following features: Cranium: glabellar region, superciliary arch, frontal and parietal eminence, frontal inclination, mastoid process, zygomatic process, relief of nuchal plane, external occipital protuberance, zygomatic process, zygomatic bone, supraorbital margin, shape of orbits; Mandible: total aspect, mental eminence, mandibular angle, inferior margin; Pelvis: praeauricular sulcus, greater sciatic notch, subpubic angle, arc composé, complete pelvis, obturator foramen, body of ischium, iliac crest, iliac fossa, greater pelvis, acetabular fossa/femoral head; Long bones: robusticity of humerus and femur. Characteristic features were graded between +2 (definitely male) and -2 (definitely female) and weighted according to their relevance. Pelvic features were given more weight than cranial features. 
Table 2. Summary of the results from tooth cementum annulation analysis of 14 individuals from Unterhautzenthal, compared to morphologically determined sex and age. The means and standard deviations of the TCA counts were calculated from three independent counts of subsequent cross-sections of the middle third of premolar roots from the lower jaws. Age at death is calculated by adding the means of counts to the average tooth eruption ages (after AlQAhtani, Hector, Liversidge 2010). An error range of \pm 5 years is assumed for the resulting age.

\begin{tabular}{|c|c|c|c|c|c|c|c|c|c|}
\hline \multirow[t]{2}{*}{ Histo ID } & \multirow[t]{2}{*}{ Individual } & \multirow[t]{2}{*}{ Sex } & \multirow[t]{2}{*}{ Age } & \multirow{2}{*}{$\begin{array}{l}\text { Tooth } \\
\text { FDI }\end{array}$} & \multicolumn{2}{|c|}{$\begin{array}{l}\text { TCA counts in } \\
3 \text { sections }\end{array}$} & \multirow{2}{*}{$\begin{array}{l}\text { Average tooth } \\
\text { eruption in } \\
\text { years* }\end{array}$} & \multicolumn{2}{|c|}{$\begin{array}{l}\text { Estimated TCA age in } \\
\text { years }\end{array}$} \\
\hline & & & & & Mean & SD & & Mean & \pm \\
\hline 5549 & $38 \mathrm{~A}$ & $\begin{array}{l}\text { indetermined } \\
\text { (+ foetus) }\end{array}$ & $14-15$ & 34 & 7.0 & 1.0 & 10.5 & 17.5 & 5.0 \\
\hline 5550 & 90 & female & $40-50$ & 45 & 26.3 & 0.6 & 11.5 & 37.8 & 5.0 \\
\hline 5551 & 93 & female & $35-45$ & 35 & 24.7 & 1.5 & 11.5 & 36.2 & 5.0 \\
\hline 5533 & 95 & female & $35-45$ & 44 & 31.0 & 2.0 & 10.5 & 41.5 & 5.0 \\
\hline 5534 & 100 & female & $17-25$ & 45 & 8.0 & 0.0 & 11.5 & 19.5 & 5.0 \\
\hline 5552 & 102 & female? & $25-35$ & 44 & 19.0 & 1.0 & 10.5 & 29.5 & 5.0 \\
\hline 5535 & $103 \mathrm{~A}$ & female & $16-20$ & 35 & 10.0 & 1.4 & 11.5 & 21.5 & 5.0 \\
\hline 5553 & $116 \mathrm{~A}$ & female & $45-60$ & 45 & 35.0 & 2.0 & 11.5 & 46.5 & 5.0 \\
\hline 5531 & $122 \mathrm{~A}$ & male & $35-40$ & 34 & 34.0 & 4.2 & 10.5 & 44.5 & 5.0 \\
\hline 5532 & $122 \mathrm{~B}$ & female & $17-20$ & 45 & 9.3 & 1.2 & 11.5 & 20.8 & 5.0 \\
\hline 5554 & 123 & female? & $40-50$ & 44 & 33.0 & 1.4 & 10.5 & 43.5 & 5.0 \\
\hline 5555 & 124 & male & $35-50$ & 44 & 50.0 & 2.0 & 10.5 & 60.5 & 5.0 \\
\hline 5556 & 128 & female & $40-50$ & 44 & 47.7 & 0.6 & 10.5 & 58.2 & 5.0 \\
\hline 5557 & 134 & female & $30-40$ & 44 & 9.7 & 0.6 & 10.5 & 20.2 & 5.0 \\
\hline
\end{tabular}

*AlQAhtani, Hector, Liversidge 2010 for combined sexes.

old at death, the adolescent male from the settlement pit Feature 18 between 14 and 15 years old. Other age corrections concern adult and mature individuals and are usually within five years $(16,109 \mathrm{~A}, 111,116,125,128$ and 138$) .^{23}$

Tooth cementum annulation (TCA) analysis was conducted in a pilot stud ${ }^{24}$ that included fourteen individuals from Unterhautzenthal, two men $(122 \mathrm{~A}, 124)$ and twelve women (38A, 90, 93, 95, 100, 102, 123, 128, 134, 103A, 116A, $122 \mathrm{~B})$. TCA is primarily used as a histological alternative

23 Methods of ageing adapted from Todd 1920. - Wolff-HeidegGer 1954. - Bass 1971. - Fazekas, Kósa 1978. - Stloukal, Hanáková 1978. - SzILVÁssy 1978. - UbeLAKER 1978. - KóSA 1989. Age at death in children was determined following Wolff-Heidegger 1954. - Bass 1971. - Fazekas, Kósa 1978. - Stloukal, Hanáková 1978. - Ubelaker 1978. - Kósa 1989. - Lewis 2007. - CunNingham, SCHEUER, BLACK 2016 are based on bone length measurements, tooth eruption patterns and epiphyseal fusion in children; adults are aged on the basis of tooth abrasion, changes at the pubic symphysis, fusion of endo- and ectocranial sutures, changes at the sternal joint surface of the clavicle and epiphyseal fusion.

24 F. Kanz, K. Rebay-Salisbury and D. Pany-Kucera are currently preparing a paper titled "Using tooth cementum annulation for age estimation, seasonality and life event investigations in Bronze Age individuals from Austria: a pilot study". to morphological age estimation; this method counts and analyses incremental growth lines of dental cementum in thin sections derived from the roots of teeth (Table 2). Each pair of a light and a dark band corresponds to a full seasonal cycle; adding the number of paired lines to the estimated year of eruption of the analysed tooth ${ }^{25}$ indicates the histological age of the individual. ${ }^{26}$ In addition to age and possible season of death, some studies ${ }^{27}$ have pointed out that lines of increased thickness correspond to life events such as pregnancies, skeletal traumata and certain diseases.

Four previously undocumented individuals were identified in the skeletal collection. Feature 38, the grave of a 14-15-year-old adolescent, also included cranial and post-cranial elements of a foetus/neonate. Grave 109 included a 50-60-year-old mature woman as well as the femur of foetus/neonate. The 16-20-year-old adolescent woman from Feature 103 was buried with the humerus and scapula

25 AlQahtani, Hector, Liversidge 2010.

26 E.g. Wittwer-Backofen, Gampe, Vaupel 2004. - Bertrand et al. 2016. - Blondiaux et al. 2016. - Naji et al. 2016.

27 Kagerer, Grupe 2001. - Strott, Grupe 2003. - Knothe, KüNZIE 2009. 


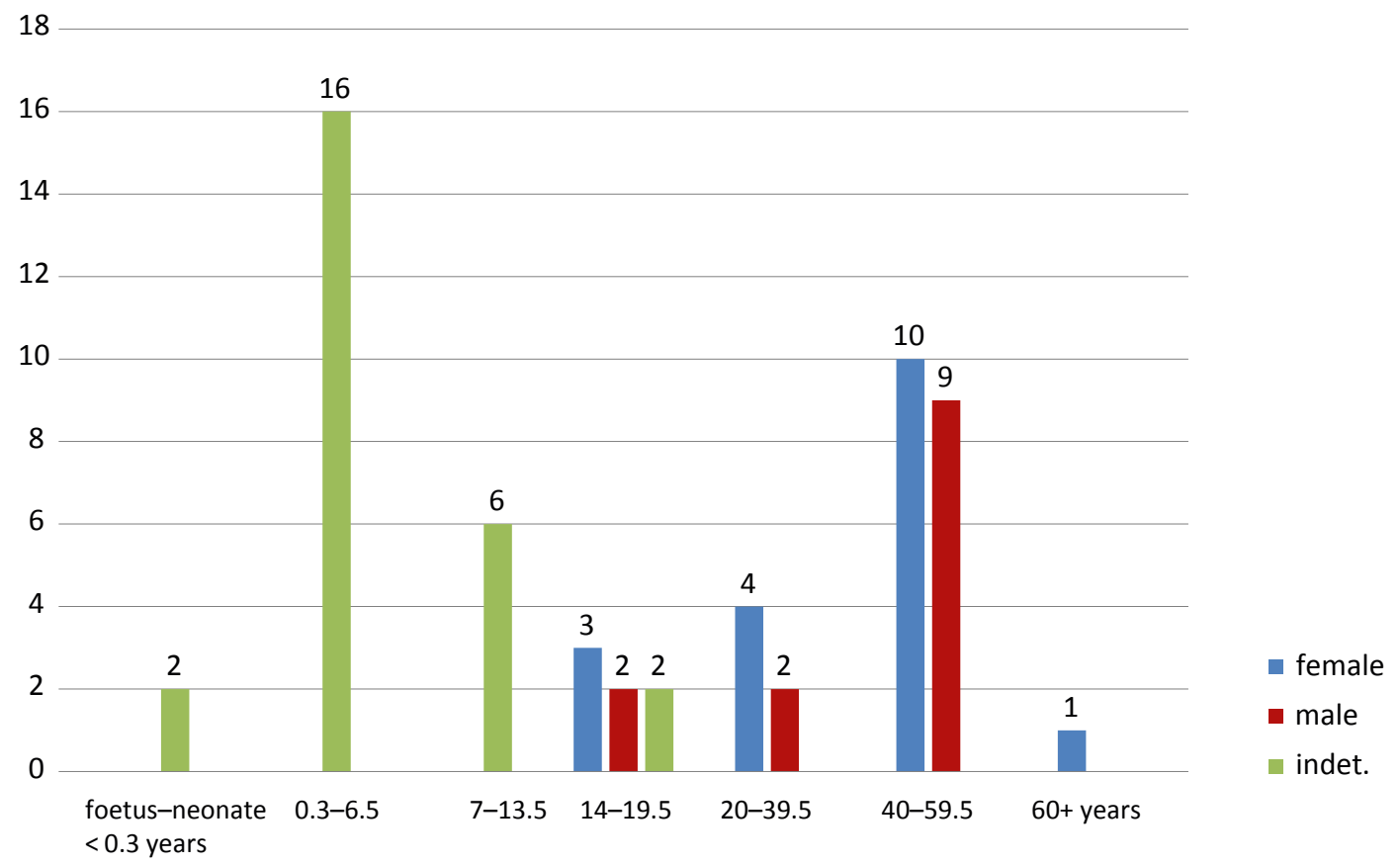

Fig. 1. Morphological age and sex distribution of the individuals from Unterhautzenthal.

of a c. three-year-old child. Vertebral arches of a 4-6-yearold child were found with the remains of a 45-60-year-old mature woman from Grave 116. The individual from Feature 121 could not be located in the collection of the Anthropological Department of the Natural History Museum in Vienna.

In total, the number of individuals excavated at the settlement and in the cemetery of Unterhautzenthal stands now at 58, 57 of which were anthropologically analysed for this study. Of these, 17 were identified as female and 13 as male. The basic morphological characteristics of skull, mandible and pelvis for sex assessment were consistent for the sexes, and there were no contradictions with the archaeological determination of gender via association with grave goods. The population included $32(55 \%)$ individuals under 20 years of age. Fourteen children died under the age of five, including two foetuses/neonates, one 3-6-month-old and one 1-year-old. Ten individuals were between 5 and 15 years of age at death (Fig. 1).

\section{Burial Practices at Unterhautzenthal}

\section{1. Grave Structures and Body Placement}

Bodies were found both in settlement features and in grave pits. They were usually recovered singly, with several exceptions: Feature 27, a re-purposed storage pit, contained two children in an embrace (Fig. 2); Feature 95 was the grave of a woman with two children; and Feature 122 was the grave of a man, a woman, and a baby. Further seemingly single graves included the disarticulated remains of children. Repurposed storage pits, round in form and slightly wider at the bottom than at the top, held the remains of three men, the individuals 16, 18 and 23. The pits were 1.7, 2.3 and $2.1 \mathrm{~m}$ deep and measured and 2.9 by $2.7 \mathrm{~m}, 3.3$ by $2.9 \mathrm{~m}$, and 1.2 by 1.2 m respectively.

Graves were normally rectangular in shape, with depth varying from 0.4 to $2.5 \mathrm{~m}$ and clearly dependent on age and gender. The shallowest graves were used for children and the deepest for men. The average grave depth for children under 14 is $1.08 \mathrm{~m}$ (0.4 to $2.2 \mathrm{~m}$ ), whereas it is $1.38 \mathrm{~m}$ for adolescents and adults ( 0.7 to $2.5 \mathrm{~m})$. Women were buried in graves averaging $1.3 \mathrm{~m}$ in depth ( 0.75 to $2.2 \mathrm{~m}$ ), whereas men were buried $1.5 \mathrm{~m}$ deep $(0.7$ to $2.5 \mathrm{~m})$. The area at the bottom of the features, although not recorded in all cases, averaged $2.7 \mathrm{~m}^{3}$. Again, age and gender accounted for most of the variability: on average, children under 14 occupied only $1.7 \mathrm{~m}^{2}$ (1.4 to $6.4 \mathrm{~m}$ in a triple burial), adolescents and adults $3.4 \mathrm{~m}^{2}\left(1\right.$ to $\left.6.4 \mathrm{~m}^{2}\right)$, women $2.8 \mathrm{~m}^{2}\left(1.01\right.$ to $\left.6.4 \mathrm{~m}^{2}\right)$ and men $3.8 \mathrm{~m}^{2}\left(1.13\right.$ to $\left.6.4 \mathrm{~m}^{2}\right)$. Remains of wooden coffins were documented in four cases (features 81, 90, 111 and 116), all in adult male and female graves of considerable depth. It is likely that other individuals were also buried in wooden structures that were not preserved.

Almost all bodies were placed on their right side, with arms bent in front of the body and legs flexed to varying degrees. Several bodies were packed tightly with extremely 


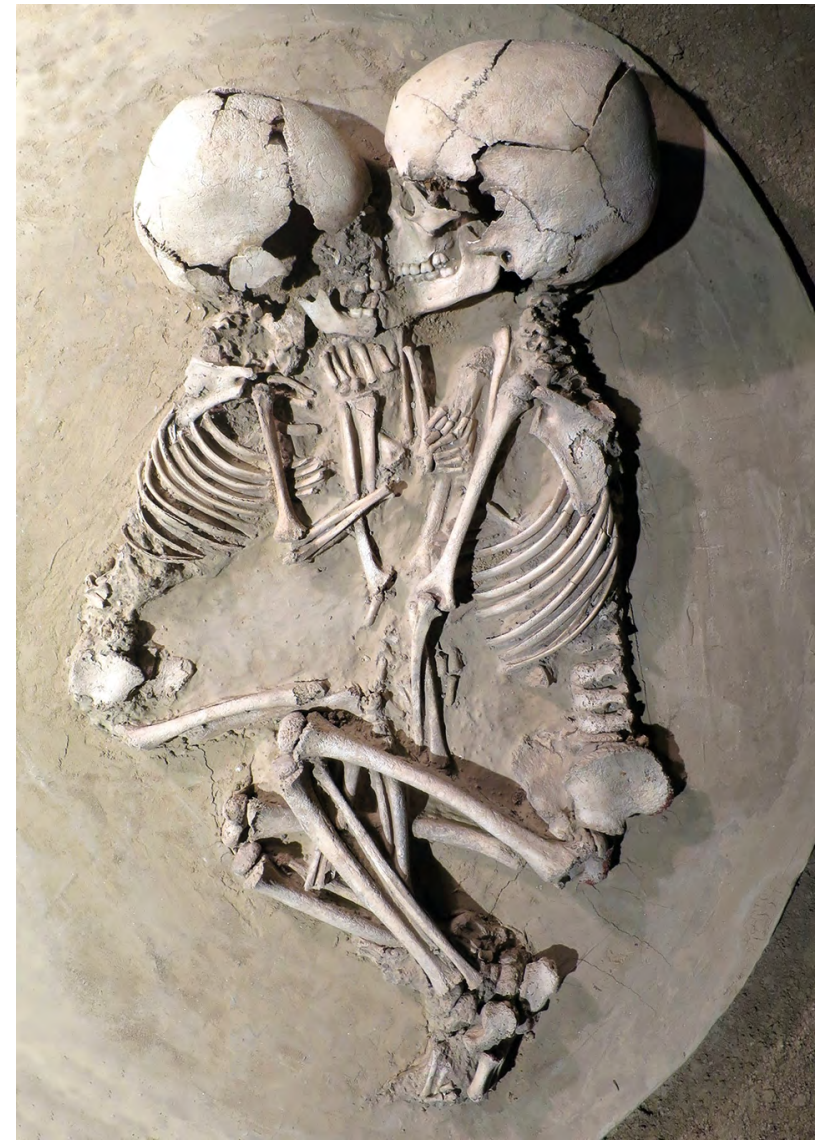

Fig. 2. The children from Feature 27, a two-year-old (left) and sixyear-old (right) in an embrace, preserved in situ and displayed in the Museum MAMUZ Schloss Asparn (Photo: K. Rebay-Salisbury).

flexed legs. The extent of the body-flexing does not appear to be related to age, gender, or the size of the grave pit. The 9-11-year-old in Feature 136, for example, was packed tightly into the grave pit, whereas the 14-15-year-old only occupied about a quarter of Feature 38.

This 'regular placing' was followed, with some variations, for both the settlement and cemetery deposition. The individual from Feature 16, a 35-50-year-old man was placed on his right side along the wall of a storage pit; the 30-50-year-old man from pit 23 was placed in half-prone position, but also flexed and on the right side.

Of the 48 bodies for which the position could be determined, 41 were found lying on their side, one in proneflexed position and five in supine-flexed position (with upper bodies on the back and legs flexed). The upper body of the 2-3-year-old child from Grave 105 was found in a supine position, although the legs were flexed and tilted to both sides. The child was found to bear extensive new bone formation at the dorso-lateral side of the femoral shafts - a possible case of scurvy that may explain the unusual position. Only one body, that of a 35-50-year-old female from Grave 88, was placed in an entirely supine position, with arms parallel to the body and the right hand in the pubic area.

The right body side was preferred for 42 burials. In the double burial, Feature 27 (Fig. 2), which included two children in an embrace, the normative right side was reserved for the older, the 6-year-old child, whereas the 2-year-old was placed in the opposite position. This may reveal an age-based ranking. In the triple burial, Grave 122, both the adolescent woman and the adult man were found lying on their right sides with the woman placed in front of the man. The location of the baby is not known. The body of the 3.5-4-year-old from Grave 87 was found disturbed, but the legs may have been flexed to the left side. Similarly, the 30-40-year-old woman buried in Grave 134 was found in a supine position, whilst her legs were flexed and tilted to the left side.

The prevailing body orientation was with the head to the south/south-west, south, and south-west (average 197\%), with a few exceptional cases oriented to the north (86, a 40-60-year-old man, 93, a 35-45-year-old female with traces of interpersonal violence, and 129, a 3-5-year-old child).

Grave 95, a triple burial, held the remains of a 35-45-year-old woman and two children. The younger child, a 2-3-year-old, was placed parallel to, and in front of, the head of the woman lying on her right side, head to the south-west, whereas the elder child, about 4-5 years old, was placed in the empty space behind her legs with a northwest orientation.

\subsection{Material Culture and the Life-Cycle}

Most bodies at Unterhautzenthal were found with jewellery, bronze dress elements, tools, and/or pottery; only 12 were found entirely without material culture. The selection of grave goods was closely connected to the buried person's gender and age, whereas differences in social status seemed to play a lesser role.

Amongst the most common functional bronze artefact types are pins. They appear in graves of children as young as two years old, and remain in use into mature age. Pin types include Rollenkopf, Schleifen- and Hülsenkopfnadel. ${ }^{28}$ Two pins were found with the 3.5-4-year-old in Grave 87, in the chest/shoulder region and behind the cranium. A pair of bronze pins was present in the chest/shoulder region of Individual 101, a 12-year-old buried with a dagger. Single bronze pins were found in 13 graves, of which six were under 20 years old, and seven over 20 years (three men and six

28 Lauermann 1995, 85. 
women). Pins were sometimes found positioned in the head area in a manner that suggests their use as fasteners for skins or textiles to wrap the body (e.g. 95, 99, and 105). The most common location, however, was the shoulder/chest region, in particular the right shoulder (e.g. 102, 103A and 111). A bone pin was placed behind the head of the mature woman in Grave 90.

Bronze awls found in similar positions as pins in adult male graves might represent objects of the same functional type. Bronze awls were discovered in front of the chest area in Feature 94 and near the pottery set placed in front of the face in Feature 111. Bone awls were found with one adolescent man and four women of all ages. A bone awl took the place of a pin in the shoulder/chest area of the mature woman in Feature 125. Bone awls were found behind the pelvic area of the man in Grave 81 and the woman in Grave 123. In Grave 102, an awl was found in front of the woman's pelvic area and in Grave 103, another had been placed near the woman's feet.

An Ösenbalsring was part of the elaborate jewellery assemblage of the woman in Grave 90, who also had a Spiralröllchen necklace. It has been suggested that the man in Grave 81 may have originally had a neck-ring that was removed during grave re-opening, as the cervical vertebrae appear dislocated. ${ }^{29}$ Bronze band neck-rings were associated with a 3-4-year-old and an eight-year-old. Spiralröllchen necklaces are composed of a number of small bronze spirals and worn around the neck. Only a few graves contained whole necklaces, most only contained a few individual spirals. They were found with a 5-6-year-old, an eight-yearold, and with women of adolescent to adult age (14-18, 16$20,17-25,25-35,40-50$, and $40-50$ years old). In Grave 122, the necklace associated with the $35-40$ year-old male (122A) could also have belonged to the co-buried 17-20-year-old woman $(122 \mathrm{~B})$ in the same grave; the bones were found heavily disturbed.

Noppenringe, common bronze jewellery items, were found in 20 graves. They appeared in graves of children perhaps as young as 1.5-2 years (Grave 131, Noppenring reconstructed on the basis of green bone discolouration) and without question from the age of 3.5-4 (Grave 87). They were found in women's graves of all age brackets up to old age (45-65, Grave 138). Large Noppenringe were found in the pelvic area of graves 88,100 and $102^{30}$ and were probably part of the costume (e.g. rings for woven belts). The only male individual with whom wire fragments of Noppenringe

29 LAuermann 1995, Fig. 8. - See below for a discussion of this grave's disturbance.

30 Lauermann 1995, 86. were found was the 35-50-year-old from Grave 83. The bronze fragments were found under the skull and were therefore probably worn on the right side of the head. The 8-9-year-old child from Grave 127 had wire fragments of Noppenringe in exactly the same position.

Arm-rings were primarily worn by children; they were associated with the graves of children aged $0-6,2,2.4-3$, $3-4,3-5,4-5$ and 6-8-years. In addition, a 12-year-old boy (Grave 101), an adolescent female (14-18 years old, Grave 99), and an adult male (35-50 years old, Grave 124) wore arm-rings. Two types of arm-rings can be distinguished at Unterhautzenthal: simple, thin bronze wire rings and solid cast ones. ${ }^{31}$ The six-year-old from Grave 89 had wire armrings on both lower arms, but most individuals wore a single one. The adult male in Grave 124 was the only one who wore his on the left arm; individuals from graves 101, 105 and 133 wore arm-rings on the right arm. The arm-ring in Grave 133 was worn by a 3-4-year-old, sickly child, who had a badly healed fracture of the right humerus. There was no arm-ring recovered in Grave 129, but the right ulna of the 3-5-year-old was stained green, so it seems likely that the object was removed after decomposition of the body. The wire arm-rings worn by small children such as the ones from graves 89, 96 and 103 look very similar to Noppenringe with a diameter of $4-6 \mathrm{~cm}$ : it is possible that mothers gifted their children one of their own dress items as arm-rings during the funerary ritual.

Jewellery of materials other than bronze include an amber bead found with the 2-3-year-old child from Grave 105 and dentalia, jewellery components made of marine molluscs of the genus Dentalium, which were found in the hair/ head region of two mature women aged $35-50$ and $40-50$ $(88,123)$.

Daggers $^{32}$ were found with four burials; three securely sexed as males: 81 (aged 17-20), 111 (aged 30-40) and 83 (aged 35-50). Another one was found in Grave 101, that of a 12-year-old. The position of the daggers suggests that in most cases they were placed near the hands. The dagger in Grave 81 was found under the left phalange, in the right elbow/lower arm region, the dagger in Grave 83 was found under the right lower arm, and the dagger in Grave 101 near the right shoulder; only in Grave 111 was the dagger found slightly off the body near the pottery placed close to the head. The 4-5-year-old buried with a woman and another child in Grave 95 was associated with a bone ring similar to the one from Grave 83, where it covered the end of the

31 Lauermann 1995, 86.
32 Of the Griffplatten type: Lauermann 1995, 85. 
dagger's hilt; the excavator interpreted it as a pendant, ${ }^{33}$ but it might be indicative of a dagger.

Small cutting blades made of chert were found in the graves of four women (103A aged 16-20, 93A aged 20-25, 95 aged $35-45$, and 116 aged $40-60$ ). All but the heavily disturbed Individual 93 A were possible mothers (see below).

The average number of pottery vessels associated with each individual is 2.14 , about 3 vessels per grave. All 18 women had pottery vessels in the graves; the average number per woman is 3.2. Four out of 14 men had no ceramic grave goods, and the average number is lower than that of the females, with 2.4 per male. Neonates are not associated with pottery; the youngest child with a small beaker is the 1.5-2-year-old from Grave 131. One bowl was found in Grave 105 with a 2-3-year-old, and another small beaker was found associated with the 3-4-year-old in the triple burial, Grave 95. From the age of about four, pottery sets are common in children's graves just as they are for adults.

In summary, the only gender specific pieces of material culture for men were daggers. Moreover, men wore fewer, often single, pieces of bronze dress elements or jewellery in comparison with females. Women tended to adorn their hair and neck with Noppenringe, Spiralröllchen and other rings; older women are often found in association with Dentalium jewellery. Arm-rings and perhaps amber were typically associated with children. The age of social recognition of gender, interpreted as whether the Unterhautzenthal community buried a child as a typical woman or a man, appears to be relatively young; the 7-8-year-old in Grave 104 had an assemblage with a full set of pottery and jewellery, including dress pin, neck-ring and set of Lockenringe, no different than that expected for a woman. The 12-year-old from Grave 101 was buried with a dagger as a man.

\subsection{Grave Re-Opening, Object Removal and the Reconstruc- tion of Missing Grave Goods}

Grave re-opening, the removal of objects, and the disarticulation or removal of bones are common phenomena in the early Bronze Age. In comparison to other regions, the Moravian-Austrian region of the Únětice complex seems particularly heavily affected, with re-opening rates between 44 and $80 \%{ }^{34}$ South of the Danube, in the Unterwölbling group, grave robbing was likewise undertaken on a large scale, with evidence that several graves were opened at the same time and body parts of some individuals distributed over several graves. ${ }^{35}$ At Franzhausen I, a reconstruction of

33 LAUERMANN 1995, 88.

34 STUChlík 1990, 165.

35 Neugebauer 1991. - Neugebauer 1994, 140. missing bronze objects on the basis of green discolouration on the bones yielded good results. ${ }^{36}$ This method, however, relies on a number of preconditions, including that the decomposing body had sufficient contact with the bronze items, and that the copper salts had enough time to diffuse into the bone matrix.

The level of grave disturbance is difficult to ascertain for Unterhautzenthal, in part due to much later settlement activities. The excavator recorded disturbance to $63 \%$ of the graves in the cemetery. ${ }^{37}$ The bone preservation of some very young individuals was too poor to determine whether they had been disturbed. In some individuals, the dislocation of bones was very minor and affected primarily the neck and chest region, whereas the rest of the body was found in situ. This may be evidence for disturbance, or may be explained by bioturbation, decomposition or other taphonomic processes. Some movement of the clavicle through gravity, for example, is to be expected when the body decomposes in a void. $^{38}$

In comparison to comparable cemeteries south of the Danube, such as Franzhausen $\mathrm{I}^{39}$ or Pottenbrunn, ${ }^{40}$ the graves appeared to be relatively intact; many of the disturbed individuals had some, if not all bronze grave goods still present and for all but two individuals, the original body position could be inferred from the bones in situ. Grading the level of disturbance is, of course, subjective. For this study, we considered 33 individuals as undisturbed, 9 as minimally disturbed, 13 as severely disturbed, and 3 as completely disturbed. The individual in Grave 93, for example, had disarticulated bones in the chest area, but many of her bronze wire Noppenringe were still present. Grave fill and dislocated neck vertebrae of the male individual in Grave 81 suggested to the excavators that a neck-ring had been removed; and yet the dagger and dress pin were still present and the skeleton seems otherwise undisturbed. The dislocation of the vertebrae may be due to rodents or the collapse of the wooden coffin structure during decomposition. ${ }^{41}$

Conversely, some seemingly undisturbed skeletons showed green discolouration that must have been caused by bronze grave goods that had been in contact with the bones $(28,105$, and 136). In these cases, bronze objects may have been very carefully removed, or alternatively, the discolouration may indicate the presence of small bronze objects such as beads that have completely decayed. The previously

36 SPRENGER 1999.

37 LAUERMANN 1995, 84.

38 Cf. Duday 2006. - Duday 2009.

39 Neugebauer, Neugebauer 1997.

40 BLESL 2006.

41 Cf. Duday 2009, 32-38. 
Table 3. Anatomical location of green discolourations on human bones and suggested grave good reconstructions.

\begin{tabular}{|c|c|c|c|c|}
\hline Feature & Sex & Age & Recorded anatomical location of green discolourations & Suggested grave good reconstruction \\
\hline 28 & female & $25-35$ & $\begin{array}{l}\text { temporal bones and skull base, left maxilla and mandible, left } \\
\text { clavicle, left cervical vertebrae } 1-4 \text {, right hand }\end{array}$ & bronze (in contact with hands) \\
\hline 38 & & $14-15$ & right clavicle, ribs, left temporal bone, left mandible & Noppenringe \\
\hline 81 & male? & $17-20$ & viscerocranium, temporal bone, clavicle & neck-ring \\
\hline $93 \mathrm{~A}$ & female & $20-25$ & $\begin{array}{l}\text { right parietal, temporal and occipital bones, right mastoid } \\
\text { process and jugular process, right maxilla and mandible }\end{array}$ & Noppenringe \\
\hline 99 & & $14-18$ & cervical vertebrae, rib fragments, both radii and ulnae, phalanges & necklace \\
\hline 105 & & $2-3$ & $\begin{array}{l}\text { right ulna and radius, phalanges, both femora shafts, left tibia } \\
\text { and fibula, vertebrae }\end{array}$ & bronze (in contact with femur/tibia) \\
\hline 128 & female & $40-50$ & $\begin{array}{l}6^{\text {th }} \text { cervical vertebra, occipital bone below foramen magnum, } \\
\text { right mandibular joint, right zygomaticus, temporal bone and } \\
\text { mastoid process }\end{array}$ & Noppenringe \\
\hline 129 & & $3-5$ & right ulna (distal), ribs, vertebrae & arm-ring \\
\hline 131 & & $1.5-2$ & right clavicle and cervical vertebrae & Noppenringe \\
\hline 133 & & $3-4$ & $\begin{array}{l}\text { right mandibular joint, right clavicle and scapula, right humerus } \\
\text { (full length of shaft) and left humerus (distal), both radii and } \\
\text { ulnae, phalanges, manubrium, sternum, right femur (distal) }\end{array}$ & bronze (more than arm-ring) \\
\hline 136 & & $9-11$ & left ilium & bronze \\
\hline
\end{tabular}

discussed individual in Grave 81 did indeed have green stains on the right side of the viscerocranium and os temporale, which are difficult to explain by the grave goods that were present, but suggest decayed bronzes such as Noppenringe. Stains on the clavicle, scapula, manubrium and humerus as well as bilaterally on the forearms most likely stem from the dagger and dress pin fragments recovered from the grave.

Recording the location of green stains on the skeletons and matching them with the location of bronzes recorded in the grave plan gave additional insights. The correlation between green stains and extant grave goods is usually very good. Missing grave goods could be reconstructed for 11 individuals (green stains were present in typical anatomical regions) but no bronze items were discovered in situ ( $\mathrm{Ta}$ ble 3). The 3-5-year-old child from Grave 129, for example, almost certainly wore an arm-ring, as suggested by green discolouration of the distal end of the right ulna, ribs and a vertebra. Reconstructed grave goods were included in the Social Index calculations below.

\subsection{The Value of a Person and the Social Index Methodology} Links between material culture and the buried persons' gender and age remain the strongest in the early Bronze Age, but we are beginning to see burial variability that may be best explained by social status. ${ }^{42}$ Bronze objects are suitable

42 Teschler-Nicola 1989. - Sprenger 1999. for accumulating and storing, as well as for displaying and distributing, wealth. During the Bronze Age, social stratification and differentiation not only seem to become firmly entrenched in society, but also become visible in the burial record. Since people do not bury themselves, ${ }^{43}$ the way in which people were buried, which objects were selected for the grave and what effort was put into the grave construction reflects in some way that the buried person was valued within his or her society - it reflects their social identity.

Rather than categorising graves simply as 'poor' or 'rich' according to modern assumptions about prehistoric values, Social Index calculations aim at deriving a quantitative and qualitative assessment of an individual's grave from its context within the burial community. Social Index calculations ${ }^{44}$ combine a range of indicators for a specific cemetery or case study, and assign each burial a value between 0 and 100 as a form of representation of the social rank of the dead individual. This representation remains an interpretation of the archaeological material and is not a direct reflection of past social realities.

Social Index calculations, however, are reproducible and can be statistically analysed with reference to the age and

43 Cf. Parker Pearson 1999.

44 E.g. Hodson 1990. - Sprenger 1999. - Burmeister 2000. - ReBAY 2006. 
Table 4. Sex and gender, age, Social Indices and Parity Index at Unterhautzenthal. Sex indicates osteologically determined sex. In some cases, the sex of the person could not be determined, but the grave goods suggest the gender (in brackets).

\begin{tabular}{|c|c|c|c|c|c|c|c|c|c|c|c|c|c|c|}
\hline 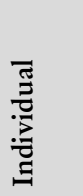 & 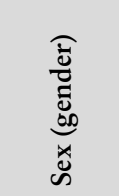 & $\stackrel{\mathscr{g}}{<}$ & 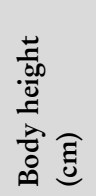 & 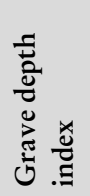 & 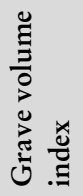 & 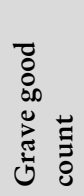 & 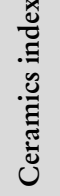 & 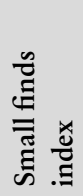 & 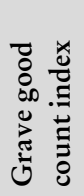 & 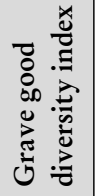 & 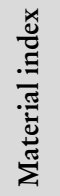 & 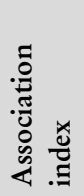 & 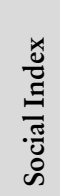 & 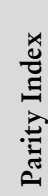 \\
\hline 16 & male & $35-45$ & 166.6 & 68 & 73 & 2 & 0 & 0 & 13 & 18 & 40 & 8 & 32 & 0 \\
\hline 18 & & 14-15 & & 92 & 100 & 0 & 0 & 0 & 0 & 0 & 0 & 0 & 20 & \\
\hline 23 & male & $30-50$ & 161.2 & 84 & 17 & 3 & 30 & 0 & 19 & 27 & 20 & 17 & 36 & 0 \\
\hline $27 \mathrm{~A}$ & & 2 & & 36 & 5 & 0 & 0 & 0 & 0 & 0 & 0 & 0 & 8 & \\
\hline $27 \mathrm{~B}$ & & 6 & & 36 & 5 & 0 & 0 & 0 & 0 & 0 & 0 & 0 & 8 & \\
\hline 28 & female & $25-35$ & 148.8 & 34 & & 5 & 10 & 50 & 31 & 36 & 40 & 24 & 36 & 40 \\
\hline 37 & & $5-6$ & & 20 & 1 & 3 & 20 & 13 & 19 & 27 & 40 & 17 & 27 & \\
\hline $38 \mathrm{~A}$ & (female) & $14-15$ & & 40 & 17 & 7 & 50 & 25 & 44 & 36 & 40 & 37 & 42 & \\
\hline $38 \mathrm{~B}$ & & $0-0.3$ & & 40 & 17 & 0 & 0 & 0 & 0 & 0 & 0 & 0 & 9 & \\
\hline 81 & male? & $17-20$ & & 78 & 55 & 11 & 60 & 50 & 69 & 91 & 80 & 68 & 83 & 0 \\
\hline 83 & male & $35-50$ & & 68 & 57 & 6 & 30 & 25 & 38 & 55 & 60 & 33 & 55 & 13 \\
\hline 84 & male & $25-30$ & 168.0 & & & 1 & 10 & 0 & 6 & 9 & 20 & 5 & 11 & 0 \\
\hline 86 & male & $40-60$ & 167.2 & 48 & & 3 & 30 & 0 & 19 & 18 & 20 & 15 & 26 & 13 \\
\hline 87 & & $3.5-4$ & & 48 & 7 & 10 & 40 & 63 & 63 & 73 & 60 & 56 & 65 & \\
\hline 88 & female & $35-50$ & 154.9 & 32 & 9 & 7 & 10 & 63 & 44 & 45 & 80 & 41 & 52 & 33 \\
\hline 89 & & $6-8$ & & 28 & & 10 & 70 & 38 & 63 & 55 & 40 & 48 & 50 & \\
\hline 90 & female & $40-50$ & 164.6 & 84 & 68 & 16 & 60 & 100 & 100 & 100 & 80 & 100 & 100 & 27 \\
\hline 91 & male & $30-50$ & 170.1 & & & 0 & 0 & 0 & 0 & 0 & 0 & 0 & 0 & \\
\hline 93 & female & $35-45$ & 160.0 & 30 & & 9 & 30 & 63 & 56 & 55 & 60 & 53 & 55 & 60 \\
\hline $93 \mathrm{~A}$ & female & $20-25$ & 143.1 & 44 & & 4 & 10 & 38 & 25 & 27 & 60 & 22 & 38 & \\
\hline 94 & male & $40-60$ & 163.9 & 60 & 24 & 3 & 20 & 13 & 19 & 27 & 40 & 17 & 35 & 13 \\
\hline 95 & female? & $35-45$ & 162.2 & 68 & 25 & 16 & 80 & 100 & 100 & 82 & 60 & 94 & 87 & 47 \\
\hline $95 \mathrm{~A}$ & & $3-4$ & & 68 & 25 & 5 & 10 & 50 & 31 & 45 & 60 & 29 & 50 & \\
\hline $95 \mathrm{~B}$ & (male) & $4-5$ & & 68 & 25 & 2 & 0 & 13 & 13 & 18 & 40 & 4 & 31 & \\
\hline 96 & & 2 & & 34 & & 1 & 0 & 13 & 6 & 9 & 20 & 2 & 15 & \\
\hline 99 & (female) & 14-18 & & 44 & & 6 & 10 & 63 & 38 & 55 & 40 & 29 & 44 & \\
\hline 100 & female & $17-25$ & 156.0 & 44 & & 8 & 20 & 63 & 50 & 45 & 40 & 42 & 48 & 33 \\
\hline 101 & (male) & 12 & & 72 & & 6 & 20 & 50 & 38 & 45 & 40 & 31 & 49 & \\
\hline 102 & female? & $25-35$ & 150.6 & 72 & & 5 & 20 & 38 & 31 & 45 & 60 & 28 & 51 & 27 \\
\hline $103 \mathrm{~A}$ & female? & $16-20$ & 159.0 & 50 & & 9 & 40 & 63 & 56 & 64 & 80 & 50 & 65 & \\
\hline $103 \mathrm{~B}$ & & $2.5-3.5$ & & & & 0 & 0 & 0 & 0 & 0 & 0 & 0 & 0 & \\
\hline 104 & (female) & $7-8$ & & 48 & 8 & 10 & 30 & 88 & 63 & 73 & 40 & 57 & 61 & \\
\hline 105 & & $2-3$ & & 64 & & 4 & 10 & 25 & 25 & 36 & 60 & 16 & 43 & \\
\hline 106 & & $1-6$ & & 28 & & 1 & 0 & 13 & 6 & 9 & 20 & 3 & 14 & \\
\hline 108 & male? & $17-20$ & & 28 & & 1 & 10 & 0 & 6 & 9 & 20 & 6 & 15 & \\
\hline $109 \mathrm{~A}$ & female & $40-60$ & 160.3 & 72 & & 9 & 30 & 75 & 56 & 45 & 40 & 54 & 58 & 73 \\
\hline 109B & & $0-0.2$ & & & & 0 & 0 & 0 & 0 & 0 & 0 & 0 & 0 & \\
\hline 111 & male & $30-40$ & & 100 & 54 & 10 & 50 & 50 & 63 & 73 & 80 & 58 & 81 & 13 \\
\hline
\end{tabular}




\begin{tabular}{|c|c|c|c|c|c|c|c|c|c|c|c|c|c|c|}
\hline 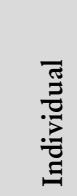 & 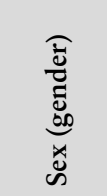 & 茂 & 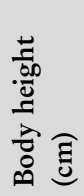 & 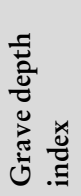 & 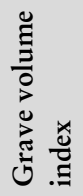 & 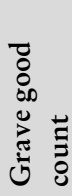 & 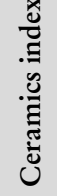 & 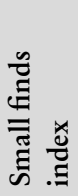 & 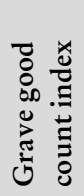 & 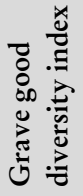 & 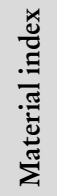 & 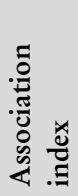 & 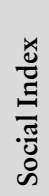 & 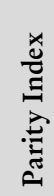 \\
\hline $116 \mathrm{~A}$ & female & $45-60$ & 157.3 & 88 & 15 & 8 & 30 & 63 & 50 & 45 & 60 & 44 & 62 & 53 \\
\hline $116 \mathrm{~B}$ & & $4-6$ & & & & 0 & 0 & 0 & 0 & 0 & 0 & 0 & 0 & \\
\hline 120 & & $6-7$ & & 28 & & 0 & 0 & 0 & 0 & 0 & 0 & 0 & 6 & \\
\hline 121 & & - & & 44 & 6 & 5 & 40 & 0 & 31 & 36 & 20 & 26 & 34 & \\
\hline $122 \mathrm{~A}$ & male & $35-40$ & 159.5 & 40 & 45 & 10 & 80 & 25 & 63 & 45 & 40 & 60 & 53 & 0 \\
\hline $122 \mathrm{~B}$ & female & $17-20$ & 161.4 & 40 & 45 & 11 & 100 & 13 & 69 & 55 & 40 & 62 & 57 & 47 \\
\hline $122 \mathrm{C}$ & & $0.25-0.5$ & & 40 & 45 & 0 & 0 & 0 & 0 & 0 & 0 & 0 & 9 & \\
\hline 123 & female? & $40-50$ & 161.7 & & & 13 & 70 & 63 & 81 & 82 & 100 & 83 & 93 & 80 \\
\hline 124 & male & $35-50$ & 164.4 & 48 & 12 & 3 & 20 & 13 & 19 & 27 & 40 & 13 & 32 & 13 \\
\hline 125 & female & $45-60$ & & 48 & 11 & 2 & 10 & 13 & 13 & 18 & 40 & 12 & 28 & 33 \\
\hline 127 & & $8-9$ & & 36 & 4 & 3 & 10 & 25 & 19 & 18 & 40 & 17 & 28 & \\
\hline 128 & female & $40-50$ & & 44 & & 4 & 20 & 25 & 25 & 27 & 40 & 19 & 33 & 100 \\
\hline 129 & & $3-5$ & & 16 & & 1 & 0 & 13 & 6 & 9 & 20 & 2 & 11 & \\
\hline 130 & & 1 & & 28 & & 0 & 0 & 0 & 0 & 0 & 0 & 0 & 6 & \\
\hline 131 & & $1.5-2$ & & 20 & & 2 & 10 & 13 & 13 & 18 & 40 & 10 & 22 & \\
\hline 132 & male & $35-50$ & 168.8 & 36 & & 0 & 0 & 0 & 0 & 0 & 0 & 0 & 8 & \\
\hline 133 & & $3-4$ & & 38 & & 1 & 0 & 13 & 6 & 9 & 20 & 2 & 16 & \\
\hline 134 & female & $30-40$ & 153.0 & 48 & & 7 & 10 & 63 & 44 & 27 & 60 & 40 & 47 & 60 \\
\hline 136 & & 9-11 & & 28 & & 2 & 10 & 13 & 13 & 18 & 40 & 8 & 23 & \\
\hline 138 & female & $55-65$ & 152.0 & 48 & & 6 & 20 & 50 & 38 & 36 & 40 & 34 & 42 & 13 \\
\hline
\end{tabular}

gender of the buried individuals, as well as other factors of interest such as motherhood. In order to find out how motherhood was valued as a concept and component of identity, we use the Social Indices of graves and compare them to the individual life histories of buried women and their parity status. Graves that have been disturbed and where objects were removed can nevertheless be included in the analysis. Some values, such as the depth and volume of the grave remain unaffected by re-opening. For object-related indices, the values have to be understood as minimum values.

We calculated indices for grave depth, grave volume, grave good count, grave good diversity, grave good materials, number of ceramics and number of small finds, as well as an association index for the settlement and cemetery burials of Unterhautzenthal (Table 4).

\section{Grave depth index}

In the excavation reports, the depth of the graves is given from the upper surface of the modern topsoil (Humusoberkante).
The deepest grave, at $2.5 \mathrm{~m}$, was 111, represented by the index value 100; the shallowest grave, $0.4 \mathrm{~m}$ deep, was represented by the value 16 . The other 50 burials for which data on depth were available ranged between these values. The average grave depth index value was $49(n=52)$. Individuals sexed as females were associated with an average value of 53 $(\mathrm{n}=16)$, and males with $60(\mathrm{n}=11)$. There was also a significant difference with regard to age, with under 20-year-olds having an average grave depth index value of $43(n=29)$ and over 20-year-olds of $57(\mathrm{n}=22)$. The 12 to 20 year age bracket, however, was more closely associated with adult values (average 54, $\mathrm{n}=9$ ), whereas the 23 graves of under 12-yearolds reached an average grave depth index value of only 38 .

\section{Grave volume index}

The volume of the grave fill was calculated by taking the area of the grave measured at the deepest level multiplied by the grave depth. The grave with the largest volume was the former storage pit $18\left(14.35 \mathrm{~m}^{3}\right)$, which was assigned the 
value 100 . The smallest measured grave, Feature 37 , with a volume of $0.2 \mathrm{~m}^{3}$ was assigned the value 1 . Information on grave area was not available for all graves, so only 27 individuals were assigned a grave volume index. Trends regarding sex and age were similar to the grave depth index. As this index is in part dependent on grave depth, it was not used in the subsequent analysis.

For the indices based on grave goods, the following functional types were differentiated and counted per individual:

Bronze artefacts: dagger, dress pin, awl, wire neck-ring, Ösenhalsreif neck-ring, Spiralröllchen necklace, Spiralröllchen, wire arm-ring, cast arm-ring, large Noppenring $(5 \mathrm{~cm}$ diameter), small Noppenring (1.5-2.5 cm diameter), small ring, fragment. For assemblages of Noppenringe and Spiralröllchen, two pieces were counted as one.

Artefacts of other materials: Dentalium pendants (two counted as one), chert, stone, bone pin/awl. Singular artefacts that were only found in one grave included a sewing needle, a round ceramic disk with hole, a ceramic cist, a bone ring, a bone disc, and an amber bead. Ceramic artefacts included a vessel, jug, beaker, cup, bowl, large storage vessel fragment. Animal bones, representing food offerings, were counted as one artefact.

\section{Grave good count index}

This index represents the number of grave goods associated with each individual. The highest number of grave goods, 16, was found in two women's graves: the 35-45-year-old from Grave 95 and the $40-50$-year-old from Grave 90 . The average number of grave goods per grave was $4.67(n=58)$. Women were, on average, associated with 8.18 grave goods $(\mathrm{n}=17)$, men with only with $4.07(\mathrm{n}=13)$. The age bias was not as strong as the gender bias, but adults were, on average, associated with 6.08 grave goods $(\mathrm{n}=25)$ and sub-adults with only $3.56(\mathrm{n}=32)$. At Unterhautzenthal, 12 bodies were not associated with any objects, and six with only one.

The average grave good count index is $29(\mathrm{n}=58)$ : $51(n=17)$ for women and $25(n=13)$ for men, $28(n=25)$ for adults and $22(\mathrm{n}=32)$ for sub-adults.

In order to investigate trends within the ceramics and small finds groups, ceramic vessels and small finds were counted separately per individual. In double and triple burials, the pottery was assigned to individuals when possible, and counted only once per grave. The largest number of vessels, 10, was associated with the 17-20-year-old woman in Grave 122. The average number of vessels per individual was $2.13(\mathrm{n}=58)$. Women were accompanied by an average of $3.35(\mathrm{n}=17)$ vessels, men by $2.62(\mathrm{n}=13)$, adults by 2.72 $(\mathrm{n}=25)$ and sub-adults by $1.62(\mathrm{n}=32)$. An average of 2.26 small finds were found in each burial; the largest number of small finds, 9, was found with the 40-50-year-old woman in Grave 90. Women were buried with an average of 4.41 $(\mathrm{n}=17)$ small finds, men with $1.08(\mathrm{n}=13)$, adults with 2.96 $(\mathrm{n}=25)$, sub-adult with $1.78(\mathrm{n}=32)$. It can be concluded that both ceramics and small finds follow the overall pattern of object inclusion.

\section{Grave good diversity index}

This index represents the number of different types of object associated with one individual, as opposed to multiplications of the same object type in one grave. The greatest number of different objects, 11, was again found with the 40-50-year-old woman from Grave 90 . Women were, on average, associated with 5.41 different objects $(n=17)$, men with $3.38(\mathrm{n}=13)$, adults with $4.28(\mathrm{n}=25)$ and sub-adults with $2.81(\mathrm{n}=32)$.

The average grave good diversity index was $31(n=58)$ : $49(\mathrm{n}=17)$ for women and $31(\mathrm{n}=13)$ for men, $39(\mathrm{n}=25)$ for adults and $26(\mathrm{n}=32)$ for sub-adults (under 20 years old).

\section{Grave good material index}

Seven groups of materials were present at Unterhautzenthal: bronze, ceramics, chert/stone, molluscs, amber, animal bone as raw material and animal bone as food remains. This index counts the number of materials associated with each burial, reflecting material diversity. The highest number of materials, five, was found with the body of a 40-50-year-old woman in Grave 123. Four materials each were associated with two men and three women. The average number of materials associated with each body was 1.82: $2.88(\mathrm{n}=17)$ for women and $1.77(n=13)$ for men, $2.36(n=25)$ for adults and $1.44(\mathrm{n}=32)$ for sub-adults. Gender is more significant than age when it comes to material choice.

The average grave good material index was $37(n=58)$ : $58(\mathrm{n}=17)$ for women and $35(\mathrm{n}=13)$ for men, $47(\mathrm{n}=25)$ for adults and $29(\mathrm{n}=32)$ for sub-adults.

\section{Association index}

Following Frank Roy Hodson, who developed this index based on the material from the cemetery of Hallstatt, ${ }^{45}$ the value of a specific artefact type (Table 5) can be derived from the average number of finds associated with this type per individual; the value of a grave good assemblage is the sum of all individual grave good associated values.

Calculating the average number of grave goods associated with each object type allows insights into the early Bronze Age value system. It is perhaps surprising that the

45 Hodson 1990. 
Table 5. The average number of grave goods associated with each object type.

\begin{tabular}{|c|c|}
\hline Object type & \\
\hline ceramic cist & 16.00 \\
\hline bronze cast neck-ring & 13.50 \\
\hline ceramic pot & 11.37 \\
\hline Dentalium pendant & 10.00 \\
\hline bone pin/awl & 9.66 \\
\hline bronze Spiralröllchen & 9.11 \\
\hline animal bones (food remains) & 9.30 \\
\hline chert & 9.25 \\
\hline bronze pin & 9.00 \\
\hline bronze Noppenring, small & 8.67 \\
\hline ceramic fragments of large vessel & 8.50 \\
\hline ceramic cup & 8.36 \\
\hline bronze dagger & 8.25 \\
\hline bronze ring small & 8.17 \\
\hline ceramic jug & 8.15 \\
\hline ceramic bowl & 8.14 \\
\hline bronze sewing needle & 8.00 \\
\hline bronze wire neck-ring & 7.50 \\
\hline stone & 7.50 \\
\hline bronze Noppenring, large & 7.33 \\
\hline ceramic beaker/small bowl & 7.13 \\
\hline ceramic handled bowl & 7.00 \\
\hline bronze awl & 6.50 \\
\hline ceramic disk with hole & 5.00 \\
\hline bronze fragment & 4.33 \\
\hline amber bead & 4.00 \\
\hline bronze cast arm-ring & 3.75 \\
\hline bronze wire arm-ring & 3.33 \\
\hline bone disc & 2.00 \\
\hline bone ring & 2.00 \\
\hline
\end{tabular}

ceramic cist, found in one of the richest grave assemblages, comes out top, but it is a unique form. Cast Ösenbalsreif neck-rings also appear to have a high social value, whereas daggers are barely of higher value than the average of 7.97 . Interestingly, both wire and cast arm-rings are of similar value according to this calculation while the amber bead is of low value. Both were found in children's graves.

The average association index is $26(n=58): 47(n=17)$ for women and $23(\mathrm{n}=13)$ for men, $35(\mathrm{n}=25)$ for adults and $19(\mathrm{n}=32)$ for sub-adults.

\subsection{Social Index for Unterhautzenthal}

The combined Social Index selects five indices (grave depth, grave good count, grave good diversity, material index, association index), calculates their average and scales them to 100. This index was used for comparison with the bio-anthropological data (Table 4). In contrast to Silvia Sprenger, who differentiated between men and women before her calculations and used different methods for each group ${ }^{46}$ the combined social index for Unterhautzenthal aims to cover burials of all ages and both genders the same way. As we have seen in the discussion of individual indices, values for grave depth and construction are highest for men, whereas in all grave good related indices, women come out on top and sub-adults score lower than do adults. The mean combined Social Index is $56(n=17)$ for women and $36(n=13)$ for men.

The cut-off age for adults, from 20 years old, used for the analyses above is arbitrary, albeit biologically based; further investigations into the age structure of Social Indices is therefore necessary ${ }^{47}$ Neonates were not normally associated with any specific objects and were found in graves together with women. The depth of their graves is thus that of their (presumed) mothers. From the age of about 12, juveniles were buried in graves of similar depth as those of adults. During childhood, all grave good related indices broadly increased with age, up to middle childhood. Because subadults usually do not have fully developed morphological sex characteristics, it is unclear if this trend applies to girls and boys equally. Interestingly, the adolescents achieved higher values than the adults did, while the highest values were again reached by mature adults (Table 6).

\section{Physical Characteristics, Health, Sickness and Trauma of the People at Unterhautzenthal}

Some life history events of Bronze Age people remained inscribed in their bones. A palaeopathological analysis was carried out to better understand the health status of the buried individuals as well as the diseases and traumata that directly affected their quality of life. Traces of pregnancies and childbirth cannot be investigated in isolation; body physique, general and obstetric health are linked in many complex ways.

\subsection{Body Stature and Height}

The population of Unterhautzenthal appeared to be morphologically relatively homogenous. Contemporary early Bronze Age groups south of the Danube (differentiated

46 SPRENGer 1999, 67.

47 Cf. Bickle, Fibiger 2014. 
Table 6. Mean Social Index in relation to age.

\begin{tabular}{|l|l|c|c|c|c|c|c|c|c|}
\hline & \multicolumn{1}{|c|}{ Age } & $\mathbf{n}$ & $\begin{array}{c}\text { Grave } \\
\mathbf{d e p t h} \\
\text { index }\end{array}$ & $\mathbf{n}$ & $\begin{array}{c}\text { Grave good } \\
\text { count } \\
\text { index }\end{array}$ & $\begin{array}{c}\text { Grave good } \\
\text { diversity } \\
\text { index }\end{array}$ & $\begin{array}{c}\text { Material } \\
\text { index }\end{array}$ & $\begin{array}{c}\text { Association } \\
\text { index }\end{array}$ & $\begin{array}{c}\text { Social } \\
\text { Index }\end{array}$ \\
\hline baby & $0-1$ years & 2 & 40 & 3 & 0 & 0 & 0 & 0 & 6 \\
\hline toddler & $1-4$ years & 10 & 38 & 11 & 14 & 19 & 27 & 11 & 23 \\
\hline young child & $4-8$ years & 5 & 36 & 6 & 16 & 17 & 20 & 11 & 20 \\
\hline middle-aged child & $8-12$ years & 3 & 37 & 3 & 32 & 36 & 40 & 27 & 37 \\
\hline adolescent & $12-20$ years & 9 & 54 & 9 & 41 & 44 & 42 & 36 & 47 \\
\hline adult & $20-40$ years & 14 & 55 & 16 & 34 & 36 & 45 & 31 & 42 \\
\hline mature adult & $40+$ years & 8 & 61 & 9 & 45 & 44 & 51 & 42 & 53 \\
\hline total & & 51 & & 57 & & & & & 4 \\
\hline
\end{tabular}

according to their material culture as belonging to the Unterwölbling group and the Wieselburg group in western and eastern Lower Austria, respectively) are characterised by a conspicuous phenotypic variation mirrored in significant mean differences of cranial and post-cranial dimensions. In comparison, the predominant skull form of the people north of the Danube appears as long, small and high. In addition, their long bones are larger and more robust. ${ }^{48}$

More recently, the cranial morphology of 171 individuals selected from these three regions was investigated using a geometric morphometric approach in order to gain better insights into mean form differences between populations and between sexes, and to identify a probable migration effect. The results were analysed statistically using principal components analysis (PCA), which supported the observed differences between the Únětice population north of the Danube and the Wieselburg population in eastern Lower Austria. The Unterwölbling group in western Lower Austria, which probably played a key role in trade, overlapped with the other two groups. Moreover, this approach showed that female mean forms were more similar to each other than to male mean forms. This result points to a larger marriage pool of females than males and thus suggests a patrilocal social system. ${ }^{49}$

In our study, the maximum length of the femur was measured, ${ }^{50}$ and from this, the body height of adults from Unterhautzenthal was estimated. ${ }^{51}$ Femora are best represented at Unterhautzenthal and the Fe1 measurement appears to give the most reliable results. Women were on average $156.9 / 160.0 \mathrm{~cm}$ tall, men $165.5 / 168.1 \mathrm{~cm}$. In comparison to other early Bronze Age communities in Austria,

48 Teschler-Nicola 1992, 198.

49 Pellegrini et al. 2011.

50 Fe1, Martin, Saller 1957.

51 Sjøvold 1990. - Ruff et al. 2012. - SLÁdeK et al. 2015. the numbers appear low: Maria Teschler-Nicola ${ }^{52}$ estimated women at $160 \mathrm{~cm}$, men at $170 \mathrm{~cm}$ (Table 7).

There is a positive correlation between women's social index values and body height at Unterhautzenthal ( $\mathrm{n}=15$, $r=0.80, p=<0.001$ ), suggesting that taller women had a higher social status. Interestingly, the reverse is true for men: there is a negative correlation between men's social status and body height $(\mathrm{n}=9, \mathrm{r}=-0.92, \mathrm{p}=<0.001)$, although this may be an artefact of the small sample size. ${ }^{53}$ Body height further appears to be a significant factor in the formation of the preauricular groove (see below).

\subsection{Pathologies}

In order to arrive at a holistic assessment of the health status of children and adults, the skeletal remains were investigated for palaeopathological alterations (Table 8). Amongst the skeletal and dental pathological markers of stress, we recorded porotic hyperostosis, cribra orbitalia, enamel hypoplasias, periostitis, sinusitis, pleurisy, endocranial changes, Harris lines, osteoporosis/demineralisation, and vitamin C and $\mathrm{D}$ deficiency. Caries and tooth loss were used to indicate dental and periodontal disease. Trauma was systematically recorded, differentiating neurocranial from viscerocranial and postcranial lesions. Degenerative joint diseases, if they affected the femoral head or lumbar vertebrae, were noted, as they may have had an effect on the morphology of pelvic features. ${ }^{54}$

52 Teschler-Nicola 1992, 341. - Teschler-Nicola 1994, 173, following Breitinger 1937 and BACH 1965.

53 At Gemeinlebarn, the men's body height differed significantly between the upper and lower social class, whereas the difference was less pronounced in women: cf. Teschler-Nicola 1989.

54 Larsen 1997. - Ortner 2003. - Roberts, Manchester 2005. Steckel et al. 2006. - Judd 2008. - Gresky, Schultz 2011. - Martin, Harrod, Pérez 2013. - Grupe, Harbeck, McGlynn 2015. 
Table 7. Estimation of mean body height of female and male adult individuals from Unterhautzenthal based on femoral measurements using two different formulae (SJøvold 1990. - RuFF et al. 2012).

\begin{tabular}{|c|c|c|c|c|c|c|c|c|c|}
\hline Individual & $\begin{array}{c}\text { Femur 1: } \\
\text { maximum } \\
\text { length }(\mathrm{cm})\end{array}$ & $\begin{array}{c}\text { Body } \\
\text { height } \\
\text { females* }\end{array}$ & $\begin{array}{l}\text { Body } \\
\text { height } \\
\text { males* }\end{array}$ & Individual & $\begin{array}{c}\text { Femur 1: } \\
\text { maximum } \\
\text { length }(\mathrm{cm})\end{array}$ & $\begin{array}{c}\text { Body } \\
\text { height } \\
\text { females } *\end{array}$ & $\begin{array}{c}\text { Body } \\
\text { height } \\
\text { males }^{* *}\end{array}$ & $\begin{array}{l}\text { Minimum } \\
\text { body } \\
\text { height } * \%\end{array}$ & $\begin{array}{c}\text { Maximum } \\
\text { body } \\
\text { height** }\end{array}$ \\
\hline 28 & 39.8 & 150.6 & & 28 & 39.8 & 153.7 & & 149.2 & 158.2 \\
\hline 88 & 37.0 & 143.1 & & 88 & 37.0 & 146.1 & & 141.6 & 150.6 \\
\hline 90 & 43.3 & 160.0 & & 90 & 43.3 & 163.2 & & 158.7 & 167.7 \\
\hline 93 & 43.8 & 161.4 & & 93 & 43.8 & 164.6 & & 160.1 & 169.0 \\
\hline 95 & 42.3 & 157.3 & & 95 & 42.3 & 160.5 & & 156.0 & 165.0 \\
\hline 100 & 42.9 & 159.0 & & 100 & 42.9 & 162.1 & & 157.6 & 166.6 \\
\hline 102 & 44.1 & 162.2 & & 102 & 44.1 & 165.4 & & 160.9 & 169.9 \\
\hline 109 & 43.9 & 161.7 & & 109 & 43.9 & 164.8 & & 160.3 & 169.3 \\
\hline 116 & 45.0 & 164.6 & & 116 & 45.0 & 167.8 & & 163.3 & 172.3 \\
\hline $122 \mathrm{~B}$ & 41.8 & 156.0 & & $122 \mathrm{~B}$ & 41.8 & 159.1 & & 154.6 & 163.6 \\
\hline 123 & 43.4 & 160.3 & & 123 & 43.4 & 163.5 & & 159.0 & 168.0 \\
\hline 128 & 41.4 & 154.9 & & 128 & 41.4 & 158.1 & & 153.6 & 162.5 \\
\hline 134 & 40.3 & 152.0 & & 134 & 40.3 & 155.1 & & 150.6 & 159.6 \\
\hline 138 & 40.7 & 153.0 & & 138 & 40.7 & 156.2 & & 151.7 & 160.6 \\
\hline 16 & 46.8 & & 170.1 & 16 & 46.8 & & 172.7 & 168.2 & 177.2 \\
\hline 23 & 45.5 & & 166.6 & 23 & 45.5 & & 169.2 & 164.7 & 173.7 \\
\hline 83 & 44.7 & & 164.4 & 83 & 44.7 & & 167.0 & 162.5 & 171.5 \\
\hline 84 & 46.3 & & 168.8 & 84 & 46.3 & & 171.3 & 166.8 & 175.8 \\
\hline 86 & 46.0 & & 168.0 & 86 & 46.0 & & 170.5 & 166.0 & 175.0 \\
\hline 94 & 42.9 & & 159.5 & 94 & 42.9 & & 162.1 & 157.6 & 166.6 \\
\hline 111 & 43.5 & & 161.2 & 111 & 43.5 & & 163.7 & 159.3 & 168.2 \\
\hline $122 \mathrm{~A}$ & 45.7 & & 167.2 & $122 \mathrm{~A}$ & 45.7 & & 169.7 & 165.2 & 174.2 \\
\hline 124 & 44.5 & & 163.9 & 124 & 44.5 & & 166.5 & 162.0 & 170.9 \\
\hline Mean & & 156.9 & 165.5 & Mean & & 160.0 & 168.1 & & \\
\hline
\end{tabular}

* RufF et al. $2012 \quad *$ S

Table 8. Health status indicators recorded for Unterhautzenthal.

\begin{tabular}{|l|l|l|}
\hline \multirow{3}{*}{$\begin{array}{l}\text { Skeletal and dental pathological } \\
\text { markers of deprivation }\end{array}$} & $\begin{array}{l}\text { Non-specific indicators } \\
\text { of stress and infections }\end{array}$ & $\begin{array}{l}\text { porotic hyperostosis (stage 0-3) } \\
\text { cribra orbitalia (stage 0-3) } \\
\text { enamel hypoplasia (stage 0-3, in which 3 is more than one lesion present) } \\
\text { periostitis (adapted stage 0-4) } \\
\text { sinusitis and pleurisy (absent/present) } \\
\text { endocranial changes (vessel impression, new bone formation, perisinusitis; } \\
\text { absent/present) }\end{array}$ \\
\cline { 2 - 3 } & Metabolic diseases & $\begin{array}{l}\text { Harris lines (absent/present) } \\
\text { osteoporosis/demineralisation (absent/present) } \\
\text { Vitamin C deficiency (scurvy, stage 0-3, 3 = possible scurvy) } \\
\text { Vitamin D deficiency (rickets, stage 0-3, 3 = possible rickets) }\end{array}$ \\
\hline Dental and periodontal disease & caries and tooth loss (stage 0-3, 3 indicating two or more caries lesions/intravitally lost teeth) \\
\hline Degenerative joint disease & femoral head (stage 0-5) \\
\cline { 2 - 3 } & lumbar vertebrae (stage 0-3) \\
\hline Trauma & neurocranial/viscerocranial/postcranial lesions (absent/present, healed/unhealed) \\
\hline
\end{tabular}




\section{Non-specific indicators of stress and infections}

Porotic hyperostosis and cribra orbitalia are conditions exhibiting lesions at the outer table of the cranial vault and the orbital roofs, indicative of nutritional stress. They do not necessarily occur together, ${ }^{55}$ and chronic anaemias in childhood and adolescence, especially the megaloblastic form caused by dietary deficiencies and parasites, seem to be the most probable cause for porotic hyperostosis. ${ }^{56}$ The multifactorial causes include vitamin $\mathrm{C}$ deficiency, vitamin B12 deficiency especially during nursing, and increased gastrointestinal infections around the time of weaning. ${ }^{57}$ Cribra orbitalia was present in three and absent in 25 adults. Two female individuals (28 and 134) were found with a small cluster of fine foramina, and one male individual had a substantial area covered by foramina (16, from a storage pit). Cribra orbitalia was also found in six of nine observable children. They were 3-4 (133), 6 (27B), 6-7 (120), 7-8 (104), 8-9 (127) and 9-11 (136) years old when they died. Three of them had substantial areas of the orbital roofs covered by lesions.

Porotic hyperostosis in the form of slight pitting or severe parietal porosity was recorded in three males $(16,84$, $86)$ and two females (93A, 116A) of 19 adult individuals. The 14-15-year-old from storage pit 18 had slight porotic hyperostosis at both parietals and the occipital bone.

Linear enamel hypoplasias are disruptions in the formation of enamel in form of hypoplastic lines visible at the outer tooth surface. They indicate periods of physiological stress in early childhood and can be due to nutritional and therefore metabolic stress. ${ }^{58}$ Recent clinical studies also point to causes like fever, infectious diseases and crisis periods in childhood. ${ }^{59}$ Transverse lines on the surface of the tooth crowns in incisors and canines are caused by events during the second to sixth year of age and are often related to dietary changes such as weaning. ${ }^{60}$ Enamel hypoplasias in stages 2-3 were visible in the mandibular deciduous canines of a two-year-old from the double burial, Feature 27, and the 3-4-year-old from the triple burial, Grave 95, suggesting stress from around the fifth month in utero to the eighth month after birth. ${ }^{61}$ In the adult sample, enamel hypoplasias were investigated in 12 incisors and 13 canines of the upper

\footnotetext{
55 And often have different etiologies, WALKER et al. 2009.

56 Grupe, Harbeck, McGlynn 2015, 347-348.

57 Martin, Harrod, Pérez 2013, 161.

58 White, Black, Folkens 2012, 455. - Martin, Harrod, Pérez 2013,160 .

59 Grupe, Harbeck, McGlynn 2015, 351.

60 Goodman, Rose 1990. - King, Humphrey, Hillson 2005

61 Reid, Dean 2006. - Steckel et al. 2006. - White, Black, Folkens

2012, 387. - Grupe, Harbeck, McGlynn 2015, 351.
}

jaw, as well as 10 incisors and 21 canines of the lower jaw. Male individuals 81, 94 and 124 as well as female individuals 93A, 95, 102 and 122B were affected. Enamel hypoplasias may correspond to weaning ages in younger children, whereas in later life they may be connected to childhood diseases (Fig. 3).

Periostitis is an inflammation of the periosteum, the tissue covering all the bones in the body, and is primarily caused by bacterial infection, although other factors such as local trauma, vitamin $\mathrm{C}$ deficiency or autoimmune diseases may play a role. ${ }^{62}$ One male (81) and four females (93A, $100,103 \mathrm{~A}, 122 \mathrm{~B}$ ) of a sample of 20 adults were affected by striations at the femora caused by osteoperiostitis. Four males $(16,81,86,111)$ and three females $(93,103 \mathrm{~A}, 122 \mathrm{~B})$ were symmetrically affected by osteoperiostitis at the tibiae. Three further women had osteoperiostitis at the right tibiae (only the right side of Individual 95 was affected, the left tibiae of $93 \mathrm{~A}$ and 138 were not available). In children, osteoperiostitis was noted in six of 15 right femora and four of 17 left femora, as well as six of 13 right tibiae and four of 10 left tibiae. New bone formation, presumably from active periostitis, was present in the two-year-old from Grave 96. The 3-4-year-old buried in the triple burial, Grave 95, had osteoperiostitis on the tibial fragments, and the 4-5-yearold from the same grave exhibited striae from healed osteoperiostitis on femoral and tibial fragments.

Two of the paranasal sinuses, the maxillary and frontal sinuses, were analysed for signs of sinusitis. The causes of the bone manifestations are severe acute (often virally caused) or chronic respiratory infections, and in individuals with a weakened immune defence system, infants and elderly, a bacterial superinfection is possible. Sinusitis is associated with narrow anatomical structures as well as unfavourable living and climatic conditions. ${ }^{63}$ Sinusitis of the sinus frontalis was found in two female individuals $(102,128$, of $n=19)$ and none of the four investigated children. Pathologies in the maxillary sinus were found in four females $(28,123,88$, and 128) and one male (132) out of 23 adult individuals, and in three out of seven children (14-15-year-old from Feature 18, 3.5-4-year-old from Grave 87, 9-11-year-old from Grave 136).

Perisinusitis is represented through disseminated fine secondary new bone formations in the region of the venous sinuses at the internal lamina of the skull (Sinus sagittalis superior, Confluens sinuum, Sinus transversus, Sinus sigmoideus). They can be caused by a thrombosis of the sinus

62 Martin, Harrod, Pérez 2013, 162. - Grupe, Harbeck, McGLYNN 2015, 367.

63 Schultz 1988. - Gresky, Schultz 2011. 


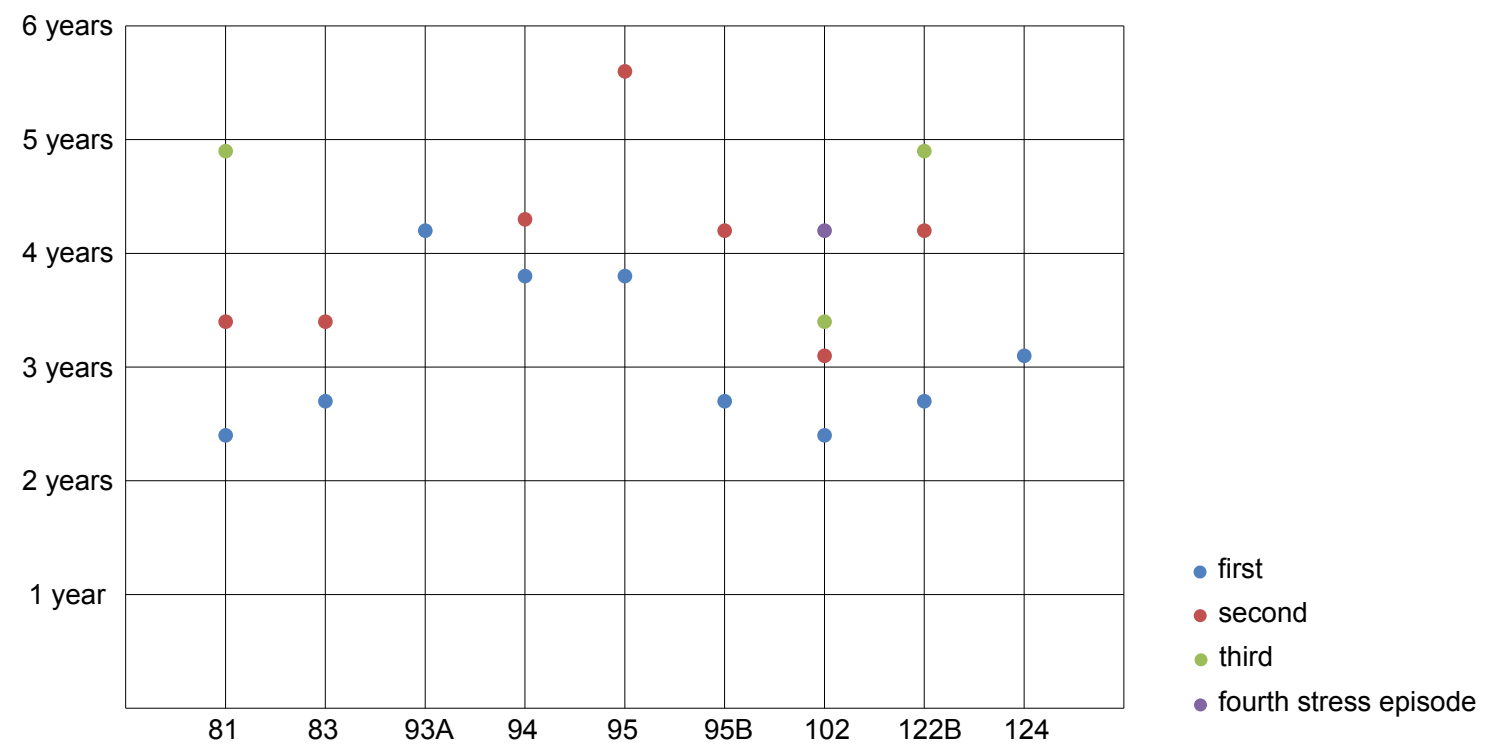

Fig. 3. Enamel hypoplasias and the estimated ages of formation in adult individuals.

or, more frequently, by a purulent inflammatory process of the middle ear. ${ }^{64}$ No pathologies were found at the superior sagittal sinus on the inside of the skull $(n=24)$. Only one male individual (111) of 23 adults showed pathological alterations of the transverse sinus. Generalised new bone formation on the internal lamina of the skull typically indicates an acute inflammation of the meninges, usually resulting from bacterial infection. ${ }^{65}$ It was noted in two female individuals $(102,109 \mathrm{~A})$ out of 27 . However, the local new bone formation at the fossae anteriores and the left fossa medialis of 109A suggest a haematoma. New bone formation in children was noted in two out of 12 , the 3-4-yearold from Grave 133 and the 9-11-year-old from Grave 136. This child shows finely porous new bone formation in the pronounced imprints of the gyri of the frontal bone (impressiones digitatae), indicating an inflammation of the meninges accompanied by increased brain pressure. ${ }^{66}$ Further, this child suffered from severe cribra orbitalia (stage 3 ) and stomatitis, and showed a weakly developed Harris Line in the left distal femur and proximal tibia.

Intensified vessel impressions on the internal lamina of the cranium were present in one male and two female individuals (of 27). The 40-60-year-old man from Grave $86(n=21)$ had fine vessel imprints at the left sigmoid sinus, perhaps related to a haemorrhagic-inflammatory process. The 35-45-year-old mother in Grave 95 showed deep

64 SChultz 1988, 489.

65 SChultz 1988. - Lewis 2004, 84.

66 Schultz 1993, 51. impressions of the arteria meningea media, whereas the 40-50-year-old woman from Grave 128 had weak impressions of the arteria meningea media visible at the surface of the parietal bones.

Pleurisy, which is an inflammation of the membranes surrounding the lungs, can be caused by an encroachment of infectious-inflammatory processes of the pulmonary tissue (e.g. pneumonia, pulmonary tuberculosis, pulmonary abscess or infarction). Traces of these processes are frequently noticed at the inside of the ribs. ${ }^{67}$ Pleurisy was found in two male $(16,84)$ of 24 individuals; it was further present in four of 14 children (129, aged 3-4, 127, aged 8-9, 139, aged 9-11 and 18, aged 14-15).

\section{Metabolic diseases}

Three children were $\mathrm{x}$-rayed to search for Harris lines (more correctly called recovery lines) as indicators of arrested growth in childhood. These can be seen as dense transverse lines in the radiographs of long bones. The interpretation of Harris lines remains controversial: the primary reasons for their presence are attributed to nutritional deficiencies or diseases during childhood, but mental stress is also taken into consideration. ${ }^{68}$ It has recently been suggested that Harris lines are the results of normal growth spurts and growth. ${ }^{69}$ The radiographs of femora and tibiae of the

67 KLINGNER 2016, 480.

68 Roberts, Manchester 2005, 240. - Grupe, Harbeck, MCGLYNN 2015, 349.

69 Papageorgopoulou et al. 2011. 
3-4-year-old from Grave 133 and the 2-3-year-old from Grave 195 did not show recovery lines, but the 9-11-yearold from Grave 136 had one weak recovery line at the distal end of the left femur and the proximal end of the left tibia.

Osteoporosis is a decrease in bone mass, characterised by qualitatively normal but quantitatively deficient bone. ${ }^{70}$ The micro-architectural bone deterioration and subsequent bone fragility causes an increased risk of fracture. ${ }^{71}$ It occurs two to three times more frequently in women than in men due to low oestrogen levels. ${ }^{72}$ Most often, bone changes are visible in radiographs of the axial part of the skeleton. ${ }^{73}$ Osteoporosis and osteomalacia, conditions linked to reduced mineral content in the bone, can occur as hybrid disease patterns and cannot be clearly differentiated radiographically. ${ }^{74}$ Osteoporosis is frequently caused by pregnancies, as the foetal organism develops via the calcium metabolism of the mother. If insufficient calcium is taken in through the diet of the mother, bone loss will occur. ${ }^{75}$ Breastfeeding may also contribute to this mechanism. Long-term breastfeeding, together with a high birth rate, has been found to be a risk factor for developing postmenopausal osteoporosis. ${ }^{76}$ Conversely, other studies based primarily on modern, well-nourished populations, have found that breastfeeding reduces the risk of osteoporotic fracture. ${ }^{77}$

Bone loss is indicated by lightweight bones in the skeletal analysis. At Unterhautzenthal, this condition was noted in individuals 16, 18, 28, 88, 122B, 128 and 134. Radiographs of the fourth or fifth lumbar vertebra confirmed the condition in three individuals: the 14-15-year-old adolescent from settlement Feature 18 with generally very light bones showed an increased radiolucency of the fifth lumbar vertebra. This condition may be the result of malnutrition, in particular scurvy. ${ }^{78}$ The 35-50-year-old woman from Feature 88 and the 40-50-year-old woman from Feature 128 both show a high radiolucency in the fifth lumbar vertebra. In these two women, the loss of bone may be related to recurrent pregnancies and long-term breastfeeding. ${ }^{79}$

Scurvy, a disease caused by vitamin C deficiency, may be linked in some populations to weaning patterns and

70 Resnick, Niwayama 1995, 1783.

71 Guglielmi, Muscarella, Bazzocchi 2011, 1343.

72 Grupe, Harbeck, McGlynn 2015, 378.

73 Guglielmi, Muscarella, Bazzocchi 2011, 1347-1348.

74 Schamall 2008, 10.

75 Resnick, Niwayama 1995, 1785-1788.

76 Dursun et al. 2006, 654.

77 DuAn, Wang, JiAng 2017.

78 Resnick, NiwAyama 1995, 1785.

79 Cf. KNEISSEL et al. 1994. childhood diets. ${ }^{80}$ In the skeleton, severe cases of scurvy are recognisable by substantial new bone appositions, for example at the long bone shafts; in children, they are seen in particular at the maxilla and the sphenoid. ${ }^{81}$ Signs of scurvy were found in one of 27 adult individuals at Unterhautzenthal. The young man from Grave 81, 17-20 years old, exhibited the typical layer of fine porous bone on the left scapula, the right clavicle, humeri, radii and ulnae on both sides, femora, tibiae and fibulae on both sides, the dorsal right ilium, the cervical vertebrae, ribs, as well as carpals and finger bones. Signs of scurvy were also present in four of 17 children. The 1-6-year-old from Grave 106 had extensive new bone formation at fragments of the femora, tibiae, radius and ulna fragments; the 2-3-year-old from Grave 105 at the dorso-lateral side of both femoral shafts, and the 3-4-yearold from Grave 133 at both ulnae and at the right femur. Localized but distinct signs of scurvy were also found on the right clavicle and both dorsal humeri of the 14-15-yearold individual from settlement pit Feature 18, most likely causing the bone loss described above.

Fourteen children were checked for signs of rickets, a disease related to vitamin $\mathrm{D}$ metabolism, ${ }^{82}$ with no indication of this disease in our sample.

\section{Dental and periodontal disease}

Intravital tooth loss was noted in the 35-50-year-old woman from Grave 88 and the 50-60-year-old woman 109A, whose tooth loss may have coincided with her cranial injury. In the maxilla, only the right third molar remained, and the mandible held only the second and third molar on the left side, one of which was affected by caries. This is one of the few incidents of caries at Unterhautzenthal. The 45-60-year-old woman from Grave 125 had no molars left in the mandible. Tooth decay has long been associated with childbearing, although no clear causal link has been found. Substantial abrasion of the teeth was noted frequently in this group, which may be caused by habitual chewing in the course of using teeth as tools in addition to substantial amounts of grit in grain-based foodstuffs. The 40-50-year-old women from Grave 90 (Fig. 4) and 123, as well as the 45-60-yearold woman from Grave 125 were affected; the latter had lost all the teeth in her mandible, and the remaining teeth of the maxilla were strongly abraded. The 30-40-year-old man from Grave 111 showed substantial abrasion of the teeth; his first upper left molar had acquired a concave shape best

80 MAYs 2014, 55

81 Ortner 2003, 384-386. - STECKEL et al. 2006, 35. 82 Roberts, Manchester 2005, 237. - Grupe, Harbeck, MCGLYNN 2015, 376. 

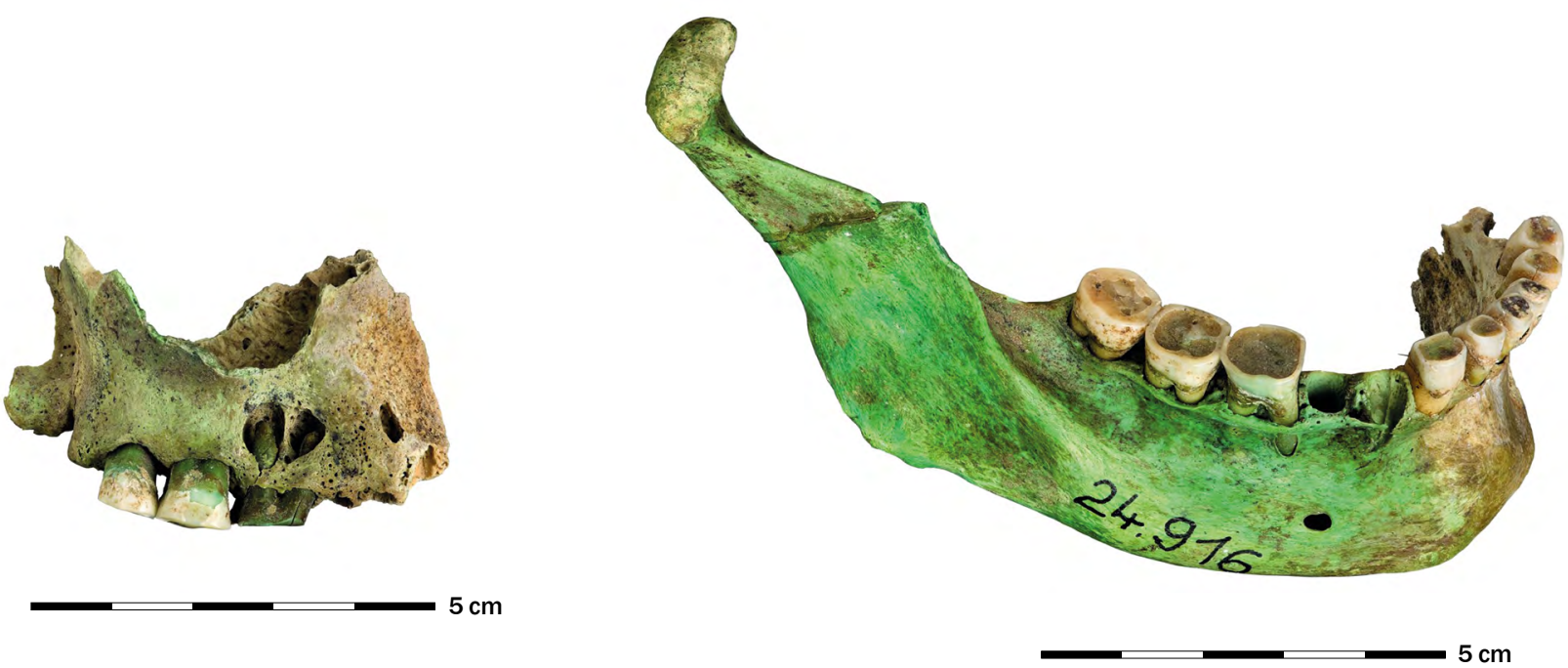

Fig. 4. Heavy dental wear at maxillary (left) and mandibular (right) teeth in the 40-50-year-old woman from Grave 90. The right upper first molar is worn down to the root, causing an apical abscess in the maxilla (Photo: W. Reichmann, ( ) NHM Vienna).

explained by the use of a specific tool..$^{83}$ Tooth abrasion particularly of the maxilla was accompanied by intravital tooth loss in the 40-60-year-old man from Grave 123.

\section{Degenerative joint disease}

Osteoarthrosis, recognisable on the skeleton as osteophytic marginal lipping of a joint and alteration of the joint surface or eburnation, is the result of workload and activity over the lifetime. It is sometimes combined with,or primarily caused by, an inflammatory process. ${ }^{84}$ Predictably, older individuals were affected by more severe degenerative conditions at Unterhautzenthal. Nearly all vertebrae of the 35-50-yearold male from Feature 83 were affected by substantial osteophyte growth, especially at the lower thoracic and lumbar vertebrae, where the formation of bony junctions had begun; the sixth and seventh cervical vertebrae were fused (perhaps congenitally). Further, this man exhibited signs of asymmetrical wear during his lifetime: severe osteoarthritic changes at the last cervical and first thoracic vertebrae were visible on the left side. In combination with the pronounced muscle insertions in the shoulder region and the right hand, this suggests the carrying of heavy loads..$^{85}$ Three more men, the 40-60-year-old from Grave 94, the 35-40-year-old from the triple burial, Grave 122, and the 35-50-year-old from Feature 132 showed degenerative changes of the spine.

83 WoOd 1992.

84 Osteoarthritis: Schultz 1988. - Steckel et al. 2006, 31. - WalDRON 2009, 26-40.

85 Cf. Pany-Kucera 2015.
In women, osteoarthrosis may be linked to repeated weight bearing during pregnancies, ${ }^{86}$ as well as the strain of carrying children after birth. ${ }^{87}$ Substantial osteophyte growth at the thoracic and lumbar vertebral bodies was noted in the 35-50-year-old woman from Feature 88. The 40-50-year-old woman from Feature 123 showed degenerative changes at some of her cervical intervertebral joints and the fourth to fifth lumbar vertebra, as well as at the left shoulder joint and joints of the hands. The 40-50-year-old from Feature 128 had several degenerative joint changes, at the axis, the second cervical vertebra and the lumbar spine; the carpal and tarsal bones showed strong arthroses and substantial marginal ridges had formed at the knee joints. Her shoulder was affected by trauma that impeded movement (see below); her skeleton appeared emaciated by a life of hard work. The oldest woman at Unterhautzenthal, the 55-65-year-old from Grave 138, likewise had degenerative changes at the shoulder, corresponding to strong muscle insertions at the humeri and ulnae.

\section{Trauma}

Two male $(16,81)$ and two female $(93,109 \mathrm{~A})$ individuals had signs of neuro- and viscerocranial fractures (out of 31 and 28 observable individuals respectively). A round, healed depression fracture, c. $50 \mathrm{~mm}$ in diameter, on the left parietal bone was present in the 35-45-year-old male from storage

86 BLIDDAL et al. 2016.

87 LeE 1972. - Thompson 2013. 


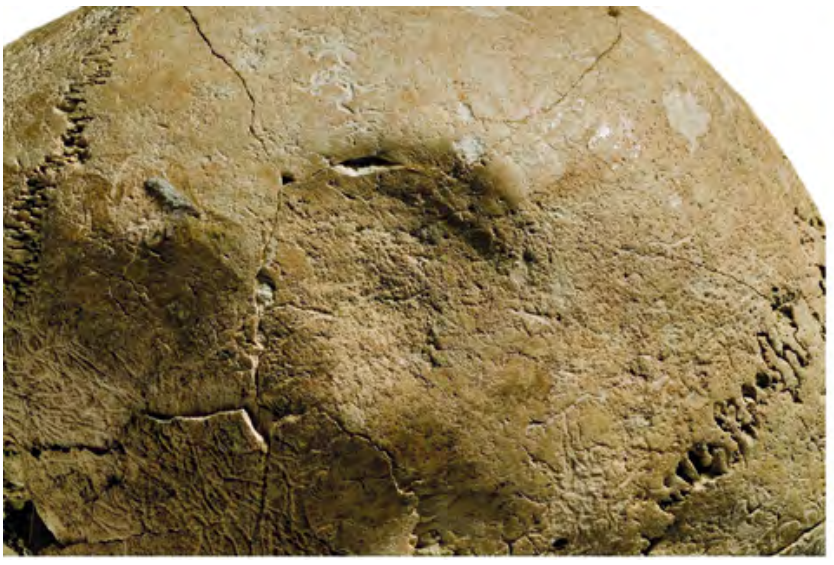

$5 \mathrm{~cm}$

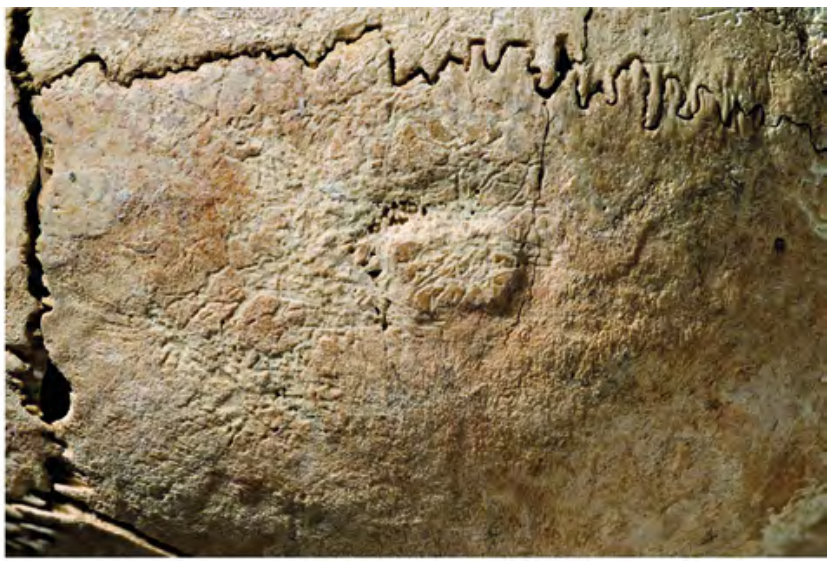

$5 \mathrm{~cm}$

Fig. 5. Left: Healed depression fracture at the parietal of the 35-45-year-old male from pit Feature 16. Right: Semi-circular healed depression fracture at left parietal of the 17-20-year-old male from Grave 81 (Photo: W. Reichmann, @ NHM Vienna).

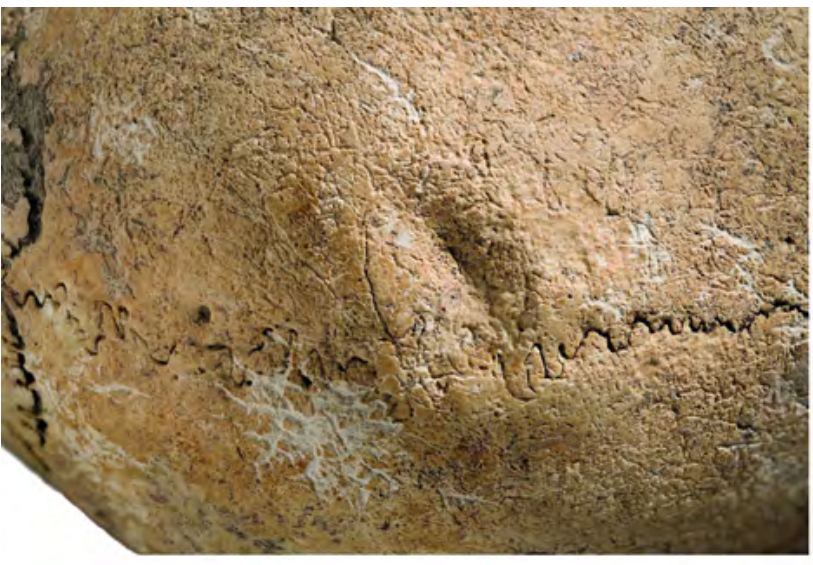

$5 \mathrm{~cm}$

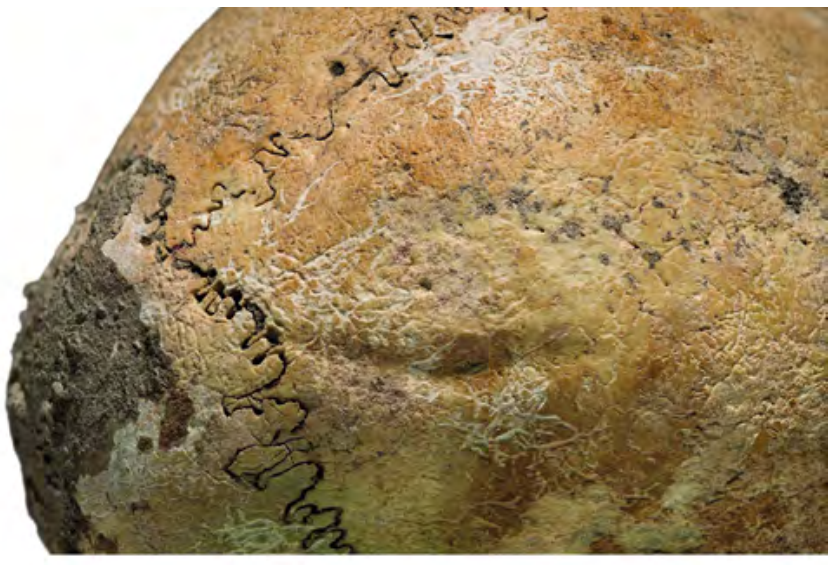

$5 \mathrm{~cm}$

Fig. 6. Healed depression fractures at the left and right parietals of the 35-45-year-old woman from Grave 93 (Photo: W. Reichmann, (C) NHM Vienna).

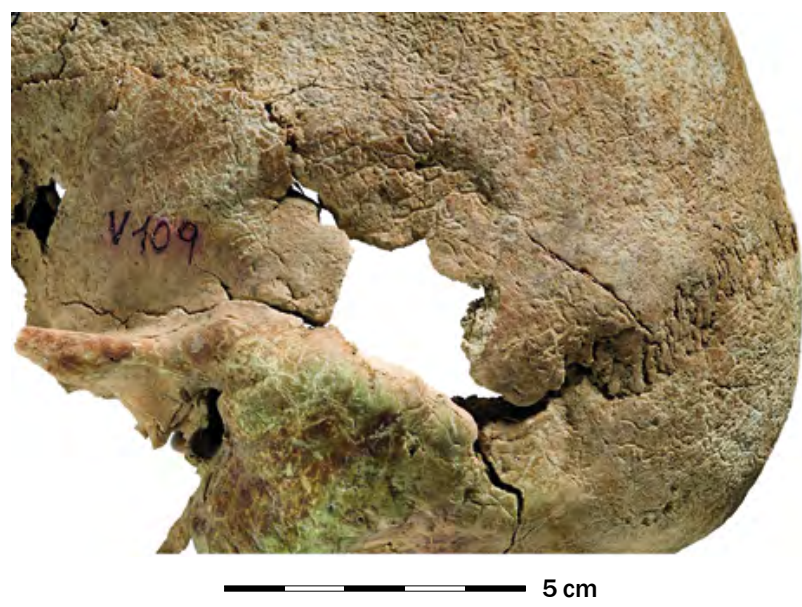

Fig. 7. Healed depression fractures at the left parietal/occipital and left parietal/temporal bone of the 40-60-year-old woman from Grave 109 (Photo: W. Reichmann, ( ) NHM Vienna).

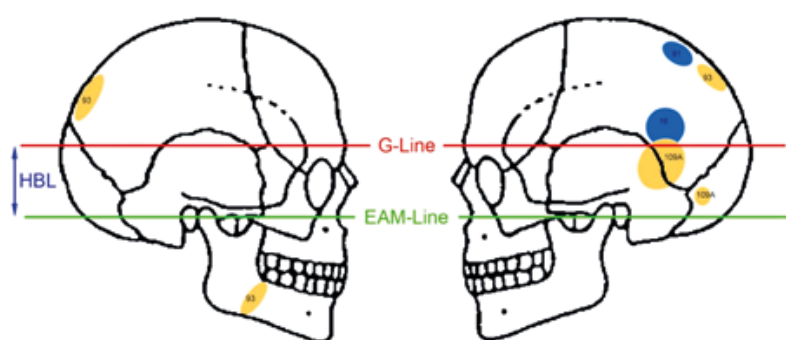

Fig. 8. Location of cranial fractures in Unterhautzenthal adults, in relation to the Hat Brim Line (HBL, G-Line: glabella, EAM-Line: external auditory meatus (Photo: W. Reichmann, () NHM Vienna). 
pit Feature 16 (Fig. 5 left). The 17-20-year-old male from Grave 81 had a healed, superficial depression fracture on the left parietal bone. The rounded margins of this 20 by $15 \mathrm{~mm}$ diameter semi-circular lesion may indicate scraping for medical treatment (Fig. 5 right).

The two women were affected by multiple skull traumata of the neuro- and viscerocranium. The 35-45-yearold woman from Grave 93 showed two healed depression fractures of the neurocranium, one on the left parietal bone close to the sagittal suture (c. 20 by $30 \mathrm{~mm}$ ), and one on the right parietal bone (c. 40 by $10 \mathrm{~mm}$, Fig. 6). She also had a healed fracture of the mandibular ramus.

The 40-60-year-old woman from Grave 109, buried with remains of a neonate, had two healed depression fractures, one located on the left parietal/occipital bone (lambdoid suture) close to the mastoid (oval, c. 15 by $10 \mathrm{~mm}$ ) and one on the left parietal/temporal bone (rectangular with rounded edges, c. 40 by $20 \mathrm{~mm}$, Fig. 7). She also had a healed greenstick fracture of the left distal ulnar shaft. Of the 13 children and adolescents for which trauma of the skull could be observed, only the six-year-old from double burial, Feature 27 , showed traces of a perimortem fracture of the right parietal bone. However, this may have been caused by placing the child on the right side in the grave for burial, which may have involved the application of a significant force.

The location of cranial fractures in the Unterhautzenthal adults were concentrated on the left side of the cranium, in particular the left parietal and temporal bones. This indicates inter-personal violence by a right-handed attacker. Traumatic lesions above the Hat Brim Line ${ }^{88}$ are more likely the result of blows than accidental falls. At Unterhautzenthal, most injuries were above the Hat Brim Line (Fig. 8). Unterhautzenthal, and the comparable community at Pottenbrunn south of the Danube, appear to show similar rates of healed depression fractures of the skull (4 in 28 and 5 in 36, respectively), whereas individuals buried at Hainburg-Teichtal farther down the Danube were less affected by head injuries that left traces on the skeleton (7 in 172 cases). ${ }^{89}$

Healed postcranial fractures on the upper body were observed in four women (109A, 116A, 125, and 128) and one man (86) out of 30 individuals. Greenstick fractures of the left distal ulnar shaft were present in 109A and 125; in addition, 125 had an incomplete fracture of one rib fragment. The middle of the corpus of the right clavicle was fractured in 116A, and 128 had a fracture of the left clavicle as well as healed rib fractures. The $40-50$-year-old female

88 Kremer et al. 2008. - Kremer, SAuvageau 2009.

89 SPANnAgl-STEINER et al. 2016. from Feature 128 also had a humeral subluxation of the right shoulder that was not reset properly. These conditions may be due to accidents. The male individual from 86 had an atrophic acromial end of the left clavicle, possibly due to a fracture. The 3-4-year-old from Grave 133 had a fracture of the right distal humeral shaft, which was partially healed in malposition (Fig. 9), as well as finely porous new bone formation on both ulnae and the right femur.

The one-year-old from Feature 130 appeared to have a local haematoma with finely porous new bone formation on the lateral side of a rib fragment. The 8-9-year-old from Feature 127 showed reactive osteomyelitis on one rib, possibly caused by trauma.

Healed post-cranial fractures of the lower body were found in two females $(90,102)$ and one male $(81)$ out of 29 individuals. The female from Grave 90 had a splintered fracture of the posterior process of the left talus and the female from Grave 102 a longitudinal fracture of the left patella. The left tibia shaft of the young male from Grave 81 was
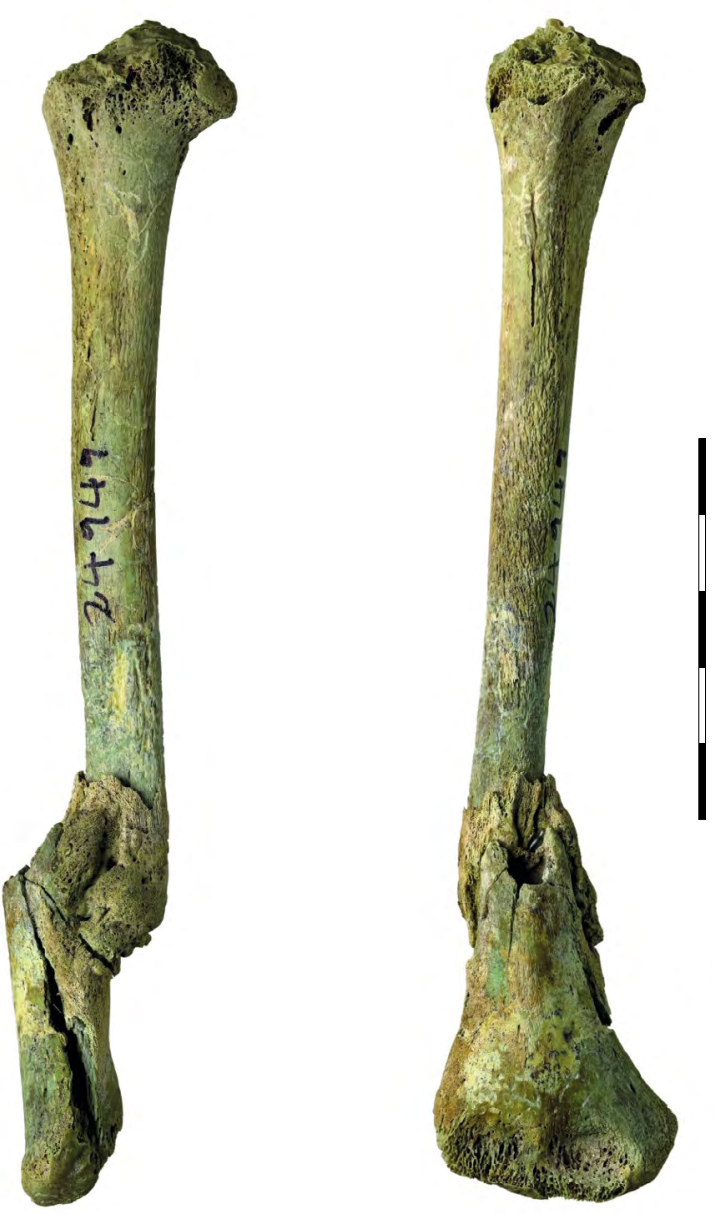

Fig. 9. Fracture of the right distal humeral shaft in the 3-4-year-old from Grave 133 (Photo: W. Reichmann, (C) NHM Vienna). 
thickened at the upper part above the nutritional foramen (callus), perhaps due to a greenstick fracture, with strong surrounding osteoperiostitis.

There was no relationship between the incidence of traumata and the Social Index of the buried individuals. Even the two women who were most likely to have been the subjects of abuse, 93 and 109, had above-average Social Index values of 55 and 58 , respectively. The high rate of traumatic injuries at Unterhautzenthal suggests repeated interpersonal violence.

\subsection{Pelvic Features}

Pregnancy and childbirth are events of high physical strain that can leave physiological traces on the female skeleton. Specific bone reactions in the pelvis may relate to obstetric events, although their presence cannot determine with certainty if a woman has given birth. Evidence for distinct changes in more than one of the pelvic features - also known as 'parity features' and 'scars of parturition' - increases the reliability of parity assessment. ${ }^{90}$ Pelvic features vary between individuals and populations; they stand in a causal relationship with a variety of factors, including age, weight, stature, biomechanical and musculoskeletal conditions, pelvic dimensions, hormonal influences, and childbirth positions. Their detailed interconnections are still poorly understood ${ }^{91}$ and both women who have never given birth and men sometimes have pelvic features in various forms. ${ }^{92}$ However, studies indicate that frequent birth events intensify pelvic changes. ${ }^{93}$

In order to move the discussion forward, this study investigated pelvic features that may be related to birth events (Table 9) and correlated these with information pertaining to body stature and other skeletal health indicators, as well as archaeological context information such as the co-presence of neonates and small children. Pelvic changes were recorded in ten male and fifteen female individuals with preserved pelvic remains; they were all adults apart from three adolescents aged between 17 and $20(81,100,122 \mathrm{~B})$.

The preauricular sulcus, a depression at the ilium next to the sacroiliac joint, was examined to determine its stage of development, ${ }^{94}$ length, width, depth ${ }^{95}$ and shape. ${ }^{96}$ Lesions on the dorsal pubic surface, also known as 'dorsal pubic

90 Kelley 1979. - Galloway 1995.

91 Putschar 1931, 185. - Cox 2000. - Tague 2000. - Ubelaker, De

La Paz 2012. - MaAss, Friedling 2016.

92 Perréard Lopreno, Bruzek 2010.

93 Putschar 1931. - Decrausaz 2014. - MaAss, Friedling 2016.

94 After STECKEL et al. 2006.

95 After Decrausaz 2014.

96 After BRŮŽEK 2002. pitting', were also recorded. ${ }^{97}$ Extensions of the pubic tubercle, to which the inguinal ligament of the external oblique abdominal muscles is attached at the pubic bone, were noted and measured..$^{98}$

In addition to the pelvic features noted in the literature, we also recorded exostoses at the margin of the sacroiliac joint (the auricular surface of the ilium), as well as exostoses and lesions on the ventral pubic surface and muscle markers of the gluteal muscles. Fractures of the ischium, pubis and sacrum, which often relate to accidents, but may also be related to the birth process, ${ }^{99}$ were not found in our sample. Degenerative and congenital changes at the spine, the hip and the knee affect the mobility of the pelvic girdle biomechanically, and were therefore recorded in conjunction with the pelvic features. Pelvic changes were documented separately for the left and right sides, although most were symmetrical (Appendix 1); both sides were not available for study in all cases. The strongest signal measured on either the right or the left side was taken as indicative for the analysis.

The region of the preauricular sulcus at the pelvic bones was available in 22 of 31 individuals: 9 males and 13 females. The area of the sulcus showed a smooth surface in eight males and one female, the 25-35-year-old from the archaeologically unremarkable Grave 102. A weakly developed sulcus was present in one male $(124,35-50$ years old) and six females $(90,109 \mathrm{~A}, 116,122 \mathrm{~B}, 128,134)$. A moderately developed sulcus was exclusively observed in females, specifically the five women from graves 88, 93, 100, 123 and 125. The female from Grave 28 showed a large, well-defined sulcus at the left side (Fig. 10).

There is a clear association between sex and the presence of the preauricular sulcus (Table 10, $p=0.001$, Fisher's exact test, Monte Carlo $95 \%$ ). Kendall's tau c for ordinal variables $(\tau=0.826)$ revealed a strong association ( $\mathrm{p}$-value $<$ 0.001 , Monte Carlo test). However, a significant association was expected, considering that the preauricular sulcus is one criterion of sex determination.

The region of the pubic tubercle was available for study in 4 males and 11 females. A small, extended tubercle was found only in females, the six women: 95, 109A, 122B, 123, 128 (Fig. 11), and 134. Pyramidal or ridge-like elevations at the pecten ossis pubis, located somewhat dorsally to the pubic tubercle, were found in individuals 109A and 123; sharp ridges on the pecten ossis pubis were observed in

97 After Stewart 1970. - Ullrich 1975.

98 After SNOdgrass, Galloway 2003. - MaAss 2012.

99 Wurdinger et al. 2002. - Brandon et al. 2012. - Proisy et al. 2014. 
Table 9. Pelvic features recorded for Unterhautzenthal.

\begin{tabular}{|c|c|}
\hline Pelvic feature & Description of pelvic feature (stages/shape) \\
\hline $\begin{array}{l}\text { preauricular sulcus stage (after STECKEL et } \\
\text { al. 2006) }\end{array}$ & $\begin{array}{l}0 \text { - trait unobservable } \\
1 \text { - area is smooth, with no clear evidence of a sulcus } \\
2 \text { - a small, weakly developed preauricular sulcus is clearly present } \\
3 \text { - a preauricular sulcus is moderately developed } \\
4 \text { - a large, well-defined sulcus is present }\end{array}$ \\
\hline $\begin{array}{l}\text { preauricular sulcus shape (after BRŮŽEK } 2002 . \\
\text { - PERRÉARd LopRENO, BRƯŽEK 2010) }\end{array}$ & $\begin{array}{l}\text { evaluation of three criteria: evaluation of the development of negative relief (depression), } \\
\text { boundary shape of grooves or pitting, development of positive relief (tubercle) } \\
\text { f - typical female expression } \\
\mathrm{m} \text { - typical male expression } \\
\mathrm{i} \text { - intermediate form } \\
\text { summarised as } \\
\text { F - specific female shape (f-f-f): deep depression, pits or groove with closed circumference } \\
\text { (true preauricular groove), associated with a lack of tubercle } \\
\text { M - typical male form (m-m-m): smooth or very slight relief, with open border, associated } \\
\text { with a presence of tubercle } \\
\text { I - intermediate morphology with majority of intermediate criteria }\end{array}$ \\
\hline $\begin{array}{l}\text { dorsal pubic pitting (after STEWART 1970. - } \\
\text { ULLRICH 1975) }\end{array}$ & $\begin{array}{l}0 \text { - trait unobservable } \\
1 \text { - smooth surface, no lesion present } \\
2 \text { - small lesion }(\mathrm{s}) \text { present }(<2 \mathrm{~mm}) \\
3 \text { - medium to large lesions present }(>2 \mathrm{~mm})\end{array}$ \\
\hline extended pubic tubercle (after MaAss 2012) & $\begin{array}{l}0 \text { - trait unobservable } \\
1 \text { - surface of pubic tubercle is smooth } \\
2 \text { - small extended pubic tubercle present }(1-3 \mathrm{~mm}) \\
3 \text { - large extended pubic tubercle present }(>3 \mathrm{~mm})\end{array}$ \\
\hline exostoses at the margin of the sacroiliac joint & $\begin{array}{l}0 \text { - trait unobservable } \\
1 \text { - no exostoses present } \\
2 \text { - exostoses present }\end{array}$ \\
\hline exostoses at the ventral pubic surface & $\begin{array}{l}0 \text { - trait unobservable } \\
1 \text { - smooth surface, no exostoses present } \\
2 \text { - exostoses present }\end{array}$ \\
\hline lesions at the ventral pubic surface & $\begin{array}{l}0 \text { - trait unobservable } \\
1 \text { - smooth surface, no lesions present } \\
2 \text { - small lesions present }(<2 \mathrm{~mm}) \\
3 \text { - medium to large lesions present }(>2 \mathrm{~mm})\end{array}$ \\
\hline $\begin{array}{l}\text { fractures at the os pubis, os ischium and os } \\
\text { sacrum }\end{array}$ & $\begin{array}{l}0 \text { - trait unobservable } \\
1 \text { - no fracture present } \\
2 \text { - fracture present } \\
3 \text { - two or more fractures present }\end{array}$ \\
\hline $\begin{array}{l}\text { degenerative/congenital changes especially at } \\
\text { the spine, the hip and the knee joints }\end{array}$ & $\begin{array}{l}0 \text { - trait unobservable } \\
1 \text { - absent } \\
2 \text { - present }\end{array}$ \\
\hline
\end{tabular}

Table 10. Stages of the preauricular sulcus and their relationship to sex.

\begin{tabular}{|l|l|c|c|c|c|c|}
\hline \multicolumn{2}{|l|}{ Preauricular sulcus } & Smooth & Small, weakly developed & Moderately developed & Large, well defined & Total \\
\hline \multirow{2}{*}{ Sex } & Male & 8 & 1 & 0 & 0 & 9 \\
\cline { 2 - 8 } & Female & 1 & 6 & 5 & 1 & 13 \\
\hline Total & 9 & 7 & 5 & 1 & 22 \\
\hline
\end{tabular}



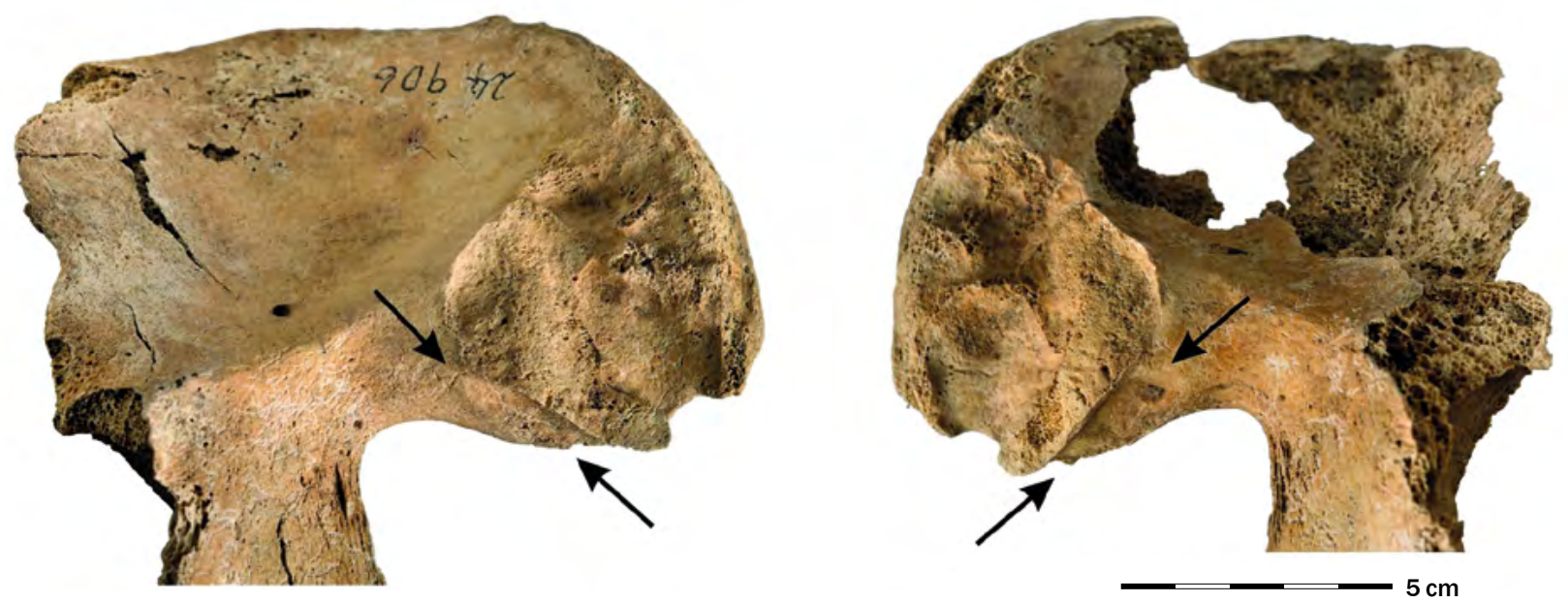

Fig. 10. Right and left ilium of the 25-35-year-old woman from Feature 28 with well-defined preauricular grooves (Photo: W. Reichmann, (c) NHM Vienna).

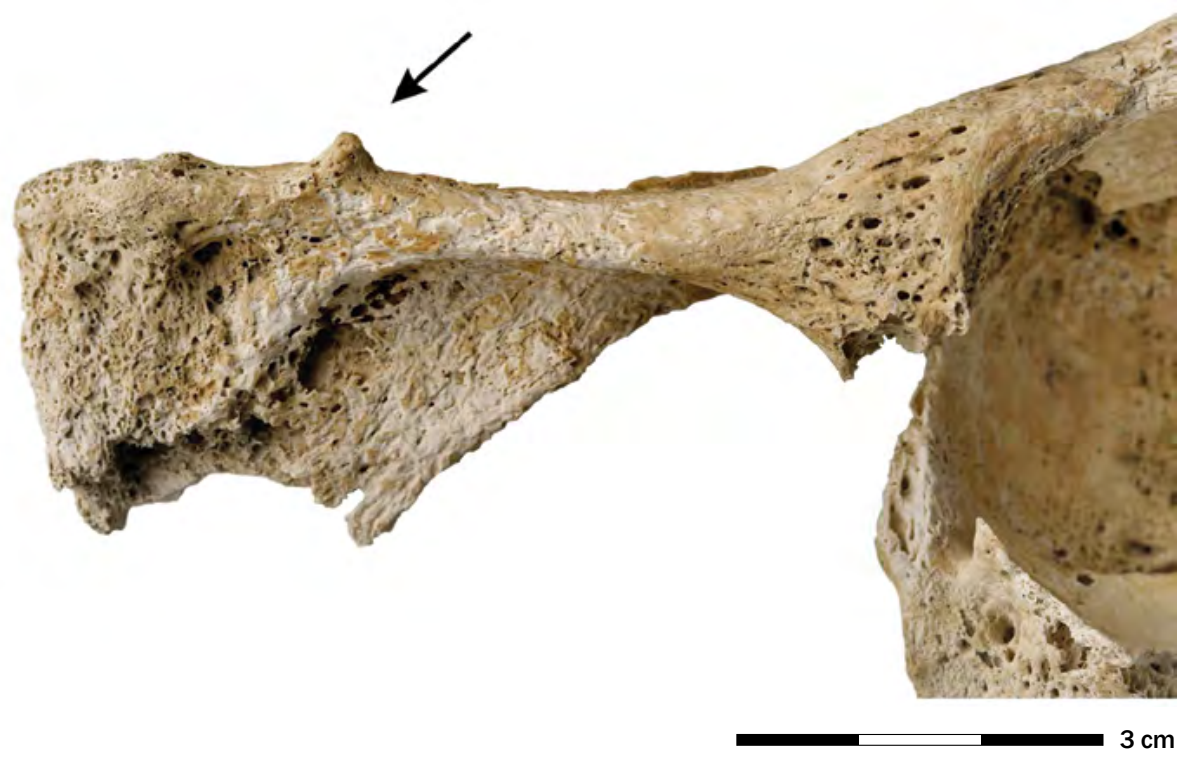

Fig. 11. Extended pubic tubercle and sharp ridges at the pecten ossis pubis of the 40-50-year-old woman from Grave 128 (Photo: W. Reichmann, ( $)$ NHM Vienna).
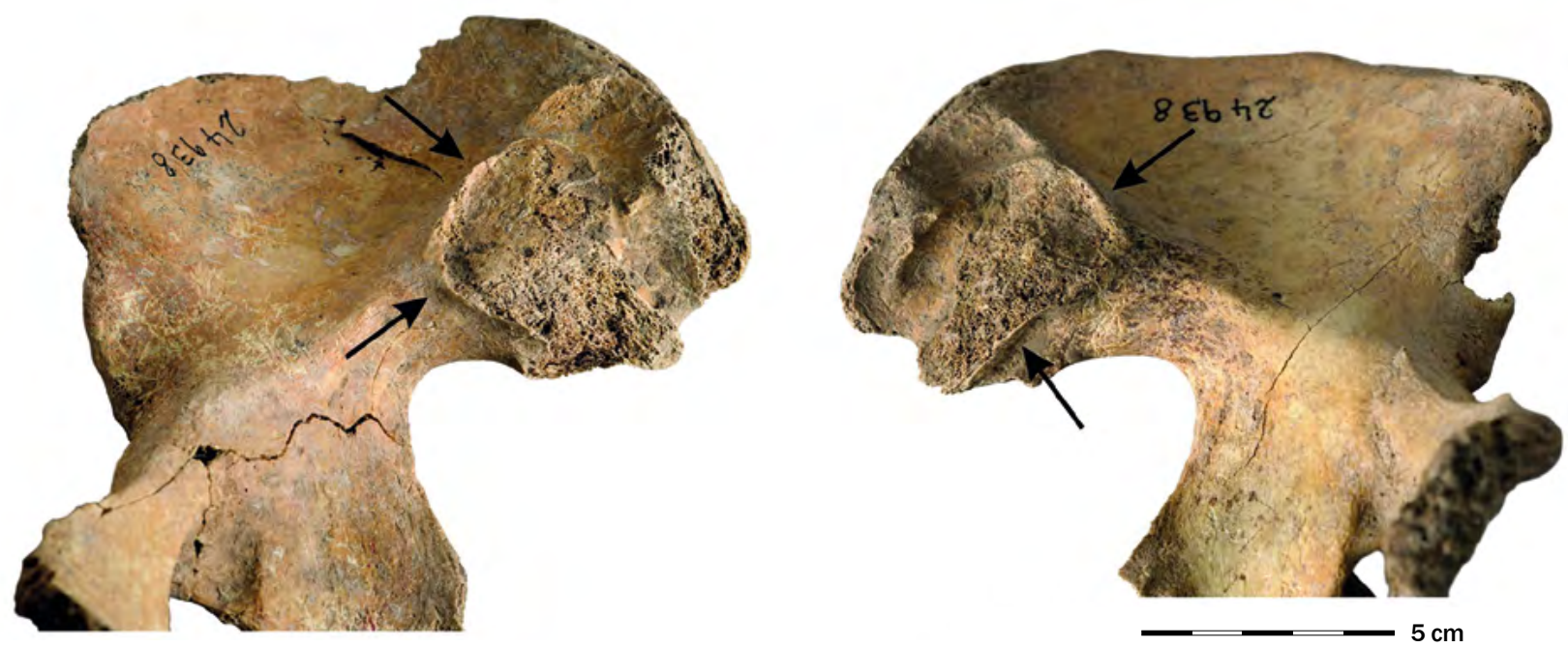

Fig. 12. Exostoses at the margin of the auricular surface of the 17-20-year-old woman from Grave 122 (Photo: W. Reichmann, (C) NHM Vienna). 


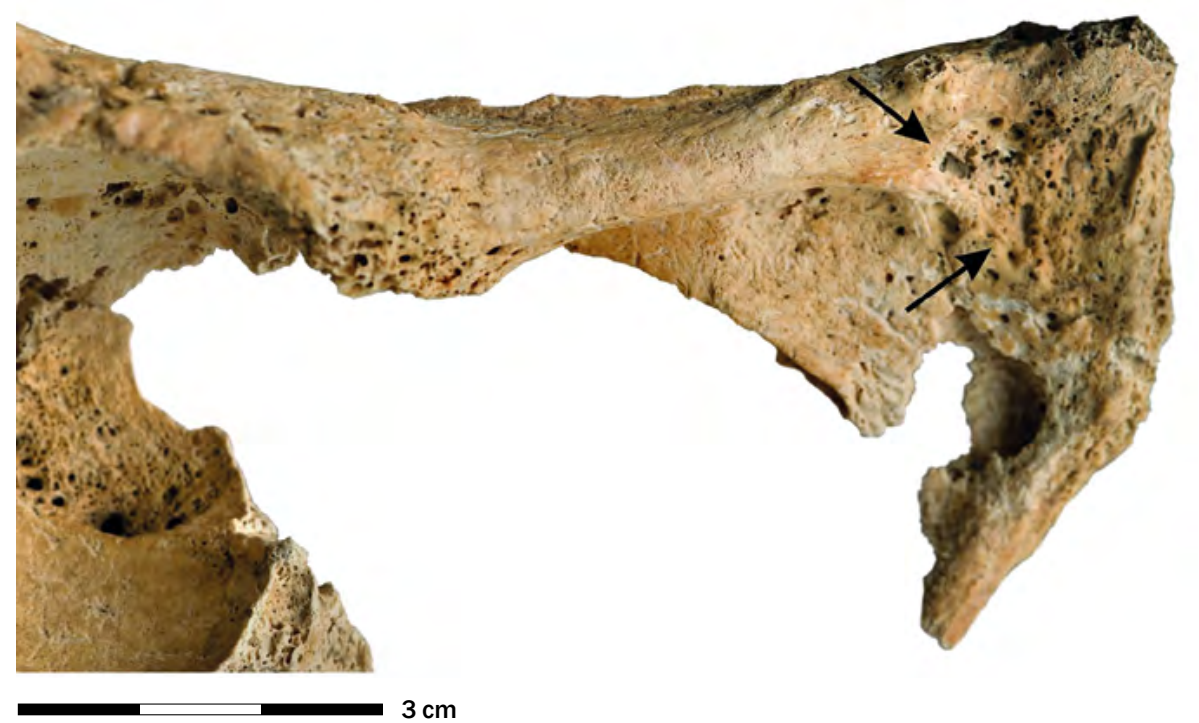

Fig. 13. Exostoses and lesions at the ventral pubic surface of the 40-50-year-old woman from Grave 128 (Photo: W. Reichmann, (C) NHM Vienna).

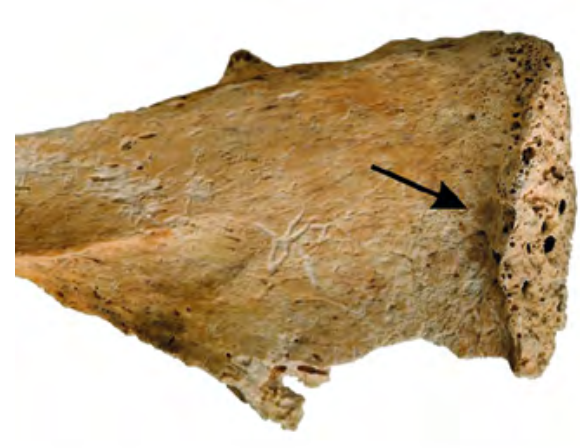

$3 \mathrm{~cm}$

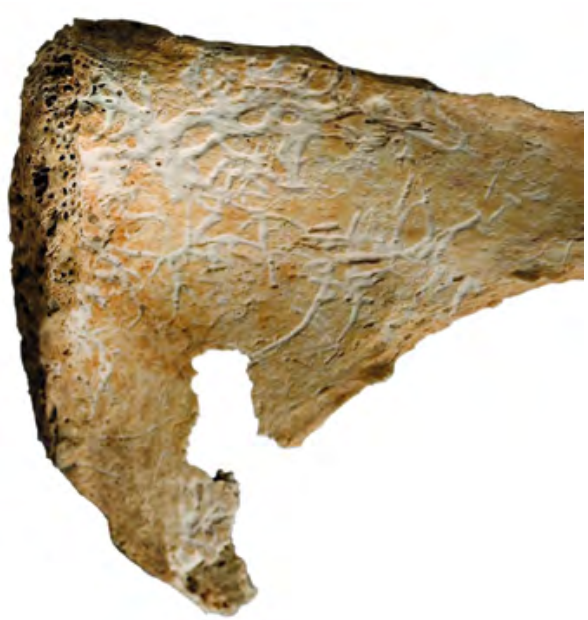

Fig. 14. Lesions at the dorsal pubic surface ('pubic pits') of the 40-50-year-old woman from Grave 128 (Photo: W. Reichmann, (C) NHM Vienna). individuals 109A, 128 (Fig. 11) and 134. All individuals with these features were late adult or mature women.

Exostoses at the margin of the auricular surface (sacroiliac joint, Fig. 12) were present in two of seven observable males $(86,94)$ and 12 of 13 observable females $(28,88,90,93$, $100,102,109 \mathrm{~A}, 122 \mathrm{~B}, 123,125,128,134)$ on the right and left sides. There is an association between sex and the presence of the exostoses at the margin ( $p=0.007$, Fisher's exact test), and a positive association is denoted by the coefficient $\phi$ value of 0.663 .

Exostoses at the ventral pubic surface were visible in one of six males (83, 35-50 years old) and five of eight female individuals $(102,109 \mathrm{~A}, 123,128,134)$.

Lesions at the ventral pubic surface were present in one of six males $(111,30-40)$ and six of nine females (100, $109 \mathrm{~A}, 116,123,128,138)$. A distinct ridge at the pectineal line of the pubis was found in two females, in both cases in combination with the presence of an extended pubic tubercle (Fig. 13).

Lesions at the dorsal pubic surface (dorsal pits) were found in four of eight females $(93,95,116$, and 128), but none of the six investigated males (Fig. 14).

The full range of pelvic features was present in the 40-50-year-old woman from the disturbed Grave 128. In addition to a weakly developed preauricular groove, she had an extended pubic tubercle and exostoses at the margin of the auricular surface as well as exostoses at the ventral and lesions at the ventral and dorsal pubic surfaces. In addition, a sharp edged ridge was found at the pecten ossis pubis. Distinct, ridge-like changes at muscle insertion sites of the gluteal muscles were found on the dorsal side of the ilium. The pelvic changes co-occur with several pathologies (see above), which indicate high bodily strain. The archaeological context, however, was unremarkable. The disturbed 


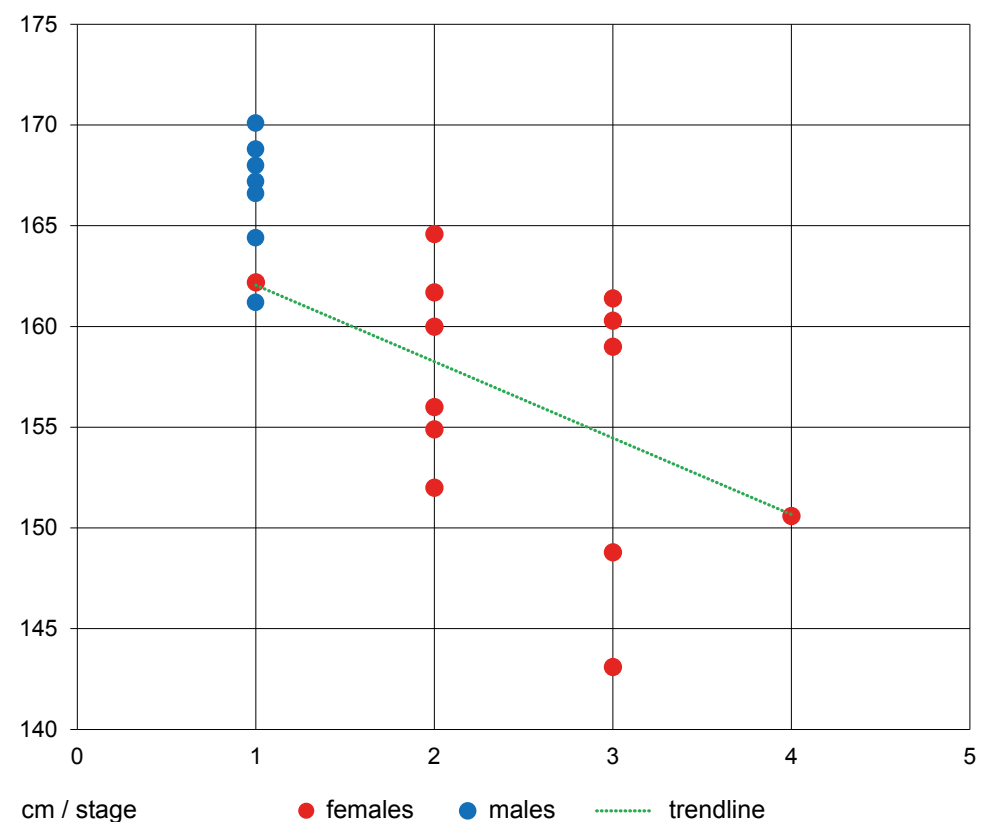

Fig. 15. Body height in relation to expressions of the preauricular sulcus (stage 1-4) at Unterhautzenthal ( $\mathrm{n}=21$, red: females, blue: males). grave contained two pieces of pottery, and bronze stains on the bones indicated that she was buried with bronze grave goods, of which none was recovered during excavation.

Due to the small sample size, the significance of associations between pelvic features and sex could only be statistically demonstrated ${ }^{100}$ for the preauricular sulcus and the exostoses at the margin of the auricular surface. At the population level at Unterhautzenthal, the presence and severity of pelvic features does not show any significant associations with age at death, nor with any of the recorded pathologies.

Individuals from Unterhautzenthal showed a distinct sexual dimorphism in height, with females measuring $157 \mathrm{~cm}$, on average, and males $166 \mathrm{~cm}$. The one-way ANOVA test revealed a statistically significant result for an association between body height and the presence of a preauricular sulcus at the os ilium: shorter stature is positively correlated with a more pronounced preauricular groove (ANOVA between sex groups $=0.009$ ). The two shortest individuals (Individual $28=150.6$ and Individual $88=143.1 \mathrm{~cm}$ ) had the deepest preauricular groove (Fig. 15).

Women of short body height often have small pelvic dimensions, which presents a disadvantage in birthing children

100 Crosstabs were calculated in SPSS 23 to look for associations between sex, age, body height and the pelvic features, as well as selected pathologies. Furthermore, a Monte Carlo confidence test for small sample sizes was performed (95\% confidence level). Although nominal and ordinal data were both present, an ordinal approach was chosen for the final calculations. In many cases, the small sample size led to smaller tables because the different stages of the characteristics were not always present in the sample. due to a disproportion between head size of the baby and inner pelvic diameters. ${ }^{101}$ They are thus more likely to be physically affected by pregnancy and childbirth than the average, and this high strain becomes marked in the parity features. Future work in our project will address the relationship between body stature, pelvic measurements and pelvic features in more detail. The two females with true preauricular grooves, ${ }^{102}$ the $25-35$-year-old from Grave 28 and the 35-50-year-old from Grave 88, also showed exostoses of the auricular facies on both sides of the sacroiliac joint.

The weight of the trunk is transferred to the lower limbs via the sacroiliac joint. Osteophyte growth at this site, and especially at the anterior-superior margin of the joint, which represents a typical location for 'reparative ossifications', can be the result of overload damage. ${ }^{103}$ The 35-45-year-old woman from Grave 93 had symmetrical lobular extensions at the auricular surface at the anterior-superior margin of the sacrum (Fig. 16) with a corresponding facet at the ilium (c. $10 \times 10 \mathrm{~mm}$ ). A margo auricularis groove was detected at the os sacrum on both sides. ${ }^{104}$

The 50-60-year-old female from Feature 109A exhibited a tongue-like exostosis (c. 15 by $20 \mathrm{~mm}$ ) at the anterior-superior margin of the right auricular facies at the ilium with a corresponding facet on the os sacrum and inflammatory changes (Fig. 17). These bony bridges between the os

101 Fischer, MitTeroecker 2015.

102 According to BRŮŽEK 2002.

103 Dihlmann 1987, 82.

104 Cf. Pany-Kucera, Spannagl-Steiner, Rebay-Salisbury 2017. 

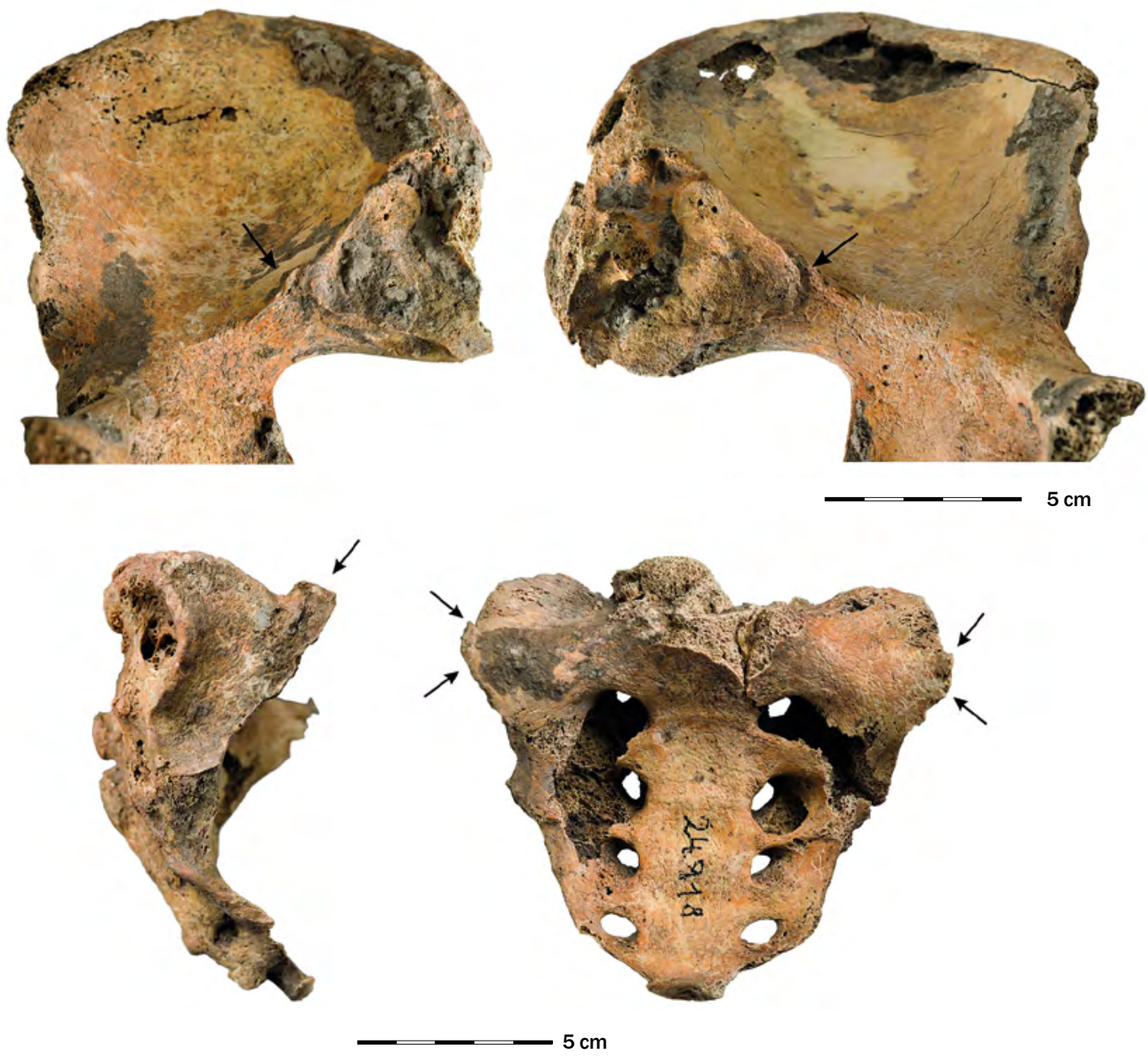

Fig. 16. Bilateral reparative ossifications on the sacrum: anterior-superior margin of the sacroiliac joint in the 35-45-year-old woman from Grave 93 (above: right and left ilium, below: lateral and frontal view of the sacrum) (Photo: W. Reichmann, (C) NHM Vienna).
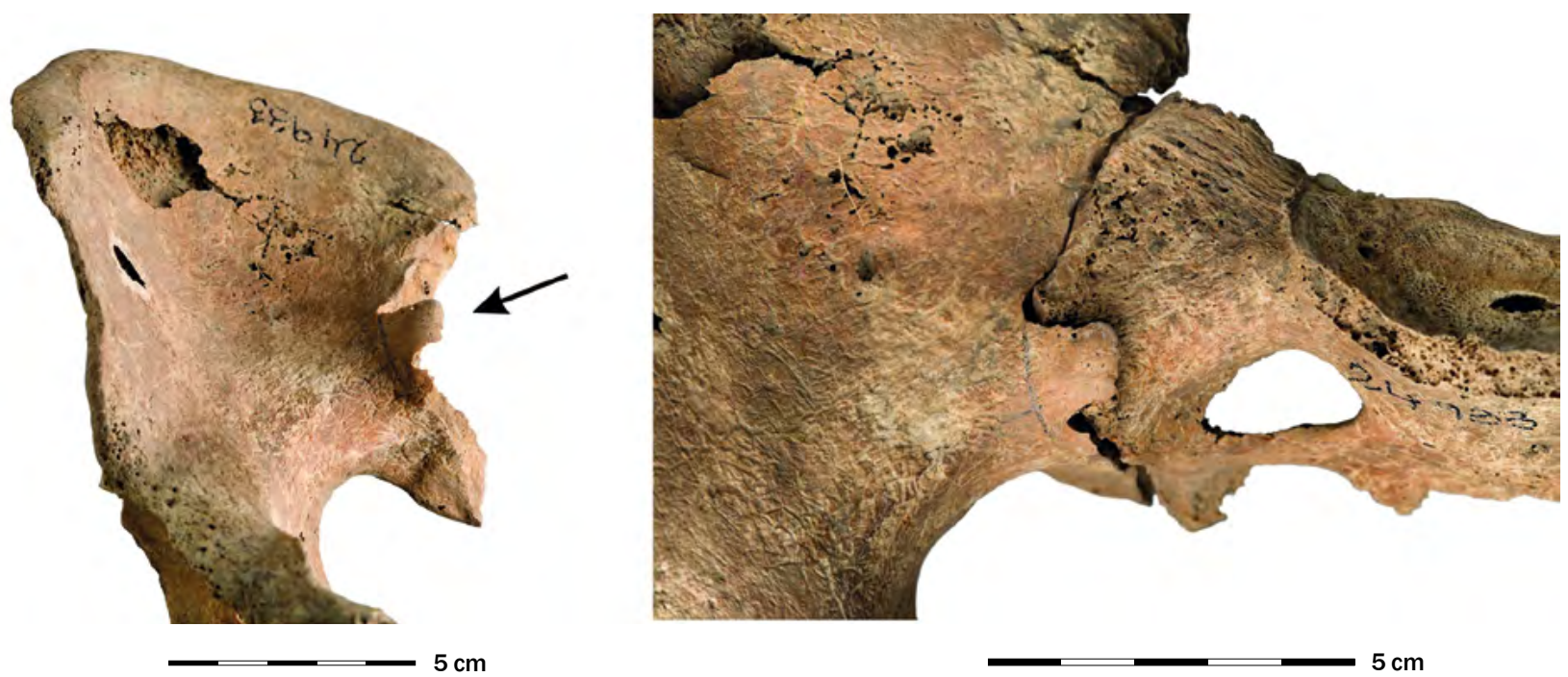

Fig. 17. Unilateral reparative ossifications at ilium: anterior-superior margin of the sacroiliac joint in the 50-60-year-old female Individual 109A (Photo: W. Reichmann, () NHM Vienna). 
sacrum and the os ilium may represent the body's support system to mitigate the late effects of multiple pregnancies. During pregnancy, increased production of the hormone relaxin causes a relaxation of the ligaments of the pelvis. For some women, the changed balance of weight-bearing causes a backwardly rotated malposition of the sacroiliac joint, which may become fixed in the wrong position when relaxin levels decrease after birth 'sacroiliac subluxation'. ${ }^{105}$

A computed tomography study of modern women ${ }^{106}$ found protruding margins (osteophyte growth) at the sacroiliac joint in women after a number of births. Anatomical analyses by Walter Putschar ${ }^{107}$ identified them in young women who had given birth multiple times. It is thought that the 'birth of the first child, rather than subsequent births have the greatest effect on the sacroiliac joint'. ${ }^{108}$

Of ten male individuals with preserved pelves, only one had a weakly developed preauricular sulcus (124, aged 35-50 years), two had exostoses at the sacroiliac joint (86 and 94 , both aged $40-60$ years), one had exostoses at the symphysis ventral (83, aged 35-50), and one had lesions at the symphysis ventral $(111,30-40)$. In contrast, none of the males had more than one of the features; pelvic changes do not occur together for males. Further, all affected men were late adults, for whom age-related degenerative changes are to be expected.

In the 15 women studied from Unterhautzenthal, pelvic features were noted in varying frequencies. Most common was the typical female expression of the preauricular sulcus (stage 2 and above), observed in 12 instances. Exostoses at the sacroiliac joint were recorded in 11 women. Six women had extended tubercula pubica, and another six had lesions at the ventral symphysis. Exostoses at the ventral symphysis were noted five times and dorsal pitting four times (Fig. 18).

In this sample, we could not demonstrate a statistically significant relationship between women's age at death and the presence or absence of pelvic features. The youngest woman, 122B, displayed a combination of a distinct preauricular sulcus, an extended tuberculum pubis and exostoses at the sacroiliac joint; in the oldest woman, 138, we observed merely lesions at the ventral pubic surface. The latter are generally present in older women. Perhaps unsurprisingly, the preauricular sulcus and exostoses of the sacroiliac joint, the two most common types of changes, frequently co-occurred. In contrast to men, women often display multiple pelvic changes in the same individual (Fig. 19).

105 Putschar 1931, 159. - Williams 1995. - Pany-Kucera, SpanNaGL-Steiner, Rebay-Salisbury 2017.

106 Faflia et al. 1998.

107 Putschar 1931, 187-188.

108 Shibata, Shirai, Miyamoto 2002.

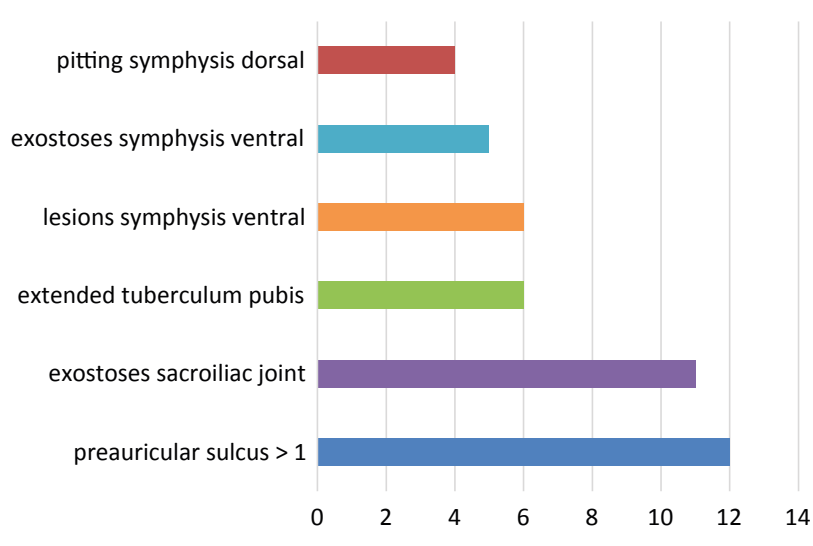

Fig. 18. Frequency of individual pelvic features in Unterhautzenthal women $(n=15)$.

The analysis of pelvic features at Unterhautzenthal has demonstrated that their expression is highly individualised and connected to the individual life histories of the persons under study. It is difficult, therefore, to understand them in isolation and to generalise their significance.

\subsection{Parity Index for Unterhautzenthal}

As an analogy to the Social Index, we are aiming to develop a Parity Index that numerically represents the aggregation of pelvic changes according to a formula that gives weight to features that may indicate parity. The Parity Index relies on visual grading of skeletal morphological traits (as described above), and thus only individuals with preserved pelves could be included.

Changes in the preauricular sulcus were assigned the following values: 0 for no change (grade 1), 50 for grade 2, 75 for grade 3 and 100 for grade 4 . For lesions at the dorsal pubic surface, a value of 40 was added, and for an extension of the pubic tubercle a value of 30 . The presence of exostoses at the margin of the auricular surface, exostoses at the ventral pubic surface and ventral symphyseal changes each increased the value by 20 . The results were scaled so that 100 represents the highest possible value (Table 4).

Female values ranged from 11 to 100 , with an average of $57(n=15)$, male values from 0 to 28 , with an average of $7(\mathrm{n}=10)$. The four women buried with foetal/neonatal remains or young children scored a mean of 58.5 , no different from the general average.

The Parity Index provides a value that can be directly compared to the Social Index to better understand whether repeated strain through pregnancy and parturition was socially rewarded after death. In other words, it was designed to test the hypothesis that women's social status 


\section{7}

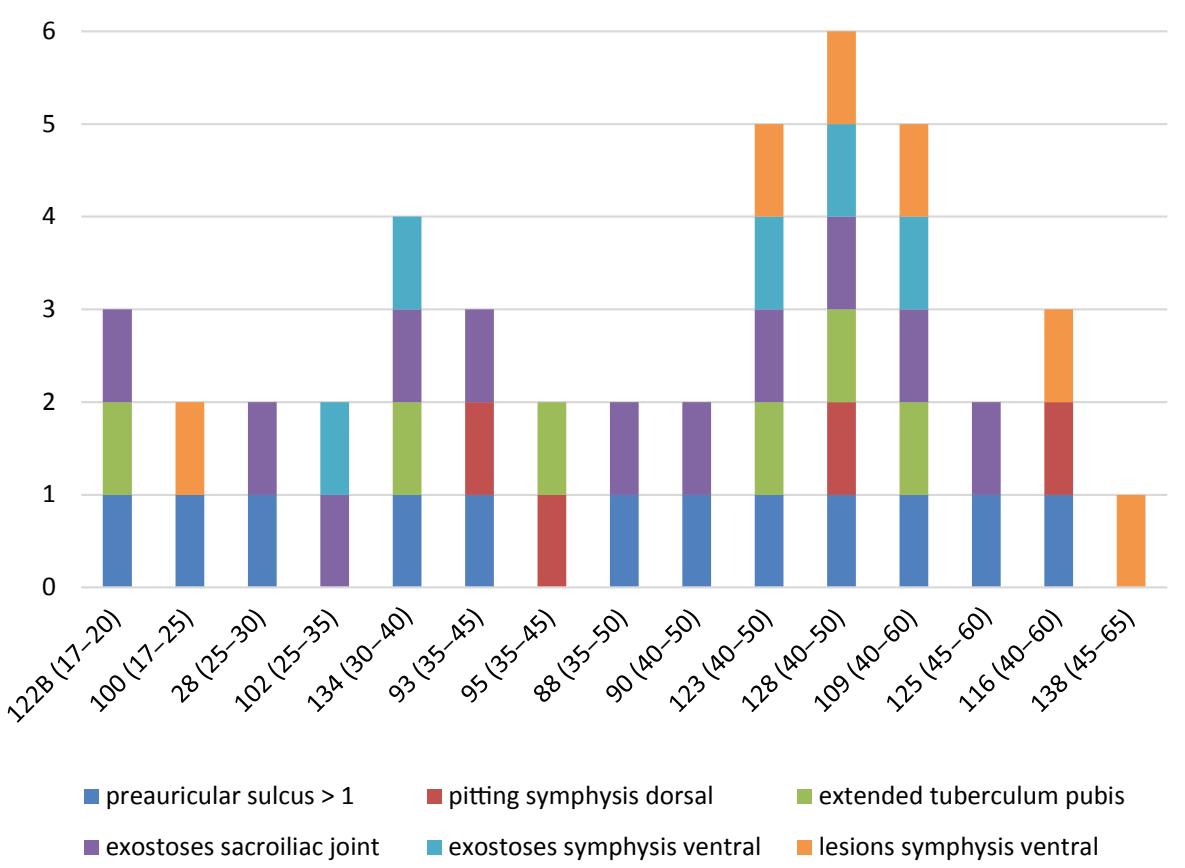

Fig. 19. Pelvic changes in 15 women from Unterhautzenthal, ordered by increasing age.

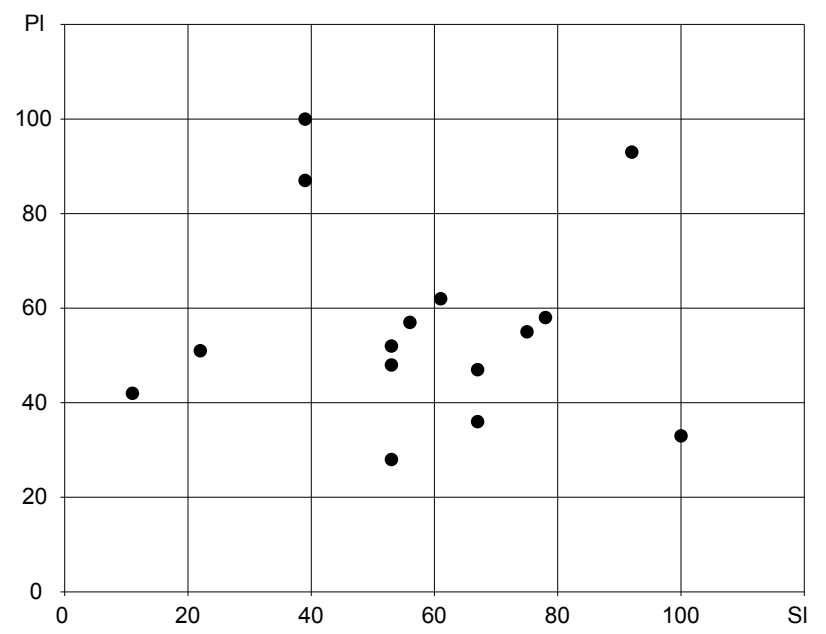

Fig. 20. Relationship between Social Index (SI, x-axis) and Parity Index (PI, y-axis).

corresponds to a higher degree of pelvic change. We excluded the male individuals from this test for obvious reasons, leaving 15 women for which both PI and SI were available.

The Spearman rank correlation coefficient is -0.018 , with a p-value of 0.95 . There is no correlation between the values at all, and the hypothesis of a relationship between pelvic strain and social status can be rejected (Fig. 20).

\section{Demographic Considerations: Population Growth Rate Estimation, Female Fertility and Infant Mortality}

The total fertility rate (the average number of children born to a woman if she survives to age 50) and the growth rate (the annual percentage change in the population size) of the population of Unterhautzenthal can be estimated based on the demographic composition of its skeletal sample. Both indicators correlate with the proportion of sub-adults in the population. ${ }^{109}$ Of the 57 skeletons present in the Unterhautzenthal sample, 54 individuals died over the age of one and 27 individuals over the age of 20 . The population growth rate for this population was calculated using the D1+/D20+ ratio, i.e. the proportion of individuals older than one year to individuals older than 20 years of age. ${ }^{110}$

The accuracy of the demographic calculations depends on the representativeness of the skeletal sample in terms of its age-at-death-composition. The cemetery of Unterhautzenthal has been fully excavated, but the low number of individuals recovered suggests that the skeletal sample might not be fully representative of a sustainable Bronze Age community. However, we did not find any evidence of a selection of specific individuals for burial that would distort the D1+/D20+ ratio. The simulation results based on the demographic composition at Unterhautzenthal give us some impression about how women experienced

109 Bocquet-Appel 2002.

110 GaleTa 2010. 
motherhood in the early Bronze Age and serve as a baseline for comparison with other populations.

A value of 20-30 years is set for life expectancy at birth, i.e. the average number of years a newborn is expected to live. The figures are thus slightly lower than those derived from life tables, e.g. 30.4 years in early Bronze Age communities in northern Lower Austria, ${ }^{111}$ to account for missing infant skeletons at the cemetery.

The childbearing period in our simulations is set between 15 and 50 years of age. Assuming a life expectancy at birth between 20 and 30 years, an average of $47 \%$ of women survived to 15 years, entering the childbearing period, and an average of $25 \%$ of women were still alive at age 50 , the common onset of menopause.

A simulation of 5000 populations with 27 adults, but different demographic characteristics (e.g. growth rate ranging from -2 to $2 \%$, life expectancy at birth between 20 and 30 years), resulted in an estimated growth rate of $1.4 \%$ per year for Unterhautzenthal ( 0.7 to $2.0 \%$ at a confidence level of $68 \%$ ) and an estimated total fertility rate of 7.9 live births per woman (5.7 to 10.2 live births per woman at a confidence level of $68 \%$, Fig. 21).

A growth rate of $1.4 \%$ is fairly high; it suggests that every year, the number of living people was $1.4 \%$ larger than in the previous year. Jean-Pierre Bocquet-Appel ${ }^{112}$ estimated that the growth rate during the Neolithic transition in Europe, a period of rapid population growth, did not exceed $1.3 \%$ per year on average. Data from the Mesolithic-Neolithic transition in Serbia ${ }^{113}$ suggests four to five children on average for Mesolithic and about seven for Neolithic populations. With an assumed life expectancy at birth between 20 and 30 years, and a total fertility rate of 5.3 , four to six children would account for a stable population.

Unterhautzenthal might have had a fast growing population, more likely driven by a high female fertility rate rather than by a low mortality rate. The high fertility rate of 7.9 children per woman at Unterhautzenthal suggests that during the reproductive years (between 15 and 49), women on average might have experienced a birth every four years. Births, however, are unevenly distributed over a woman's childbearing period; comparative data ${ }^{114}$ suggests that fertility usually peaks during the early twenties and remains high until the mid-thirties, whereas very few children are born to 45-50-year-olds. At Unterhautzenthal, women might have had one child over the five year period until they reached twenty, then gave birth every three years until age thirty,

111 Teschler-Nicola 1992, 83.

112 Bocouet-Appel 2002.

113 Jackes, Roksandić, Meiklejohn 2008.

114 Newell 1988, 46. - Chamberlain 2006, 36.

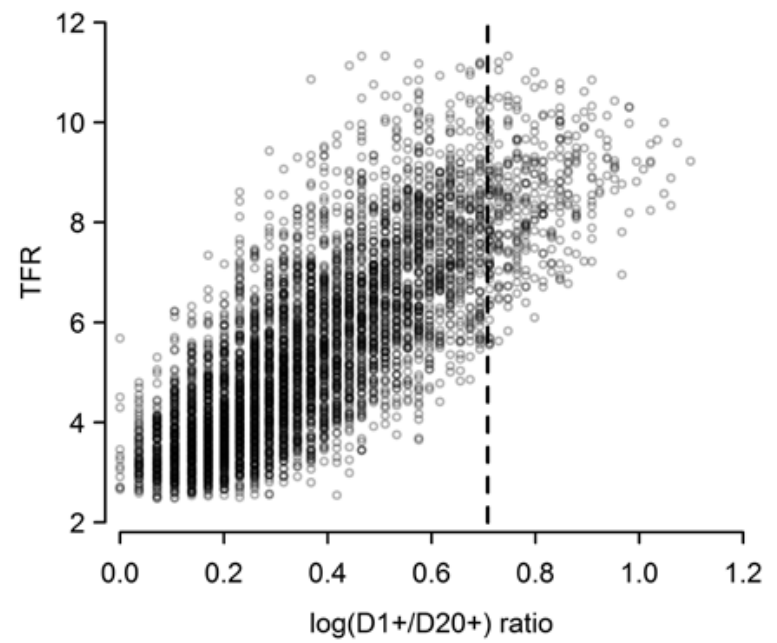

Fig. 21. The relationship between the total fertility rate (TFR) and the logarithm of the D1+/D20+ ratio in 5000 simulated skeletal samples. The dashed line indicates the ratio of the Unterhautzenthal skeletal sample.

before the gaps between siblings increased to three to four years in their thirties. One further baby might have come along after age 40 (Fig. 22). Given that up to $70 \%$ of pregnancies might have ended in foetal loss or stillbirth, ${ }^{115}$ the physical strain of pregnancy and childbirth must have been considerable.

The total fertility rate gives the number of children born to a woman if she survived to the age of 50 , which only applied to about $25 \%$ of women at Unterhautzenthal; the majority died before they could have given birth to their eighth child. Of course, not all children survived; infant and childhood mortality was high. Assuming a life expectancy at birth of between 20 and 30 years, the infant mortality (deaths under 1 year) in our 5000 simulated samples ranges between 19 and $56 \%$, with a mean of $36 \%$ (Fig. 23 ): $53 \%$ of the children died before reaching 15 years of age on average in our simulated samples.

With more than a third of babies dying before they reached their first birthday, and with about half of the children dead by the age of 15 , both the physical and emotional toll of motherhood must have been considerable even if death in childhood was so commonplace that it was expected.

\section{Mothers at Unterhautzenthal}

The cemetery of Unterhautzenthal included six females associated with the skeletal remains of babies and young children (Fig. 24). We assume that they were buried together

115 Holman, Wood, Campbell 2000. - Jackes, Roksandić, Meiklejohn 2008, 79. 


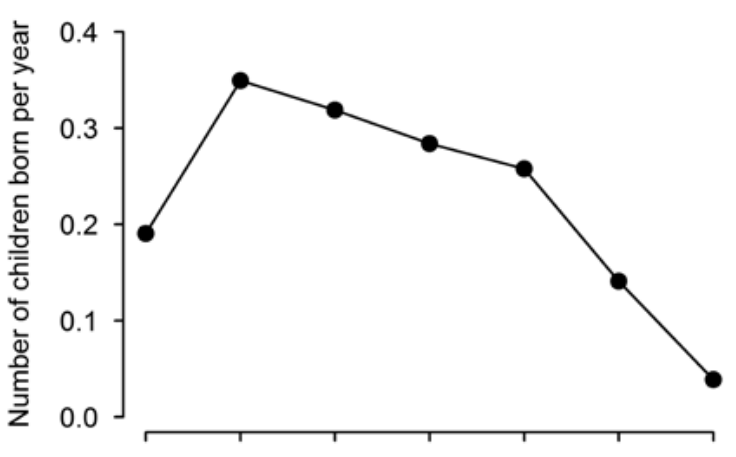

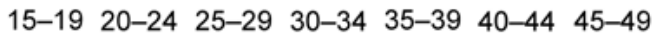

Age of mother (years)

Fig. 22. Likely number of children born to women per year at a specific age.

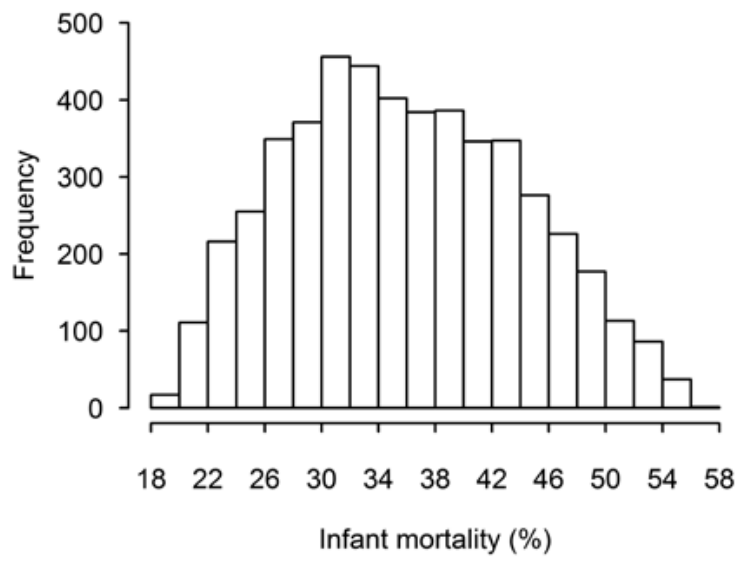

Fig. 23. Number of deaths of children under one year of age per 100 live births assuming a life expectancy at birth between 20 and 30 years of age ( $\mathrm{n}=5000$ simulated populations).
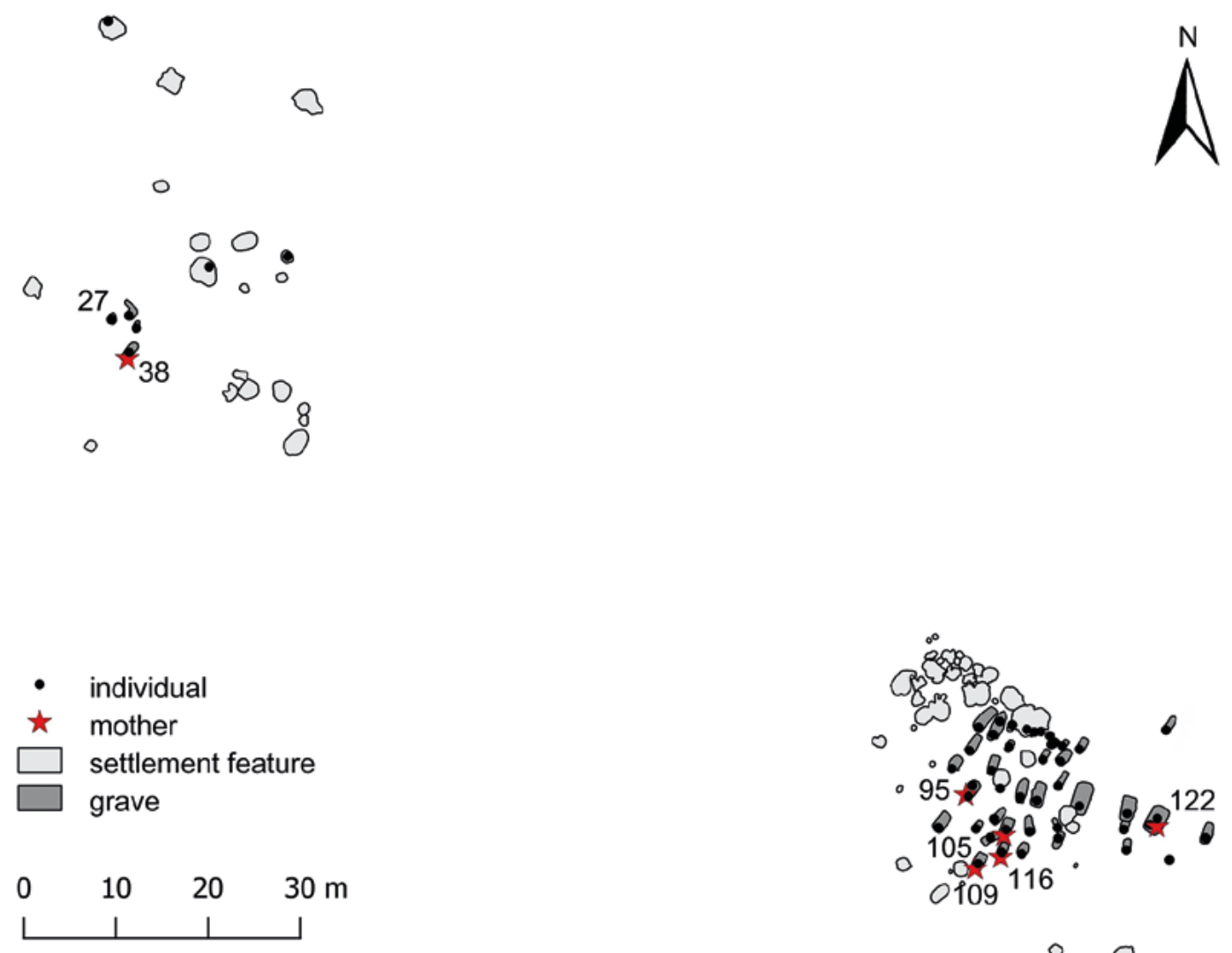

Fig. 24. Graves and settlement features with human remains at Unterhautzenthal. Women buried with foetal/neonatal or children's remains are marked with a red star (after LAUERMANN 1996, 16-17, Fig. 24). 

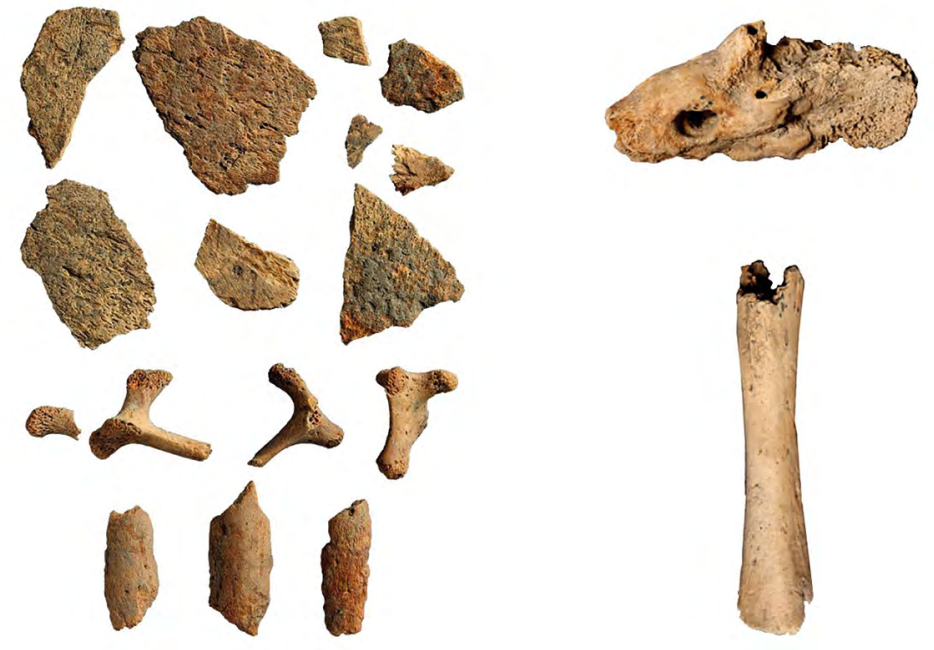

$3 \mathrm{~cm}$
Fig. 25. Cranial and postcranial bone fragments of a foetus/neonate discovered amongst the remains of the 14-15-year-old from Grave 38 (Photo: W. Reichmann, (c) NHM Vienna). because they were connected through kinship, if not in a biological, genetic sense, ${ }^{116}$ then in a social sense. By bringing together archaeological, contextual information about their burials with their osteobiographies, we sought further insights into motherhood and the lives of mothers with small children.

Feature 38 appeared $0.6 \mathrm{~m}$ below the topsoil as a large, rectangular grave pit measuring $0.85-1 \times 2.5 \mathrm{~m} .{ }^{117}$ A southwest/north-east oriented body was found in a flexed position, lying on the right side, taking up just one quarter of the grave pit. The skeleton was strongly eroded and could not be sexed as no pelvic parts were preserved. Age at death was estimated at $14-15$ years ${ }^{118}$ by osteological means; tooth cementum annulation analysis resulted in an age of $17.5 \pm$ 5. Amongst the skeletal remains, a small, calcified object was found that might represent a body stone. ${ }^{119}$ Cranial and postcranial bone fragments of a foetus/neonate were discovered amongst the bones of the teenager (Fig. 25). The length and width of the petrous bone (31 and 13.5-14 mm respectively) suggest a gestational age of $34-36$ weeks. ${ }^{120}$ The evidence points to a young woman who was pregnant when she died or who died in childbirth. There were no bronzes

116 The genetic relationships of co-buried individuals are currently being tested at the Institute of Legal Medicine of the University of Innsbruck, Austria, in cooperation with Walther Parson. Samples submitted in June 2017 were taken from individuals 27A, 27B; 38A, 38B; 95, 95A, 95B; 103A, 103B; 109A, 109B; 122A, 122B, 122C.

117 LAUERMANN 1991b, 65-67.

118 Contra Lauermann 1997, 65.

119 Cf. Teschler-Nicola, Winter 2013.

120 Fazekas, Kósa 1978. discovered in this grave, but the right clavicle, ribs, left temporal bone, and left mandible were stained green, presumably from decayed bronze jewellery such as Noppenringe. A ceramic jug with a scooping cup inside and three bowls were placed around the body, next to the skull, and at the feet. The burial was not well enough preserved to establish with certainty whether the grave was re-opened. It was assigned a Social Index of 42.

Three bodies were buried in Feature 95 (Fig. 26), a large, rectangular grave pit measuring $1.6 \times 1.3 \mathrm{~m}$ with a depth of $1.7 \mathrm{~m} .{ }^{121}$ At the centre of the grave pit, a woman had been placed on her right side with slightly flexed legs and on a south-west/north-east orientation. She probably died at around forty years of age; the morphological age span is 35 to 45 , the mean estimated age established by tooth cementum annulation is $41.5 \pm 5$ years. The sexing characteristics of the cranium and mandible were predominantly female and her height was about $157 \mathrm{~cm}$. Her pelvis was only partly preserved, due to moderate erosion. The region of the preauricular sulcus was not assessable and she did not show exostoses at the sacroiliac joint or the ventral symphysis. She had a small extended pubic tubercle at the right pubic bone (the left side was missing), ${ }^{122}$ and slight pits at the dorsal side of the symphysis. ${ }^{123}$ Pathologies included impressions of the ateria meningea media at the internal lamina on the right side of the cranium and signs of periostitis on both tibiae. One large and seven small Noppenringe were found around the

121 LAUERMANN 1995, 31-36.

122 Stage 2 after SNOdgrass, Galloway 2003. - MaAss 2012. 123 Stage 2 after STEWART 1970. 


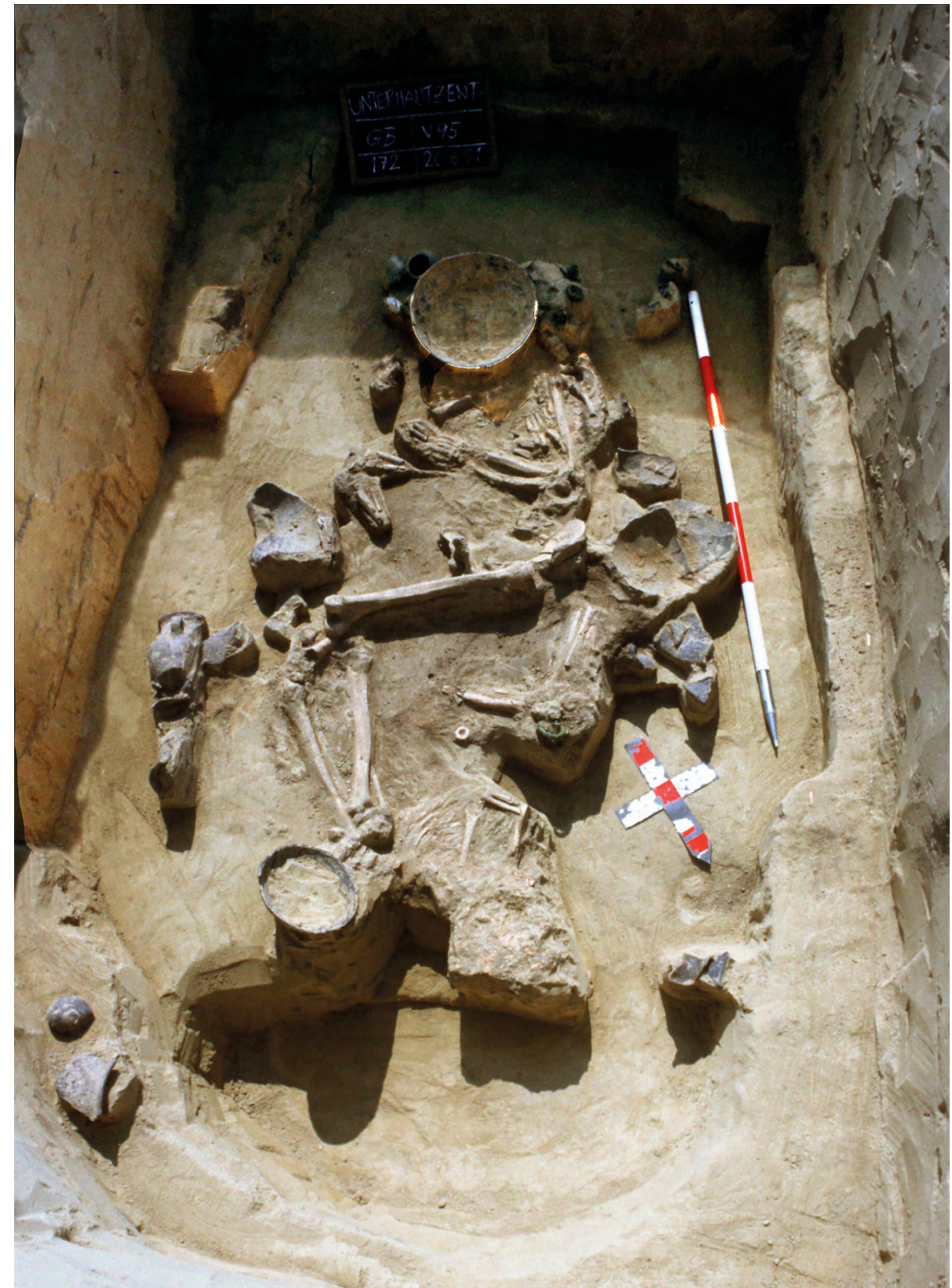

Fig. 26. The triple burial of a 35-45-year-old woman with a 3-4 and a 4-5-year-old child in Grave 95 (Photo: E. Lauermann). head; a bronze dress pin was found underneath the cranium. Two chert tools were recovered from beneath the pelvis.

The remains of a 3-4-year-old child were discovered in front of the woman's face and upper body. The body had been placed parallel to the woman, mirroring her body position. The woman's left hand was placed on the child's hip, as a mother holds her child. The child's skeleton was strongly eroded and less than half of the skeleton was preserved. Some tibial fragments exhibited signs of periosteal reactions, indicative of periostitis. A large ceramic bowl covered both the upper body of the child and the face of the woman. The child was buried with a bronze neck-ring, a dress pin and a Spiralröllchen fragment. A small ceramic beaker and a piece of worked limestone had been placed next to the child's head.

Behind the woman's legs, a third body was discovered in the grave: that of a 4-5-year-old child. The child had been placed on the right side, oriented north-east/south-west, in the opposite direction to the mother. The bodies had been deposited in close bodily contact, with the child's backside snug in the hollow of the woman's knee. The skeleton was strongly eroded and less than half of it was available for analysis. Signs of healed osteoperiostitis on the femoral and tibial fragments suggested a past episode of inflammation. The 
child was buried with a cast bronze arm-ring and a bone disk similar to the ones sometimes found on the hilts of daggers; this, in combination with the orientation inverse to that of the woman, may suggest a male gender. If sufficient nuclear DNA is preserved, the sex of the child will be revealed in the course of the DNA analysis.

Ceramic jugs, bowls and pots, as well as fragments of large storage vessels, were included in this grave, perhaps representative of a household. The other grave goods comprised jewellery and dress elements that were assigned to each individual: the mother was assigned a Social Index of 87, the young child an SI of 50, the elder an SI of 31 . All three persons in the grave were buried together in a respectful way, with reference to one another in the way the bodies were placed. The deep grave contained a comparatively high-value assortment of grave goods. No evidence of a violent death was found, but the communal burial suggests that all three died in quick succession.

Feature 103, a $1.24 \mathrm{~m}$ deep oval grave pit of about $2.2 \mathrm{~m}$ in length and $1.2 \mathrm{~m}$ in width, contained a woman placed in a south-west/north-east orientation. ${ }^{124}$ Her upper body lay in a supine position on the back, with the arms crossed in front of the body; the face looked right towards the east. ${ }^{125}$ The legs were flexed and tilted to the right. Despite the young morphological age of 16-20, the sexing characteristics of cranium and mandible appear consistently female, compared to the men of similar age in this skeletal series. Tooth cementum annulation suggests an age of death of $21.5 \pm 5$. No assessable characteristics of the pelvis were preserved. A bronze dress pin (Rollenkopfnadel) was found near the left shoulder and fragments of Spiralröllchen in the neck area. A bone awl and a chert flake were found at the feet. The pottery assemblage in the north corner of the grave included a bowl and three small beakers. The burial was assigned a Social Index of 65.

The humerus and scapula fragments of a young child of about 2.5-3.5 years were found amongst the remains of the young woman during the re-analysis of the skeletal material; it is possible that they were first described as animal bones found beneath the woman's pelvis. ${ }^{126}$ If so, the placement of the child would be consistent with the way other mother-child pairs were buried at Unterhautzenthal. The surviving bone fragments of the child were stained green

124 LAUERMANN 1995, 42-45.

125 A possible rotation of the cervical vertebrae was not observed during the excavation; a movement during decomposition can therefore not be completely ruled out.

126 LAUERMANN 1995, 42. from the copper salts of decayed bronze; this may have aided their preservation.

The woman in Feature 109 was placed on the right side, in a tightly flexed position, with the head to the south-west; the grave measured $1.7 \times 0.8 \mathrm{~m}$ and was $1.8 \mathrm{~m}$ deep. ${ }^{127}$ Estimated to have been $162 \mathrm{~cm}$ tall, she died at around 50 to 60 years of age. The woman had repeatedly been a victim of interpersonal violence. There were two healed depression fractures on the cranium: one on the left parietal/occipital bone and one on the left parietal/temporal bone. Greenstick fractures were noted on the left distal ulna shaft and one proximal hand phalanx; the left femur displayed periosteal new bone formation at the shaft. Reactive bone apposition was further noted on the frontal bone, the base of the skull and the right orbital roof. The woman had lost all but one tooth of the maxilla, perhaps in a traumatic event; the teeth of the left side of the mandible were also lost during life, whereas the remaining molars of the right side of the mandible were destroyed by caries and periodontitis. Chewing food must have been a challenge. The skull and pelvis predominately showed female traits: she had a small, weakly developed preauricular sulcus of the left ilium bone; the surface of the rights side is smooth. ${ }^{128}$ A large, tongue-like exostosis (c. $15 \times 20 \mathrm{~mm}$ ) at the anterior-superior margin of the right auricular facies with a corresponding facet on the os sacrum, possibly indicating inflammatory changes (see Fig. 17) would have inhibited movement and probably caused pain. Exostoses and lesions were present at the left ventral symphysis. Degenerative changes included osteophyte formation at the third and fourth lumbar vertebrae.

The left femur of a foetus/neonate with a length of $72 \mathrm{~mm}$ was found amongst the remains of the woman. At 10 lunar months, the mean diaphyseal length of the femur is $74.3 \mathrm{~mm} .{ }^{129}$ The exact location of the femur was not recorded during the excavation, but it was recovered together with the remains of the woman. This suggests that she had either been pregnant with a full-term foetus or was buried with her newborn, something just about possible at the end of her reproductive years. Alternatively, the remains of a baby other than her own were included in the burial. The results of the DNA analysis may help to clarify the relationship. To the excavator, the neck region appeared slightly disturbed, ${ }^{130}$ but the dislocation of the clavicles may have been due to taphonomic changes. No grave goods were obviously

127 LAUERMANN 1995, 51.

128 m-m-i/f-i-- after BRŮŽEK 2002.

129 Scheuer, Black, Christie 2004, 275.

130 Lauermann 1995, 51-52. 


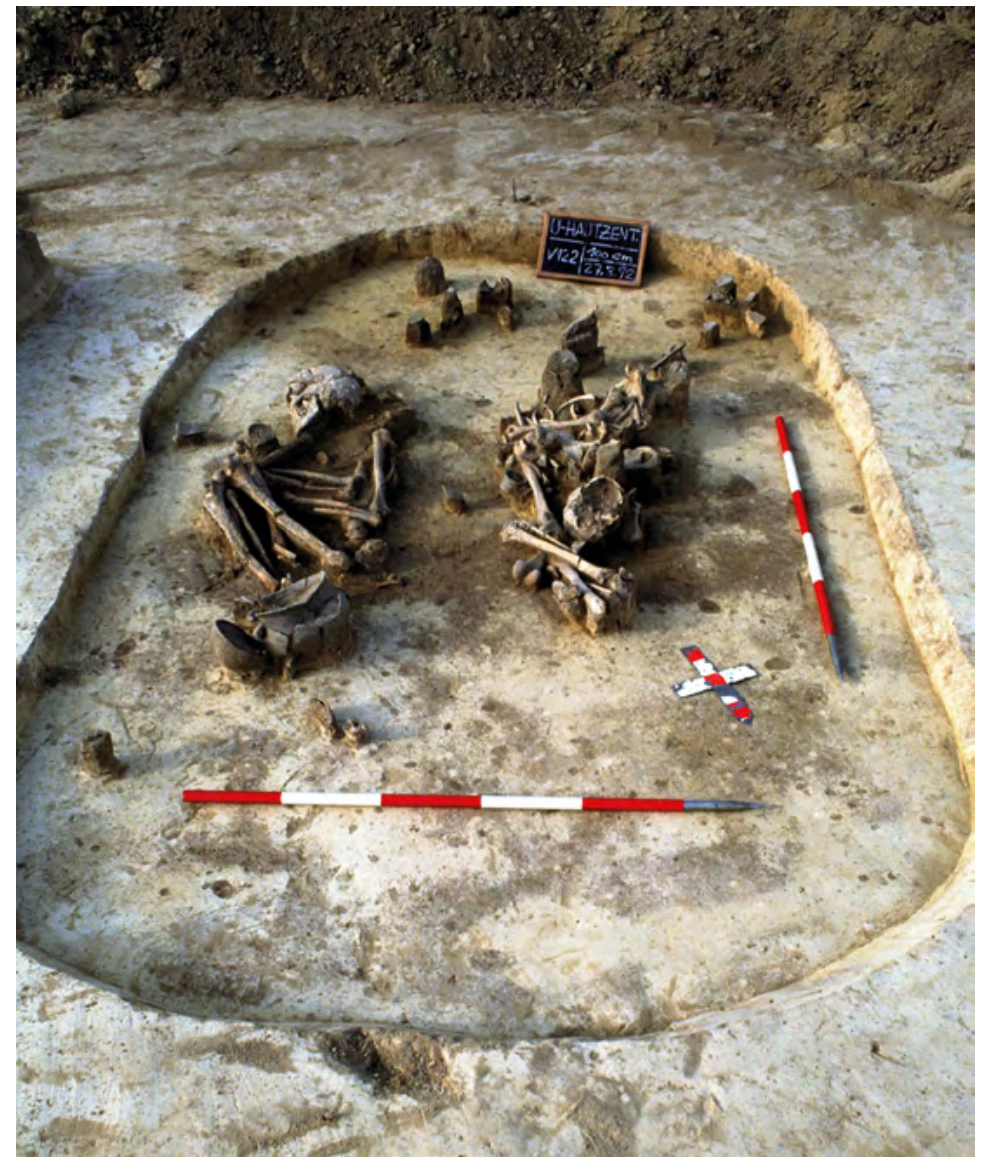

Fig. 27. The triple burial of a 35-45-year-old man, a 17-20 year-old woman and a $0.25-0.5$-year-old baby in Grave 122 (Photo: E. Lauermann). missing: a dress pin (Scbleifenkopfnadel) was found in front of the body, and the woman's jewellery set included a full set of bronze Noppenringe. A ceramic jug, a finely decorated cup and a small vessel completed the grave good set, which was assigned a Social Index of 58.

The woman from Feature 116 was most likely buried in a wooden coffin, placed in a grave of $2.2 \mathrm{~m}$ depth that measured 2.26 by $1.3 \mathrm{~m} .{ }^{131}$ She was placed on the right side, in flexed position and was south-west/north-east oriented. The dislocation of ribs and upper arms is most probably due to the decomposition in a void. ${ }^{132}$ The woman was c. $165 \mathrm{~cm}$ tall and died in the age range of 45-60 years; tooth cementum annulation analysis gives an age of $46.5 \pm 5$ years. A healed fracture of the shaft of the right clavicle was noted. There were severe arthritic changes to the right condyloid process of the mandible, several root tip granulomas on the teeth and massive calculus on the right upper third molar. Osteophyte growth was visible on the bodies of the cervical vertebrae. Her pelvis had a small, weakly developed preauricular sulcus at the left side and severe lytic lesions that led to less density at the ventral symphyseal surface, as well as slight dorsal pits at the left symphysis. The erosions might

131 LAUermann 1995, 56-57.

132 Duday 2009, 32. indicate osteitis pubis, inflammatory changes in the pelvic region due to repetitive strain, possibly related to pregnancy and childbirth.

Three fragments of vertebral arches from a 4-6-year-old child were discovered amongst the skeletal remains of this woman. Their location was not recorded during the excavation, but pig vertebrae were mapped on the grave plan in the bowl near the head of the buried woman. ${ }^{133}$ The remains stored at the Natural History Museum are, however, definitely human. It is unlikely that an entire skeleton of a child of this age would have decayed almost without a trace in this comparatively well preserved grave. The vertebrae must have been added to the women's grave during burial, intentionally or as part of the grave fill. The set of grave goods associated with this woman comprised bronze Noppenringe around the head, a bronze dress pin (Rudernadel) underneath the chin, a chert tool behind the back, as well as a ceramic bowl and jug next to the head, and a further jug at the feet. The grave was assigned a Social Index of 62 .

Feature 122 (Fig. 27) included the bodies of a man, a woman and a baby staged as a family. The grave pit was $1 \mathrm{~m}$ deep and measured 3.2 by $2 \mathrm{~m} .{ }^{134}$ The adults were placed

133 LAUERMANN 1995, 56.

134 LaUermanN 1995, 59-63. 


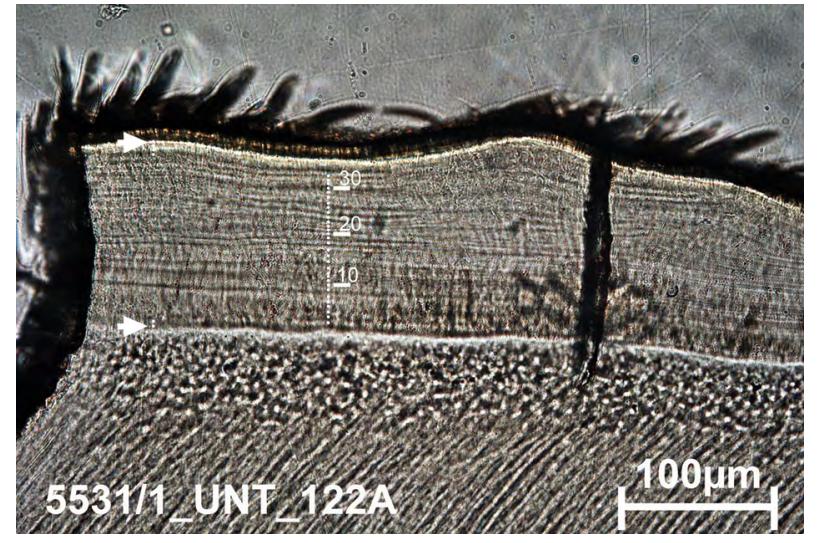

Fig. 28. One of three cross-sections of the first lower left premolar of Individual 122A under the transmitted-light microscope. Each translucent incremental line is marked with a white dot and arrows point to the first and last count. Thirty-seven incremental lines were identified in this section, 34 on average, suggesting an age at death of $44.5 \pm 5$ years (Photo: F. Kanz, ( Medical University of Vienna).

parallel to each other, on their right sides in flexed positions, oriented south-west/north-east. The women lay in front of the man. Both skeletons were found in disarray, but the man was disturbed more heavily than the woman. The exact in situ location of the skeletal remains of the baby remains unknown.

According to morphological ageing, the man (122A) was between 35 and 40 years when he died; tooth cementum annulation analysis points to a slightly higher age at death (44.5 \pm 5 years, Fig. 28$)$. The woman (122B) is estimated to have died at 17-20 years of age, which is consistent with the age estimation via tooth cementum annulation (20.8 \pm 2 years, Fig. 29).

The skull and pelvic bones of 122B appear consistently and distinctly female. She was $156 \mathrm{~cm}$ tall and did not have any visible pathologies. Hypoplastic lines on the incisors and canines, however, show three distinct episodes of stress at the age of 2.6-2.8, 4.2 and 4.9 years. Her pelvic bones were well preserved; a small, weakly developed preauricular sulcus was present on the right side, ${ }^{135}$ and a distinct tuberculum piriforme was present on the left side. ${ }^{136} \mathrm{~A}$ small, extended pubic tubercle was recorded on the right side, ${ }^{137}$ as well as exostoses at the margin of the auricular surface (see Fig. 12). The pelvic features may be indicative of motherhood at a young age.

135 f-i-- after BRŮŽEK 2002.

136 f-i-m after BRŮŽEK 2002.

137 Stage 2 after MAAss 2012.

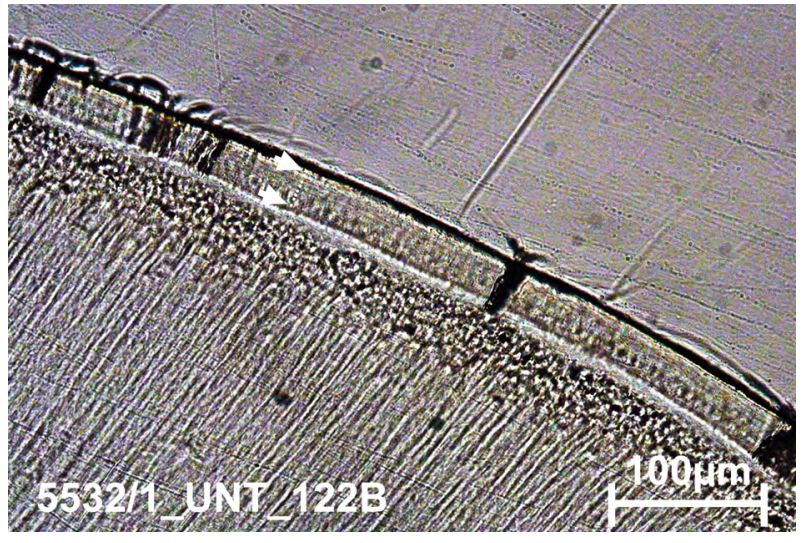

Fig. 29. One of three cross-sections of the second lower right premolar of Individual 122B under the transmitted-light microscope. Each translucent incremental line is marked with a white dot and arrows point to the first and last count. Eight incremental lines were identified in this section, nine on average, suggesting an age at death of $20.8 \pm 5$ years (Photo: F. Kanz, () Medical University of Vienna).

The third individual in this grave, $122 \mathrm{C}$, was represented by a small number of cranial remains, humerus fragments and a tibia, which point to a baby of neonatal to six months of age.

Despite the traces of grave re-opening, a bronze dress pin, along with Spiralröllchen and Noppenring fragments associated with the woman, were still present when the grave was excavated. Pottery comprising the usual set of a beaker, a jug, and a bowl was found in situ near the feet of the woman and next to her elbow. A large number of ceramic fragments and disarticulated skeletal parts from the buried individuals were found in the fill of the disturbed part of the grave. The woman was assigned a minimum Social Index of 57 , the man of 53 .

\section{Isotopic Evidence of Breastfeeding and Weaning}

Breastfeeding is an important part of the mother-child relationship, with several benefits for both mother and child, of which optimal nutrition, avoidance of contaminated food and bonding between mother and child are the most important. The duration of breastfeeding and weaning behaviour is, however, highly variable, both between individuals and between groups, and thus is culturally contingent. ${ }^{138}$

Despite the difficulties of assigning specific weaning ages to individuals and past populations, ${ }^{139}$ a combination of different bio-anthropological indicators can be used to

138 Fulminante 2015. - Rebay-SAlisbury 2017a. 139 Reynard, Tuross 2015. 
study breastfeeding. Whereas enamel hypoplasias and Harris lines may be generally associated with stress by weaning, isotope ratios and dental micro-wear provide specific insights into childhood diet. ${ }^{140}$ The isotopic composition of food and drink is recorded in all human body tissues in a predictable process of isotope fractionation. Isotope delta units $(\delta)$ are determined by comparing the heavy and light stable isotopes of an element to an international reference material. $\delta^{13} \mathrm{C}$ is the ratio of ${ }^{13} \mathrm{C}$ to ${ }^{12} \mathrm{C}$ isotopes, and $\delta^{15} \mathrm{~N}$ is the ratio of ${ }^{15} \mathrm{~N}$ to ${ }^{14} \mathrm{~N}$ isotopes. The standard for $\mathrm{C}$ is $\mathrm{PDB}-\mathrm{a}$, normalised to the value of Vienna Pee Dee Belemnite. The standard for $\mathrm{N}$ is air.

The collagen composition of archaeologically recovered human bone samples reflects the individual's diet in the last years of life: in adults, up to 10-20 years depending on the sampled bone. Carbon and nitrogen isotope ratios can provide insights into the proportion of proteins derived from plant versus animal products such as milk, fish and meat. Differences in carbon isotope values can result from the use of marine vs. terrestrial resources, from variation in the contribution of $\mathrm{C} 3$ and $\mathrm{C} 4$ plants ${ }^{141}$ to the diet, or from whether plants are sourced from open areas or woodland. Differences in nitrogen isotope values suggest variation in the amount of animal protein consumed, or, in young children, the timing of weaning. ${ }^{142}$

Breastfed infants appear enriched in $\delta^{15} \mathrm{~N}$ in comparison to their mothers, because of their position in the food chain above their mothers: $\delta^{15} \mathrm{~N}$ increases in bone collagen from diet by $+3-4 \%$ with each trophic level. Newborns are thought to have similar $\delta^{15} \mathrm{~N}$ values to their mothers, and as babies consume the mother's tissue with breastfeeding, nitrogen levels increase. Differences between maternal and infant nitrogen isotope levels therefore inform us as to whether a baby was breastfed or not.

There are, however, a number of complications with linking elevated $\delta^{15} \mathrm{~N}$ values to breastfeeding: bone turnover rates are slow, and it may take over half a year to fully reflect dietary $\delta^{15} \mathrm{~N}$ signals in body tissue. ${ }^{143}$ Values derived from young infants may reflect the mother's diet and stress rather than the child's diet. Further, elevated $\delta^{15} \mathrm{~N}$ levels may represent a negative nitrogen balance due to rapid protein

140 E.g. Jay et al. 2008. - Bourbou et al. 2013. - Howcroft 2013. BAs 2017. - SCOTT, HALCROW 2017.

141 Plants with different metabolic pathways for carbon fixation during photosynthesis, resulting in different ratios of ${ }^{12} \mathrm{C}$ to ${ }^{13} \mathrm{C}$. These differences propagate through the food chain.

142 Eriksson 2013. - Hamilton et al. 2013.

143 Tsutaya, Yoneda 2013. turnover because of illness, malnutrition or starvation prior to death. ${ }^{144}$

Samples from seven Unterhautzenthal individuals were submitted to Beta Analytic for isotope-ratio mass spectrometry (IRMS) measurement of $\% \mathrm{C}\left(\delta^{13} \mathrm{C}\right), \% \mathrm{~N}\left(\delta^{15} \mathrm{~N}\right)$ and $\mathrm{C}: \mathrm{N}$ ratio. Measurements were taken on bone collagen extracted with alkali from non-cremated bones. In order to allow inferences about age-based nutrition, four sub-adults ranging from 0.5 to six years and two adult females were selected. The two adult females were buried at the same time as two of the tested children, allowing comparison of adult and childhood diet and identification of signals associated with breastfeeding. For one individual (95B, Beta-471354), collagen was extracted from a rib and a long bone fragment. Collagen from single rib bones was used for all other samples for consistency. ${ }^{145}$

The results indicate an overall homogeneous distribution of $\delta^{13} \mathrm{C}$ and $\delta^{15} \mathrm{~N}$, with averages of -19.29 and 11.71 respectively (Table 11) suggesting a diet based on terrestrial C3 resources. Due to the geographic setting, a marine contribution to the diet is not expected in individuals from Unterhautzenthal. The slightly depleted $\delta^{15} \mathrm{~N}$ value of the six-year-old individual from storage pit 27 may be connected to a lower than average proportion of meat in the diet. The $\delta^{15} \mathrm{~N}$ values of the 3-4 and 4-5-year-old children from Grave 95 are not elevated, which suggests that weaning was completed at these ages. Likewise, the 2-3-year-old from Grave 105 does not show a nursing signal. Only the 0.25 to 0.5 -year-old from 122 has an elevated $\delta^{15} \mathrm{~N}$ isotope ratio in comparison to the mother buried in the same grave, which may be interpreted as a nursing signal. ${ }^{146} \mathrm{~A}$ slight positive shift of $\delta^{15} \mathrm{~N}$ values of a perinate from those of the biological mother in an Iberian Bronze Age context, ${ }^{147}$ however, was explained by different dietary averaging effects over several months vs. several years before death.

The isotopic evidence of breastfeeding at Unterhautzenthal was restricted to a single individual who fell into the age group for which exclusive breastfeeding is most likely. In older children, no nursing signal was detected, suggesting that breastfeeding had ceased quite some time earlier. Weaning at the age of around two years would be expected for a

144 BeAumont et al. 2015.

145 Cf. Fahy et al. 2017. - The rib sample did not yield enough collagen; hence, a supplementary sample was taken from a long bone fragment.

146 Fuller et al. 2006.

147 EsParza et al. 2017. 
Table 11. Carbon and nitrogen isotope values from Unterhautzenthal individuals (Beta Analytic sample number, individual, sex, age, sampled material, $\delta^{13}$ carbon, $\delta^{15}$ nitrogen, C:N ratio, concentration of $\mathrm{C}$ and $\mathrm{N}$ ).

\begin{tabular}{|l|c|c|c|c|c|c|c|c|c|}
\hline Lab no. & Individual & Sex & Age & Material & $\begin{array}{c}\text { IRMS } \\
\delta 13 C\end{array}$ & $\begin{array}{c}\text { IRMS } \\
\delta 15 N\end{array}$ & C:N & Wt $\%$ C & Wt $\% \mathbf{N}$ \\
\hline Beta-469622 & 27B & - & 6 years & rib & -19.3 & 10.6 & 3.2 & 41.25 & 14.96 \\
\hline Beta-469618 & 95 & female & $35-45$ years & rib & -19.2 & 12.1 & 3.2 & 41.23 & 14.97 \\
\hline Beta-469619 & $95 \mathrm{~A}$ & - & $3-4$ years & rib & -19.4 & 11 & 3.2 & 42.18 & 15.19 \\
\hline Beta-471354 & $95 \mathrm{~B}$ & - & 5 years & rib, long bones & -19.5 & 12.3 & 3.2 & 41.96 & 15.32 \\
\hline Beta-469620 & 105 & - & $2-3$ years & rib & -18.8 & 11.8 & 3.2 & 41.58 & 15.16 \\
\hline Beta-469621 & $122 \mathrm{~B}$ & female & $17-20$ years & rib & -19.3 & 11 & 3.2 & 41.68 & 15.22 \\
\hline Beta-469775 & $122 \mathrm{C}$ & - & $0.25-0.5$ years & rib & -19.5 & 13.2 & 3.2 & 41.54 & 15.12 \\
\hline
\end{tabular}

sedentary farming community with easy access to weaning food such as animal milk and grains. ${ }^{148}$ The isotopic data from Unterhautzenthal does not contradict this suggestion.

\section{Some Observations on Motherhood at Unterhautzenthal}

Taken together, the evidence from Unterhautzenthal gives interesting insights into motherhood in the early Bronze Age. The age of first motherhood was relatively young. At Unterhautzenthal, a 14-15-year-old may have been pregnant, a 17-20-year-old was buried with a neonate and a 16-20-year-old was buried with the remains of a toddler. At the other end of the reproductive time span, a 35-45-yearold woman was buried with children aged 3-4 and 4-5 and a 40-60-year-old was buried with remains of a neonate. The evidence suggests that motherhood was not restricted to young women, but extended over the entire reproductive life of Bronze Age women. If sexual relations were not socially restricted, Bronze Age women probably had limited means to control the timing and number of children. Evidence from Unterhautzenthal suggests relatively short periods of breastfeeding, which is in accordance with assumptions of high fertility and closely spaced childbirth.

The large age difference between the man and the woman in Grave $122(35-40 / 44.5 \pm 5$ and $17-20 / 20.8 \pm 5$ respectively) may be typical for Bronze Age reproductive partners and may point to remarriage when one partner died young, or to established patriarchal family systems. Comparative evidence from early Bronze Age central Europe suggests patrilocal residential patterns. ${ }^{149}$

In Grave 95, a sibling age gap of only about one year is documented. The children from Feature 27 were two and six years old when they died; if they were siblings, they would

148 Rebay-Salisbury 2017a.

149 Pellegrini et al. 2011. - Rebay-Salisbury 2017b. have been born four years apart. Children were buried in shallower graves and equipped with fewer grave goods on average, but they appear to have been treated with love and respect. The double burial of the 2-year-old and 6-year-old embracing in Feature 27 suggests the expression of emotions through body placement. The mother's hand on the hip of the child in Grave 95 equally suggests the staging of an emotional attachment. That children's lives were difficult may be exemplified by the 3-4-year-old buried in Grave 133, who showed a range of pathologies (cribra orbitalia, meningitis, scurvy, and osteoperiostitis). The child also had a fracture of the right distal humeral shaft, which partially healed in malposition. Nevertheless, the child was buried respectfully and was given a bronze arm-ring, a Noppenring of c. $30 \mathrm{~mm}$ diameter; perhaps a last gift from the jewellery of the mother. Comparing the health status of children and adults more generally, it appears that a higher proportion of children have signs of deficiency and malnutrition than adults, but fewer instances of trauma overall. Past periods of stress were preserved into adulthood in enamel hypoplasias. Enamel hypoplasias were formed between age 2.4 and 5.6, with some individuals showing repeated episodes of stress between these ages. This may be the age at which consistent and appropriate supply of nutrients via breastfeeding ceased, and childhood diseases took their toll. Overall, it is perhaps possible to characterise childhood from weaning to reaching adolescence as a period of lack of available resources or benign neglect, but not of intentional physical abuse.

The women at Unterhautzenthal were found to be of rather short stature, with an average body height of $157 \mathrm{~cm}$, which may be linked to insufficient nourishment during childhood $^{150}$ on top of genetic predisposition. Women of

150 Özaltin, Hill, Subramanian 2010, 7 
short stature are at a disadvantage in childbirth, as they are more prone to a mismatch between pelvic inlet size and the head circumference of the baby. ${ }^{151}$ These women may therefore have developed more distinct preauricular sulci due to traumatic birth experiences. Pronounced exostoses at the sacroiliac joint were found significantly more frequently in women than men at Unterhautzenthal, indicating either a more laborious life carrying heavy loads or weight bearing from multiple pregnancies. Women who have given birth to several children have more advanced degenerative-arthritic changes, especially at the lumbar spine and the sacroiliac joints. Only in comparison with age-related changes in other parts of the body, however, can such changes be interpreted as possible late effects of frequent births. ${ }^{152} \mathrm{De}-$ generative changes and bone loss further testify to physical traces of strain through pregnancy and childbirth.

Cemetery demographics suggest that, on average, women at Unterhautzenthal had 7.9 children if they survived to the age of 50, which only about a quarter of women did. The age at death composition within the burial community suggests a growing population, despite high infant and childhood mortality. The burden of childbearing affects only women, whereas the responsibility of raising them may have been shared within the community. The two women with multiple injuries at Unterhautzenthal $(93,109)$, perhaps from interpersonal violence, were still buried in a respectful manner with the usual set of jewellery and grave goods.

Mothers were not, in principle, treated differently to other women at the cemetery of Unterhautzenthal. We have found no evidence for a differentiation between women who had given birth, and women who might have not. Individuals for whom we assume motherhood were buried in the normal body position, on their right side with the lower body flexed. Their grave goods encompassed the usual set of bronze jewellery and pottery. It is perhaps interesting that three out of the four graves containing chert tools were those of mothers, the fourth being the completely destroyed burial of Individual 93A, a 20-25-year-old woman. The expedient flake tools, in some cases retouched, would have provided a very sharp cutting edge. Cutting tools in graves associated with pregnancy and childbirth are found well into the medieval period ${ }^{153}$ and may represent surgical devices, e.g. for cutting the umbilical cord.

The Unterhautzenthal community, in general, appeared to have had a rather flat social hierarchy. The selection of

151 Fischer, MitTeroecker 2015.

152 Putschar 1931, 161.

153 Cf. Löw 2010. grave goods was primarily based on gender and age, and status differences seemed to play only a minor role. Most people were equipped with a basic set of pottery and some with animal bones, which represented provisions and therefore an element of care for the dead. Women's graves included more bronze jewellery than men's did on average. Despite the apparently flat social hierarchy, the mean Social Index of the six women buried with children was slightly higher (61) than the female average (56). This difference becomes even more pronounced when excluding the pregnant teenager, who probably died with her first child. Although we did not find a direct relationship between social status and the presence of pelvic features suggesting strain through pregnancy and birth, motherhood may have contributed to women's social status.

\section{Outlook}

The detailed re-assessment of the archaeology and anthropology at Unterhautzenthal is the first of a series of case studies that will investigate the relationship between social and reproductive status in Bronze Age women. In this article, we have outlined the methodology that we are developing and adjusting to each case study and have presented preliminary results. Some analytical results from this pilot study are still pending. The results of the aDNA analysis of co-buried individuals should give us some idea if the social relationships indicated in the burial context are based on genetic relatedness, i.e. if social motherhood equals biological motherhood at this site. Studies of dental micro-wear on deciduous teeth will allow additional inferences about the process and timing of weaning, as well as the use of early supplementary foods in children's diets.

Further case studies will develop the pelvic features methodology, integrating data on body height and stature, pelvic morphology and measurements with biomechanical observations on locomotion. At present, we recommend supplementing the common methods of pelvic assessment, using the clear definitions suggested by Brůžek ${ }^{154}$ to make additional skeletal samples comparable. The methodology developed within our ongoing projects can be applied to case studies of all areas and time periods, as long as sufficient archaeological and anthropological data is available. Within the framework of the ERC Starting Grant Project VAMOS The value of mothers to society: responses to motherbood and child rearing practices in prehistoric Europe, case studies spanning the time frame of three millennia BC will be investigated for a diachronic picture of how motherhood developed over time.

154 BRŮŽEK 2000. 
Appendix 1.

Pelvic feature data of all assessable individuals from Unterhautzenthal $(n=25$, recording system see Table 5) in context with pelvic anomalies, noticeable pathologies, and archaeological observations.

\begin{tabular}{|c|c|c|c|c|c|c|c|c|c|c|c|c|c|c|c|c|c|}
\hline 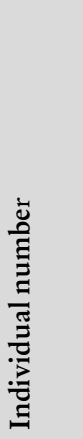 & $\stackrel{\star 凶}{\grave{~}}$ & 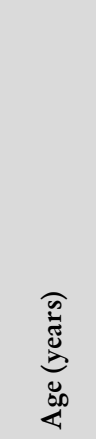 & 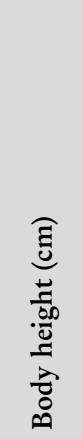 & 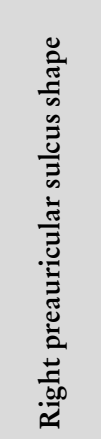 & 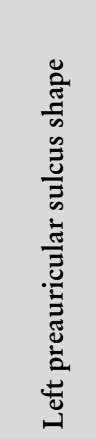 & 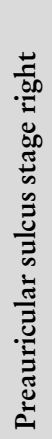 & 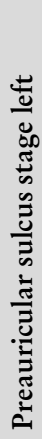 & 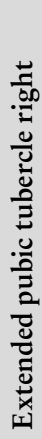 & 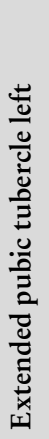 & 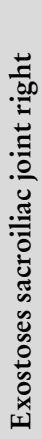 & 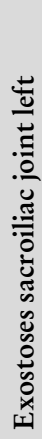 & 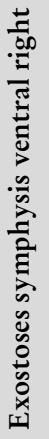 & 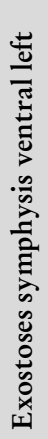 & 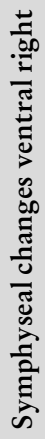 & 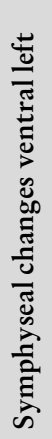 & 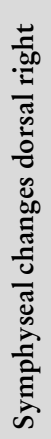 & 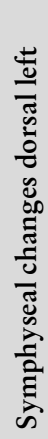 \\
\hline 16 & male & $35-45$ & 170.1 & m-m-- & m-m-- & 1 & 1 & 0 & 0 & 0 & 0 & 0 & 0 & 0 & 0 & 0 & 0 \\
\hline 28 & female & $25-35$ & 150.6 & $f-f-f$ & $f-f-f$ & 3 & 4 & 0 & 0 & 2 & 2 & 0 & 0 & 0 & 0 & 0 & 0 \\
\hline 81 & male? & $17-20$ & & $m-m-f$ & $m-m-f$ & 1 & 1 & 1 & 1 & 1 & 1 & 1 & 1 & 1 & 1 & 1 & 1 \\
\hline 84 & male & $25-30$ & 168.8 & $m-m-i$ & m-m-- & 1 & 1 & 0 & 0 & 1 & 1 & 0 & 0 & 0 & 0 & 0 & 0 \\
\hline 86 & male & $40-60$ & 168.0 & m-m-- & ----- & 1 & 0 & 0 & 0 & 2 & 0 & 0 & 1 & 0 & 1 & 0 & 1 \\
\hline 88 & female & $35-50$ & 143.1 & $f-f-f$ & $f-f-f$ & 3 & 3 & 1 & 0 & 2 & 2 & 0 & 0 & 0 & 0 & 0 & 0 \\
\hline 90 & female & $40-50$ & 160.0 & & $\mathrm{i}-\mathrm{i}-\mathrm{f}$ & 0 & 2 & 0 & 0 & 0 & 2 & 0 & 0 & 0 & 0 & 0 & 0 \\
\hline 93 & female & $35-45$ & 161.4 & $f-i-f$ & $i-i-f$ & 3 & 2 & 1 & 0 & 2 & 2 & 0 & 0 & 0 & 0 & 2 & 0 \\
\hline $93 \mathrm{~A}$ & female & $20-25$ & & & & 0 & 0 & 0 & 0 & 0 & 0 & 0 & 0 & 0 & 0 & 0 & 0 \\
\hline 94 & male & $40-60$ & 159.5 & & & 0 & 0 & 0 & 0 & 2 & 0 & 0 & 0 & 0 & 0 & 0 & 0 \\
\hline 95 & female? & $35-45$ & 157.3 & & & 0 & 0 & 2 & 0 & 1 & 0 & 1 & 1 & 0 & 0 & 2 & 2 \\
\hline 99 & female? & $14-18$ & & & & 0 & 0 & 0 & 0 & 0 & 0 & 0 & 0 & 0 & 0 & 0 & 0 \\
\hline 100 & female & $17-25$ & 159.0 & $\mathrm{i}-\mathrm{i}-\mathrm{m}$ & $f-i--$ & 2 & 3 & 1 & 1 & 0 & 0 & 0 & 0 & 2 & 2 & 0 & 0 \\
\hline 102 & female & $25-35$ & 162.2 & $m-m-f$ & $m-m-f$ & 1 & 1 & 0 & 0 & 2 & 0 & 2 & 0 & 0 & 0 & 0 & 0 \\
\hline $103 \mathrm{~A}$ & female? & $16-20$ & & & & 0 & 0 & 0 & 0 & 0 & 0 & 0 & 0 & 0 & 0 & 0 & \\
\hline
\end{tabular}




\begin{tabular}{|c|c|c|c|}
\hline 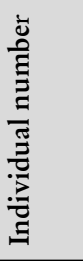 & Pelvic anomalies & $\begin{array}{l}\text { Biomechanically relevant bone } \\
\text { changes }\end{array}$ & Archaeology \\
\hline 16 & weakly developed preauricular sulcus at both ossa ilium & & burial in storage pit, SI 32 \\
\hline 28 & true preauricular groove, exostoses at sacroiliac joints bilaterally & & burial, SI 36 \\
\hline 81 & & & burial with dagger, SI 83 \\
\hline 84 & & & burial, SI 11 \\
\hline 86 & slight exostoses at the anterior border of the right sacroiliac joint & & burial, SI 26 \\
\hline 88 & true preauricular groove, exostoses at sacroiliac joints & $\begin{array}{l}\text { strong osteophyte growth at the } \\
\text { thoracic and lumbar vertebral } \\
\text { bodies }\end{array}$ & $\begin{array}{l}\text { burial in supine position, } \\
\text { SI } 52\end{array}$ \\
\hline 90 & $\begin{array}{l}\text { sulcus is very irregular, consisting of small connected cavities; } \\
\text { some exostoses at the left sacroiliac joint }\end{array}$ & $\begin{array}{l}\text { the joint surface of acetabulum } \\
\text { exhibits age related marginal ridges }\end{array}$ & burial, SI 100 \\
\hline 93 & $\begin{array}{l}\text { moderately developed preauricular sulcus on the tight pubic } \\
\text { bone, and a small one on the left side; exostoses and a thickened } \\
\text { rim at the sacroiliac joints, the anterior-superior margin of both } \\
\text { sacroiliac joints exhibit symmetrical, lobular extensions at the } \\
\text { auricular surface of the sacrum, with corresponding facets at } \\
\text { ilium (c. } 10 \times 10 \mathrm{~mm} \text { ); margo auricularis groove (stage } 2 \text { ) bilat- } \\
\text { erally developed at os sacrum; small lesions on the right dorsal } \\
\text { pubic surface }\end{array}$ & $\begin{array}{l}\text { possible sacralisation of L5: last } \\
\text { lumbar vertebra L5 and the first } \\
\text { sacral vertebra S1, seem to have } \\
\text { been grown together, but this is } \\
\text { uncertain due to strong erosion at } \\
\text { this region }\end{array}$ & burial, SI 55 \\
\hline $93 \mathrm{~A}$ & & & burial, SI 38 \\
\hline 94 & $\begin{array}{l}\text { some exostoses at the right sacroiliac joints - possibly modified } \\
\text { through erosion of bone surface }\end{array}$ & & burial, SI 35 \\
\hline 95 & $\begin{array}{l}\text { small extended tuberculum pubis at right side, slight dorsal } \\
\text { pitting bilaterally }\end{array}$ & $\begin{array}{l}\text { age related degenerative changes } \\
\text { at both knee joints (femora) and } \\
\text { some vertebral bodies }\end{array}$ & $\begin{array}{l}\text { triple burial, woman with } \\
\text { two children, SI } 87\end{array}$ \\
\hline 99 & & & burial, SI 44 \\
\hline 100 & $\begin{array}{l}\text { preauricular groove at both sides with tuberculum piriformis at } \\
\text { right side, lesions at the ventral pubic surface, similar to imprints } \\
\text { in upper symphyseal region }\end{array}$ & & burial, SI 48 \\
\hline 102 & $\begin{array}{l}\text { no clear evidence of preauricular groove, left sacroiliac joint and } \\
\text { left ventral symphysis exhibit some exostoses }\end{array}$ & $\begin{array}{l}\text { slight osteophytes at some lumbar } \\
\text { vertebra }\end{array}$ & burial, SI 51 \\
\hline $103 \mathrm{~A}$ & & & $\begin{array}{l}\text { burial with remains of } \\
\text { young child, SI } 65\end{array}$ \\
\hline
\end{tabular}


Appendix 1. continued.

\begin{tabular}{|c|c|c|c|c|c|c|c|c|c|c|c|c|c|c|c|c|c|}
\hline 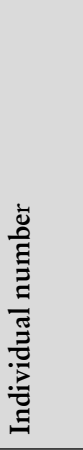 & ஸे & 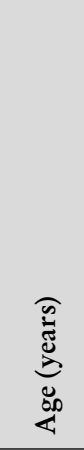 & 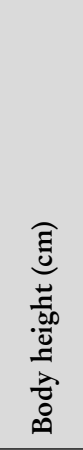 & 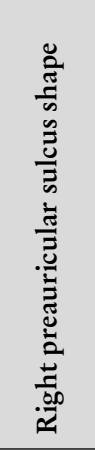 & 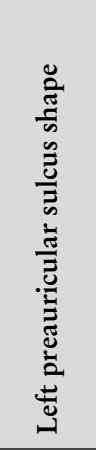 & 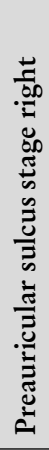 & 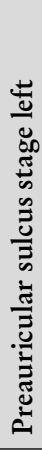 & 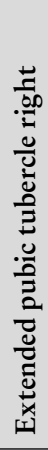 & 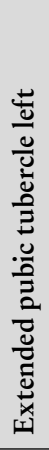 & 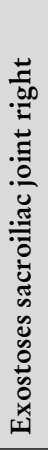 & 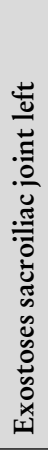 & 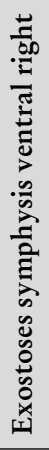 & 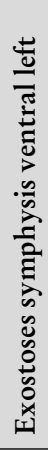 & 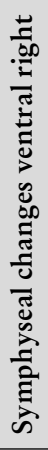 & 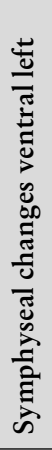 & 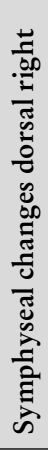 & 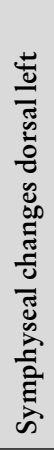 \\
\hline $109 \mathrm{~A}$ & female & $40-60$ & 161.7 & $m-m-i$ & f-i-- & 1 & 2 & 0 & 2 & 2 & 1 & 0 & 2 & 0 & 2 & 0 & 1 \\
\hline 111 & male & $30-40$ & 161.2 & m-m-- & m-m-- & 1 & 1 & 0 & 1 & 0 & 1 & 0 & 1 & 0 & 2 & 0 & 1 \\
\hline $116 \mathrm{~A}$ & female & $45-60$ & 164.6 & ----- & i-f-- & 0 & 2 & 0 & 0 & 0 & 0 & 0 & 1 & 0 & 2 & 0 & 2 \\
\hline $122 \mathrm{~B}$ & female? & $17-20$ & 156.0 & f-i-- & $\mathrm{f}-\mathrm{i}-\mathrm{m}$ & 2 & 2 & 2 & 2 & 2 & 2 & 1 & 1 & 1 & 1 & 1 & 1 \\
\hline 123 & female? & $40-50$ & 160.3 & $f-f--$ & f-i-- & 3 & 2 & 0 & 2 & 2 & 2 & 0 & 2 & 0 & 2 & 0 & 1 \\
\hline 124 & male & $35-50$ & 163.9 & m-m-- & $i-m-i$ & 1 & 2 & 1 & 1 & 1 & 1 & 1 & 1 & 1 & 1 & 1 & 1 \\
\hline 125 & female & $45-60$ & 148.8 & $f-i-f$ & $f-i-f$ & 3 & 3 & 1 & 0 & 2 & 2 & 0 & 0 & 0 & 0 & 0 & 0 \\
\hline 128 & female & $40-50$ & 154.9 & $i-i-f$ & $i-i-f$ & 2 & 2 & 2 & 2 & 2 & 2 & 2 & 2 & 2 & 2 & 2 & 2 \\
\hline 134 & female & $30-40$ & 152.0 & $m-i-f$ & $m-i-f$ & 2 & 2 & 2 & 2 & 2 & 2 & 2 & 2 & 1 & 1 & 1 & 1 \\
\hline 138 & female & $55-65$ & 153.0 & & & 0 & 0 & 1 & 1 & 0 & 0 & 0 & 0 & 0 & 2 & 0 & 0 \\
\hline
\end{tabular}




\begin{tabular}{|c|c|c|c|}
\hline 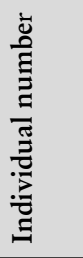 & Pelvic anomalies & $\begin{array}{l}\text { Biomechanically relevant bone } \\
\text { changes }\end{array}$ & Archaeology \\
\hline $109 \mathrm{~A}$ & $\begin{array}{l}\text { large, tongue-like exostosis (c. } 15 \times 20 \mathrm{~mm} \text { ) at the anterior-su- } \\
\text { perior margin of the right auricular facies with a corresponding } \\
\text { facet at the os sacrum indicating inflammatory changes; small ex- } \\
\text { tended pubic tubercle at the left pubic bone (stage } 2 \text { ) and a ridge- } \\
\text { like elevation on the right side (located somewhat posterior at } \\
\text { the pecten ossis pubis); exostoses and lesions at the left ventral } \\
\text { symphysis (possible causal relationship to the large exostosis at } \\
\text { the auricular facies) }\end{array}$ & $\begin{array}{l}\text { third and forth lumbar vertebrae } \\
\text { show osteophyte formation }\end{array}$ & $\begin{array}{l}\text { burial with femur of neo- } \\
\text { nate, SI } 58\end{array}$ \\
\hline 111 & left os pubis exhibits slight changes at ventral symphyseal region & & burial with dagger, SI 81 \\
\hline $116 \mathrm{~A}$ & $\begin{array}{l}\text { small, weakly developed preauricular sulcus at the left side, } \\
\text { which was not assessable at the right side; massive lytic lesions in } \\
\text { form of deep, frail structural erosions at the ventral symphyseal } \\
\text { surface as well as slight dorsal pits at the left symphysis (osteitis } \\
\text { pubis?) }\end{array}$ & & $\begin{array}{l}\text { burial with remains of } \\
\text { young child, SI } 62\end{array}$ \\
\hline 122B & $\begin{array}{l}\text { bilateral, weakly developed preauricular sulcus at the right side, } \\
\text { plus distinct piriform tubercle at the left side; small extended } \\
\text { pubic tubercle bilaterally developed; exostoses at the margin of } \\
\text { the auricular surface bilaterally }\end{array}$ & & $\begin{array}{l}\text { woman from triple burial } \\
\text { (man, woman and neo- } \\
\text { nate), SI } 57\end{array}$ \\
\hline 123 & $\begin{array}{l}\text { moderately developed preauricular sulcus at the right side and a } \\
\text { small, weakly developed sulcus at the left side; sharp-edged crista } \\
\text { at the left side of the pecten ossis pubis with a pyramid-like small } \\
\text { extended tubercle in its dorsal elongation; arthritic changes at the } \\
\text { right auricular facies and corresponding sacral joint; exostoses } \\
\text { and lytic lesions at the ventral pubic surface; severe exostoses at } \\
\text { the iliosacral joints }\end{array}$ & $\begin{array}{l}\text { degenerative changes at the in- } \\
\text { tervertebral joints of the second } \\
\text { to the third cervical vertebra and } \\
\text { fourth to fifth lumbar vertebra }\end{array}$ & burial, SI 93 \\
\hline 124 & & age related changes at hip joint & burial, SI 32 \\
\hline 125 & $\begin{array}{l}\text { moderately developed preauricular sulci at both sides, exostoses } \\
\text { at the auricular facies of the sacroiliac joints }\end{array}$ & $\begin{array}{l}\text { osteophytic lipping visible at the } \\
\text { lumbar spine (L3-L5) }\end{array}$ & burial SI 28 \\
\hline 128 & $\begin{array}{l}\text { preauricular sulcus, extended pubic tubercle and dorsal pitting; } \\
\text { exostoses are present at the margin of the auricular facies of } \\
\text { the sacroiliac joints and ventral symphysis, the latter possible } \\
\text { inflammatory changes due to osteitis pubis; a sharp edged ridge } \\
\text { was found at pecten ossis pubis, even more marked at the right } \\
\text { side; }\end{array}$ & $\begin{array}{l}\text { gracile skeleton with strong muscle } \\
\text { markings; bones strongly osteo- } \\
\text { porotic; dorsal side of the ilium } \\
\text { bones reveal distinct, ridge-like } \\
\text { changes at the insertion of the } \\
\text { gluteal muscles (joint function is } \\
\text { abduction), lumbar spine reveals } \\
\text { strong marginal lipping ventrally; } \\
\text { substantial marginal ridges at the } \\
\text { knee joints (especially at right side) }\end{array}$ & burial, SI 33 \\
\hline 134 & $\begin{array}{l}\text { small, weakly developed preauricular sulcus at both sides, sharp } \\
\text { ridge at the pecten ossis pubis with small extended pubic tuber- } \\
\text { cles at both sides, dorsal pubic changes (pits) and exostoses at the } \\
\text { facies auricularis at the sacroiliac joints and at the ventral pubic } \\
\text { surface }\end{array}$ & $\begin{array}{l}\text { sacralisation of the fifth lumbar } \\
\text { vertebra, first sacral vertebra re- } \\
\text { veals a fissure formation }\end{array}$ & $\begin{array}{l}\text { burial, supine-left flexed } \\
\text { position, SI } 47\end{array}$ \\
\hline 138 & $\begin{array}{l}\text { rare pelvic elements mostly show no changes except for lesions } \\
\text { at the left ventral pubic surface }\end{array}$ & individual possibly osteoporotic & burial, SI 42 \\
\hline
\end{tabular}




\section{Appendix 2.}

Catalogue of Human Remains from Unterhautzenthal

Unterhautzenthal, Feature 16 (pit), NHM AA ${ }^{155}$ Inv. no. 24900

Sex: male, almost all sexual characteristics are of male expression

Age: 35-45 years, cranial suture closure (S2 and S3 fused) and dental wear (IIIa)

Body height: $170.1 \mathrm{~cm}$

Bone surface preservation: moderately eroded

Green stains from bronze: none detected

Pelvic features: weakly developed preauricular sulcus at both ossa ilium (shape r/l: m-m--/m-m--, stage r/l: 1/1)

Stress/bone reactions: moderately developed porotic hyperostosis running along the sagittal suture of both parietals bones and occipital bone; both tibiae show extensive striation (healed periosteal reaction); strong new bone formation observable at the inner surface of dorsal costal arch (pleuritis); whole skeleton shows signs of bone loss

Trauma: left os parietale exhibits a large circular healed depression fracture (diameter $50 \mathrm{~mm}$ )

Degenerative changes: distinctly developed sulcus-like muscle attachment of brachialis muscle at left ulna

Other: upper first molar developed strongly sloped dental wear; moderate dental calculus visible at mandibular teeth; tooth displacement (lateral) of the upper left second incisor Anatomical variation: both humeri have a foramen olecrani Comment: measurements of long bones (right side/left side): femur $=468 / 467 \mathrm{~mm}$

\section{Unterhautzenthal, Feature 18 (pit), NHM AA Inv. no. 24901} Sex: undetermined

Age: 14-15 years, dental development and epiphyseal fusion

Body height: $130-134 \mathrm{~cm}$

Bone surface preservation: weakly eroded

Green stains from bronze: none detected

Stress/bone reactions: slight porotic hyperostosis at both parietals and the occipital bone; wallpaper-like new bone apposition in the left sinus maxillaris - sinusitis maxillaris; local, but distinct signs of scurvy, fine porous layer of new bone formation, at the right clavicle (pinhead-size) and dorsal surface of both humeri (more extensive spreading, c. $30 \times$ $10 \mathrm{~mm}$ ) and fine porous pitting at the inner surface of some ribs (pleuritis?); skeleton shows signs of bone loss

Trauma: none detected

Degenerative changes: none detected

Other: vessel imprints visible at internal lamina of ossa parietalia; prognathism - upper teeth row seems to be protruded

155 Natural History Museum Vienna, Department of Anthropology
Anatomical variation: foramina ceca at the upper right second premolar and first molar

Comment: measurement of diaphyseal length (right side/ left side): femur $=359 / 358 \mathrm{~mm}$

\section{Unterhautzenthal, Feature 23 (pit), NHM AA Inv. no. 24903}

Sex: male, most of cranial and pelvic features are of male expression

Age: $\mathbf{3 0 - 5 0}$ years, no cranial suture closure, dental wear (IIc/IIIa), facies sternalis (>III)

Body height: $166.6 \mathrm{~cm}$

Bone surface preservation: moderately eroded

Green stains from bronze: none detected

Pelvic features: anterior/distal border of facies auricularis with rim-like exostoses and a triangular bony protrusion

Stress/bone reactions: none detected

Trauma: none detected

Degenerative changes: age appropriate slight alterations; strong muscle insertions at the shoulder girdle

Other: massive, uniform tooth abrasion in the upper jaw

Anatomical variation: none detected

Comment: measurements of long bones exhibit a side laterality even in the upper and lower extremity (right side/left side): humerus $=320 / 306 \mathrm{~mm}$; femur $=455 / 448 \mathrm{~mm}$ )

\section{Unterhautzenthal, Individual 27A, Feature 27 (pit, double} burial, left side)

\section{Sex: undetermined}

Age: c. 2 years, dental mineralisation and diaphyseal length Body height: $80-84 \mathrm{~cm}$

Bone surface preservation: weakly eroded

Green stains from bronze: none detected

Pelvic features: no assessable characteristics

Stress/bone reactions: none detected

Trauma: slight vessel impression at the internal layer of ossa parietalia and moderately developed gyri impressions possibly due to intracranial pressure

Degenerative changes: none detected

Other: slight enamel hypoplasia visible at the right lower canines

Anatomical variation: small ossiculae lambdoideae

Comment: measurements of the diaphyseal length: right humerus $=117 \mathrm{~mm}$, right $\mathrm{ulna}=97 \mathrm{~mm}$; skeletons were studied in articulation (preserved in situ and displayed at Museum MAMUZ Schloss Asparn)

Unterhautzenthal, Individual 27B, Feature 27 (pit, double burial, right side)

Sex: undetermined

Age: c. 6 years, dental development and diaphyseal length Body height: 100-104 cm 
Bone surface preservation: weakly eroded

Green stains from bronze: none detected

Pelvic features: no assessable characteristics

Stress/bone reactions: cribra orbitalia visible as fine porous structure at right orbital roof

Trauma: moderately developed vessel impression at the internal layer of the right os parietale and os temporale; possible perimortal traumatic lesion at the right parietal bone with characteristic burst fracture lines

Degenerative changes: none detected

Other: none detected

Anatomical variation: none detected

Comment: measurements of diaphyseal length: left humerus $=168 \mathrm{~mm}$, left femur $=235 \mathrm{~mm}$, left tibia $=197 \mathrm{~mm}$ (in situ - right side, flexed); skeletons were studied in articulation (preserved in situ and displayed at Museum MAMUZ Schloss Asparn)

Unterhautzenthal, Feature 28 (grave), NHM AA Inv. No.24906

Sex: female, sexing characteristics of skull and coxal bones are consistently female

Age: 25-35 years, no cranial suture closure, dental wear (IIb), facies articularis sternalis (III)

Body height: $150.6 \mathrm{~cm}$

Bone surface preservation: moderately eroded

Green stains from bronze: ossa temporalia, cranial base and left side: of maxilla, mandible, clavicle, first and fourth cervical vertebra and phalanges of the right hand

Pelvic features: bilaterally developed true preauricular sulcus (shape $r / l$ : $f-f-f / f-f-f$, stage $r / l: 3 / 4$ ) and exostoses at the sacroiliac joints bilaterally

Stress/bone reactions: resorption process at left maxillary sinus (c. $10 \mathrm{~mm}$ ), emanating from a root granuloma at the left upper first molar; small cluster of fine foramina in the orbital roof - cribra orbitalia

Trauma: none detected

Degenerative changes: osteochondrosis dissecans visible as a peppercorn sized recess at right calcaneus (facies articularis talaris posterior)

Other: none detected

Anatomical variation: none detected

Comment: measurements of long bones (right side/left side); humerus $=285 / 284 \mathrm{~mm}$, radius $=224 /-\mathrm{mm}$, femur $=$ $-/ 398 \mathrm{~mm}$, tibia $=337 / 339 \mathrm{~mm}$

Unterhautzenthal, Feature 37 (grave), NHM AA Inv. no. 24907 Sex: undetermined

Age: 5-6 years, dental development

Body height: indeterminable

Bone surface preservation: weakly eroded

Green stains from bronze: bilaterally at mandibular ramus, clavicles, first rib, radii, ulnae, carpals and metacarpals; right side of os temporale, cervical vertebrae, scapula and humerus, right os coxae

Pelvic features: no assessable characteristics

Stress/bone reactions: finely porous new bone formation at right scapula (scurvy?)

Trauma, Degenerative changes, Other, Anatomical variation: none detected

Comment: no measurements of diaphyseal length possible

Unterhautzenthal, Individual 38A, Feature 38 (grave),

NHM AA Inv. no. 24908

Sex: undetermined

Age: 14-15 years, dental development, dental wear (Ia), no cranial suture closure (only C1-3 preserved), facies articularis sternalis $(\mathrm{I})$; TCA: $17.5 \pm 5$ years

Body height: indeterminable

Bone surface preservation: strongly eroded

Green stains from bronze: left side of os temporale and mandibular ramus, right clavicle and some rib fragments

Pelvic features: no assessable characteristics

Stress/bone reactions: none detected

Trauma: none detected

Degenerative changes: none detected

Other: a small (c. $10 \times 10 \mathrm{~mm}$ ), calcified body stone (sialolithiasis?) was found with this individual

Anatomical variation: none detected

Comment: no measurements possible; cranial and postcranial bone fragments of a foetus were found (38B) with this individual

Unterhautzenthal, Individual 38B, Feature 38 (grave),

NHM AA Inv. no. 24908

Sex: undetermined

Age: 34-36 gestational weeks, foetus

Bone surface preservation: strongly eroded

Comment: cranial and postcranial bone fragments of this neonate were detected among the bones of Individual 38A; measurements of pars petrosa: length $=31 \mathrm{~mm}$, width $=$ 13.5-14 mm, suggesting a gestational age of 34-36 weeks (FAzekas, Kósa 1978).

Unterhautzenthal, Feature 81 (grave), NHM AA Inv. no. 24909 Sex: male, sexing characteristics of skull are of both female and male expression, but the pelvic bones are predominantly male

Age: 17-20 years, no cranial suture closure, dental wear (Ia), facies sternalis (0), facies symphysialis (0), epiphyseal fusion (distal humerus, proximal radius, proximal femur, distal tibia)

Body height: indeterminable 
Bone surface preservation: weakly eroded

Green stains from bronze: right side of viscerocranium, os temporale, clavicle, scapula, manubrium and humerus; bilaterally at forearms; upper left second incisor singularly green stained

Pelvic features: no conspicuous features

Stress/bone reactions: signs of scurvy: finely porous layers at left scapula, right clavicle, bilaterally at humeri, radii, femora, tibiae and fibulae, right ilium (dorsally), cervical vertebrae, ribs, metacarpals and phalanges of the hand

Trauma: semi-circular shaped healed impression fracture at the left parietal bone (possibly scraped for medical treatment or cauterisation); existence of callus at the dorso-proximal part of the left tibia shows secondary bone healing after a possibly green-stick fracture, surrounded by massive osteoperiostitis (grade 5)

Degenerative changes: none detected

Other: LEH (enamel hypoplasia): severity stage 3, two hypoplastic lines at maxillary first and second incisors and three hypoplastic lines at all canines corresponding to a formation age of 2.4, 3.4 and 4.9 years

Anatomical variation: foramen caecum at the buccal side of all mandibular molars

Comment: no measurements possible

Unterhautzenthal, Feature 83 (grave), NHM AA Inv. no. 24910 Sex: male, sexing characteristics of cranium, mandible and coxal bones consistently male (pelvis strongly eroded - few assessable characteristics)

Age: 35-50 years, cranial suture closure (S3), dental wear (IIIa/b), facies articularis sternalis (>III), facies symphysialis (VII/VIII)

Body height: $164.4 \mathrm{~cm}$

Bone surface preservation: moderately eroded

Green stains from bronze: right side of os temporale, maxilla and mandible, cervical vertebrae, clavicle, radius and ulna Pelvic features: slight exostoses at right ventral symphysis Stress/bone reactions: none detected

Trauma: none detected

Degenerative changes: sixth and seventh cervical vertebrae blocked (even corpus and arch, congenital?), resulting from asymmetric load - severe osteoarthritic changes of vC7 and vTh1 at the left side; massive osteophyte growth, nearly all vertebrae affected, especially at lower thoracic and lumbar vertebrae beginning formation of bony junctions; pronounced muscle insertions in shoulder region and right hand

Other: carious lesions at maxillary second right premolars and both first molars; LEH enamel hypoplasia especially at mandibular teeth (stage 2/3), first incisor: formation age 3.4, canine: formation age 2.7
Anatomical variation: none detected

Comment: measurements of long bones (right side/left side); humerus $=-/ 332 \mathrm{~mm}$, radius $=-/ 265 \mathrm{~mm}$, femur $=$ $-/ 447 \mathrm{~mm}$

Unterhautzenthal, Feature 84 (grave), NHM AA Inv. no. 24911 Sex: male, sexing characteristics of cranium, mandible and pelvic bones are predominantly male

Age: 25-30 years, no cranial suture closure, dental wear (IIa/b), facies articularis sternalis (II)

Body height: $168.8 \mathrm{~cm}$

Bone surface preservation: moderately eroded

Green stains from bronze: none detected

Pelvic features: no conspicuous features

Stress/bone reactions: right scapula shows a local new bone apposition (subperiostal hematoma, c. $20 \times 5 \mathrm{~mm}$, partially eroded) in the supraspinous fossa; pleuritis - partially remodelled layers in dorsal costal arches;

Trauma: none detected

Degenerative changes: marked muscle insertions at right shoulder girdle

Other: none detected

Anatomical variation: none detected

Comment: measurements of long bones (right side/left side); humerus $=341 / 342 \mathrm{~mm}$, radius $=271 /-\mathrm{mm}$, femur $=$ $464 / 468 \mathrm{~mm}$, tibia $=412 / 411 \mathrm{~mm}$

Unterhautzenthal, Feature 86 (grave), NHM AA Inv. no. 24912 Sex: male, sexing characteristics of skull and especially pelvic bones are predominantly male

Age: 40-60 years, cranial suture closure (C3, S3, S4 completed; C1, S12, L12 partly fused), dental wear (IIIb), facies articularis sternalis (>III)

Body height: $168 \mathrm{~cm}$

Bone surface preservation: moderately to strongly eroded

Green stains from bronze: none detected

Pelvic features: slight exostoses at the anterior border of right sacroiliac joint

Stress/bone reactions: cranial internal layer shows fine vessel impressions at left sinus sigmoideus (not active); remodelled periostitis - striations at both tibiae (grade 2/3)

Trauma: left clavicle acromial end seems atrophic (torn ligament/ muscular tear?)

Degenerative changes: no conspicuous changes (unusual for the age)

Other: strong uniform abrasion at maxillary and mandibular teeth

Anatomical variation: none detected

Comment: measurements of long bones (right side/left side); humerus $=313 / 313 \mathrm{~mm}$, radius $=255 / 255 \mathrm{~mm}$, femur $=460 /-\mathrm{mm}$ 
Unterhautzenthal, Feature 87 (grave), NHM AA Inv. no. 24913 Sex: undetermined

Age: 3.5-4 years, dental development, measurements of diaphyseal length

Body height: $\mathbf{9 0 - 9 4} \mathrm{cm}$

Bone surface preservation: moderately eroded

Green stains from bronze: right side of os parietale, os temporale and os occipitale and viscerocranium, full surface of maxilla and mandible, both clavicles, cervical vertebrae, some ribs and left side of scapula, humerus (proximal and distal), radius (distal), right side of radius (proximal and distal), ulna, ilium, femur, tibia and fibula

Pelvic features: no assessable characteristics

Stress/bone reactions: cribra orbitalia visible as fine porotic structure at the right orbital roof; branched vessel imprints in the nasal cavity and fine porotic changes in the right sinus maxillaris - sinusitis; slight periosteal reactions at the surface of right femur and both tibiae

Trauma: none detected

Degenerative changes: none detected

Other: bone loss due to animal gnawing (rodents) at the right mandibular ramus

Anatomical variation: none detected

Comment: measurements of diaphyseal length: left humerus $=138 \mathrm{~mm}$

Unterhautzenthal, Feature 88 (grave, extended position), NHM AA Inv. no. 24914

Sex: female, sexing characteristics of cranium, mandible and pelvic bones are consistently female (only small number of skull characteristics assessable due to erosion)

Age: 35-50 years, dental wear (IIIb/c), intravital tooth loss Body height: $143.1 \mathrm{~cm}$

Bone surface preservation: moderately eroded

Green stains from bronze: right side of os temporale, os parietale, lower mandible border, scapula and clavicle, some cervical vertebrae, first rib and left femur (dorsal/medial)

Pelvic features: true preauricular groove bilaterally developed (shape r/l: f-f-f/f-f-f, stage r/l: 3/3) and slight exostoses at the sacroiliac joint on both sides

Stress/bone reactions: signs of sinusitis, extensive fine porosities, on the floor of the left maxillary sinus (maybe in causal relationship to intravital tooth loss)

Trauma: none detected

Degenerative changes: strong osteophyte growth at the thoracic and lumbar vertebral bodies; age related moderate changes at the right shoulder girdle

Other: intravital tooth loss and carious lesions (lower right second molar and lower left third molar
Anatomical variation: none detected

Comment: measurements of long bones (right side/left side); humerus $=275 / 270 \mathrm{~mm}$, femur $=370 / 369 \mathrm{~mm}$, tibia $=319 /-\mathrm{mm}$

Unterhautzenthal, Feature 89 (grave), NHM AA Inv. no. 24915 Sex: undetermined

Age: 6-8 years

Body height: indeterminable

Bone surface preservation: strongly eroded, partially sintered

Green stains from bronze: bilaterally at radii and ulnae

Pelvic features: no assessable characteristics

Stress/bone reactions, Trauma, Degenerative changes, Other, Anatomical variation: assessment not possible - bad preservation status

Comment: no measurements possible

Unterhautzenthal, Feature 90 (grave), NHM AA Inv. no. 24916 Sex: female, sexing characteristics of cranium, mandible and the pelvic bones are consistently female, skeletal elements very gracile

Age: $\mathbf{4 0 - 5 0}$ years, cranial suture closure (C1, C3, S1-4 fused), dental wear (IIIc); TCA: $37.5 \pm 5$ years

Body height: $160 \mathrm{~cm}$

Bone surface preservation: moderately eroded

Green stains from bronze: right side of neuro- and viscerocranium, maxilla and mandible, clavicle, scapula and humerus; some cervical vertebrae and some rib fragments

Pelvic features: slight preauricular groove at the left pelvis (shape $\mathrm{r} / \mathrm{l}$ : -/i-i-f, stage $\mathrm{r} / \mathrm{l}$ : -/2) - sulcus is very irregular, consisting of small connected cavities; some exostoses at the left sacroiliac joint.

Stress/bone reactions: none detected

Trauma: left talus: healed flake fracture - localized bony injury at left processus posterior tali

Degenerative changes: some phalanges of the hand, the joint surface of acetabulum exhibits age related marginal ridges

Other: dental wear - mandibular teeth distinctly worn down; carious lesions visible at the upper right first molar (and apical abscess) and the lower right second molar; dental calculus especially developed at mandibular teeth

Anatomical variation: shape of skull - rather drawn out, parietal tubera not developed (form is considerably different from the other female skulls of this site)

Comment: measurements of long bones (right side/left side); radius $=244 / 243 \mathrm{~mm}$, femur $=433 / 433 \mathrm{~mm}$, tibia $=$ $363 / 363 \mathrm{~mm}$ 
Unterhautzenthal, Feature 91 (pit), NHM AA Inv. no. 24917

Sex: male, sexing characteristics of available cranial features are distinct male

Age: 30-50 years, (only four cranial elements present showing partly closure of the main cranial sutures)

Body height: indeterminable

Bone surface preservation: moderately eroded, partially sintered

Green stains from bronze: none detected

Pelvic features, Stress/bone reactions, Trauma, Degenerative changes, Other, Anatomical variation: assessment not possible - bad preservation status

Comment: no measurements possible

Unterhautzenthal, Individual 93, Feature 93 (grave), NHM AA Inv. no. 24918

Sex: female, sexing characteristics of cranium, mandible and pelvic bones are consistently female

Age: 35-45 years, cranial suture closure (C3, S3 completed), dental wear (IIIa/b), facies symphysialis (VI/VII), facies articularis sternalis (>III); TCA: $36.2 \pm 5$ years

Body height: $161.4 \mathrm{~cm}$

Bone surface preservation: moderately eroded (skeletal elements partially sintered)

Green stains from bronze: right os parietale and right side of os occipitale, mandibular ramus, cervical vertebrae, left radius and metacarpals and phalanges of both hands

Pelvic features: moderately developed preauricular sulcus on the right pelvic bone, and a small one on the left side (shape r/l: f-i-f/i-i-f, stage r/l: 3/2); exostoses and a thickened rim at the sacroiliac joints were found, the anterior-superior margin of both sacroiliac joints exhibit symmetrical, lobular extensions at the anterior-superior margin of the auricular surface of the sacrum, with corresponding facets at the ilium (c. $10 \times 10 \mathrm{~mm}$ ); Margo auricularis groove (stage 3, UllRich 1975) bilaterally developed at the os sacrum; moreover, small lesions were found on the right dorsal pubis surface (stage r: 2); (possible sacralisation of L5: last lumbar vertebra L5 and the first sacral vertebra S1, seem to have grown together, but this is not certain due to strong erosion at this region)

Stress/bone reactions: periosteal reactions/striations at the surface of both femora

Trauma: the cranium reveals two healed depression fractures: one at the left parietal bone, close to the sagittal suture, it is of a round-oval shape $(20 \times 30 \mathrm{~mm})$, maybe caused by a blunt trauma, the second one is of elongated shape and is located at the right parietal bone $(40 \times 10 \mathrm{~mm})$, which is caused most likely by sharp force trauma; healed fracture at the right mandibular ramus, with secondary arthritic changes at caput mandibulae and corresponding mandibular fossa Degenerative changes: intervertebral joints of the first and second cervical vertebra and right occipital condyle show distinct inflammatory changes, maybe of arthritic nature; 'spiking phenomenon' at the left trochanter major and minor - due to muscle attachment or anatomical variation? Other: none detected

Anatomical variation: distinct laterality of the upper limbs (right side>left side);

Comment: measurements of long bones (right side/left side): humerus $=311 / 289 \mathrm{~mm}$, radius $=243 /-\mathrm{mm}$, femur $=$ $438 / 442 \mathrm{~mm}$ (one rib fragment of a 0-6 year-old was found with the bones of this woman)

\section{Unterhautzenthal, Individual 93A, Feature 93 (grave), NHM}

AA Inv. no. 24919

Sex: female, cranial and mandibular features are consistently of female character

Age: 20-25 years, no cranial suture closure, dental wear (Ic/ IIa), sphenobasilar joint fused

Body height: $148 \mathrm{~cm}$

Bone surface preservation: weakly eroded

Green stains from bronze: right side: os parietale, temporale and occipitale, processus and os jugulare, maxilla and mandible

Pelvic features: no assessable characteristics

Stress/bone reactions: lamina externa of parietal bones and the occipital bone exhibits fine porous structure 'porotic hyperostosis'; both maxillary sinuses show new bone formation (spiculae) due to healed sinusitis maxillaris; healed lamellar periosteal reactions at the surface of right tibia

Trauma: none detected

Degenerative changes: none detected

Other: LEH (enamel hypoplasia): severity stage $2 / 3$, one hypoplastic line at mandibular canines corresponding to a formation age of 4.2 years; both upper first molars show similar carious lesions at the distal lingual surface

Anatomical variation: impacted right maxillary canine possibly caused by a persisting deciduous tooth (canine?); malformed upper left third molar (pivot tooth) and all other third molars are not developed

Comment: measurements of long bones (right side/left side); humerus $=-/ 280 \mathrm{~mm}$

Unterhautzenthal, Feature 94 (grave), NHM AA Inv. no. 24920

Sex: male, sexing characteristics of the cranium and pelvic bones as well as the robustness of postcranial elements are consistently male 
Age: 40-60 years, cranial suture closure (C1, S4, L1 partially fused), massive dental wear ( $>45$, only isolated mandibular teeth)

Body height: $159.5 \mathrm{~cm}$

Bone surface preservation: moderately eroded

Green stains from bronze: right humerus and left side of some thoracic vertebra

Pelvic features: (some exostoses at the right sacroiliac joints - possibly modified through erosion of bone surface)

Stress/bone reactions: left facies cerebralis (ala major ossis sphenoidalis) shows spongy inflammatory changes $(10 \times$ $20 \mathrm{~mm}$ ); left fossa cranii posterior shows a lacuna like cavity possibly due to an atrophic process/aneurism/cyst?

Trauma: none detected

Degenerative changes: osteophyte growth at dens axis and fovea dentis of the first cervical vertebra; porous inflammatory changes at the intervertebral joints of the cervical spine; age related degenerative changes at some joints (e.g. elbow joint)

Other: LEH (enamel hypoplasia): severity stage 3, two hypoplastic lines at maxillary canines corresponding to a formation age of 3.8 and 4.3 years

Anatomical variation: none detected

Comment: measurements of long bones (right side/left side): humerus $=303 /-\mathrm{mm}$, femur $=429 /-\mathrm{mm}$

Unterhautzenthal, Individual 95, Feature 95 (grave), NHM AA Inv. no. 24921

Sex: female, sexing characteristics of cranium, mandible and pelvis are predominantly female

Age: 35-45 years, cranial suture closure (C3, S3 fused), dental wear (IIIa); TCA: $41.5 \pm 5$ years

Body height: $157.3 \mathrm{~cm}$

Bone surface preservation: moderately eroded

Green stains from bronze: right side of: os temporale, os occipitale, os and processus zygomaticus, mandibular ramus; some cervical vertebrae and both clavicles

Pelvic features: small extended pubic tubercle at the right os pubis (stage r: 2, left side missing) and bilateral slight pits at the dorsal side of the symphysis (stage 2).

Stress/bone reactions: fine porous periosteal reaction at both tibiae (dorsal/distal) - periostitis

Trauma: none detected

Degenerative changes: age related degenerative changes at both knee joints (femora) and some vertebral bodies Other: internal layer of right os parietale shows increased impression of the arteria meningea media; strong calculus at teeth of the lower jaw; LEH (enamel hypoplasia): severity stage $2 / 3$, one hypoplastic line at maxillary left canine and two hypoplastic lines at mandibular canines corresponding to a formation age of 3.8 and 5.6 years

Anatomical variation: os incae partitum

Comment: measurements of long bones (right side/left side): femur = - $/ 423 \mathrm{~mm}$; additional: buried with two children aged 3-4 and $4-5$ years ( $95 \mathrm{~A}$ and $\mathrm{B}$ ).

Unterhautzenthal, Individual 95A, Feature 95 (grave), NHM

AA Inv. no. 24923

Sex: undetermined

Age: 3-4 years, dentition

Body height: indeterminable

Bone surface preservation: strongly eroded

Green stains from bronze: right mandibular ramus, vertebral arches

Pelvic features: no assessable characteristics

Stress/bone reactions: striation from healed osteoperiostitis visible at some femur and tibia fragments

Trauma: none detected

Degenerative changes: none detected

Other: none detected

Anatomical variation: none detected

Comment: no measurements possible

Unterhautzenthal, Individual 95B, Feature 95 (grave), NHM

AA Inv. no. 24922

Sex: undetermined

Age: 4-5 years, dentition

Body height: indeterminable

Bone surface preservation: strongly eroded (no cranium preserved, but some isolated teeth and postcranial remains) Green stains from bronze: right distal radius and ulna

Pelvic features: no assessable characteristics

Stress/bone reactions: periosteal reactions visible at some tibia fragments - periostitis

Trauma: none detected

Degenerative changes: indeterminable

Other: LEH (enamel hypoplasia), two hypoplastic lines at the lower left canine (stage 2), corresponding to formation ages of 2.7 and 4.2 years

Anatomical variation: none detected

Comment: no measurements possible

Unterhautzenthal, Feature 96 (grave), NHM AA Inv. no. 24924 Sex: undetermined

Age: c. 2 years, dentition, measurement of pars petrosa

Body height: indeterminable

Bone surface preservation: strongly eroded

Green stains from bronze: left distal radius and ulna

Pelvic features: no assessable characteristics

Stress/bone reactions: new bone formation is visible 
(presumably active periostitis) at one tibia fragment

Trauma: none detected (strong erosion)

Degenerative changes: indeterminable

Other: none detected

Anatomical variation: none detected

Comment: no measurements possible

Unterhautzenthal, Feature 99 (grave), NHM AA Inv. no. 24925 Sex: undetermined

Age: 14-18 years, dental development (third molars not erupted), dental wear (<Ia), epiphyseal fusion (distal epiphysis of radii and ulnae open/proximal epiphysis of ulnae fused)

Body height: indeterminable

Bone surface preservation: strongly eroded

Green stains from bronze: cervical vertebrae, rib fragments, both radii and ulnae, some phalanges of hands

Pelvic features: no assessable characteristics

Stress/bone reactions: none detected (strong erosion)

Trauma: indeterminable

Degenerative changes: indeterminable

Other: indeterminable

Anatomical variation: none detected

Comment: no measurements possible

Unterhautzenthal, Feature 100 (grave), NHM AA Inv. no. 24926

Sex: female, sexing characteristics of mandible and pelvic bones are consistently female (cranium is missing)

Age: 17-25 years, open cranial sutures, dental wear ( $\mathrm{Ia} / \mathrm{b})$, facies sternalis (not fused), crista iliaca (partially fused); TCA: $19.5 \pm 5$ years

Body height: $159 \mathrm{~cm}$

Bone surface preservation: moderately eroded

Green stains from bronze: right side of some cervical vertebrae, clavicle, scapula, humerus and left radius and ulna, some rib fragments, both some phalanges of hands (right side of neuro- and viscerocranium but cranium is missing) Pelvic features: preauricular groove at both sides (shape $\mathrm{r} / \mathrm{l}: \mathrm{i}-\mathrm{i}-\mathrm{m} / \mathrm{f}-\mathrm{i}--$, stage $\mathrm{r} / \mathrm{l}: 2 / 3$ ) with tuberculum piriformis at right side, lesions at the ventral pubic surface, similar to "imprints" in the upper symphyseal region

Stress/bone reactions: none detected

Trauma: none detected

Degenerative changes: marked muscle markers in the regio nuchae at the lower part of the occipital bone

Other: both ossa capitata (wrist) show on their palmar side a fissure-like incision $(0.5 \mathrm{~cm}$ long)

Anatomical variation: foramen caecum (bilaterally at lower first and second molar)
Comment: measurements of long bones (right side/left side) : humerus $=303 /-\mathrm{mm}$, radius $=229 /-\mathrm{mm}$, femur $=$ $-/ 429 \mathrm{~mm}$, tibia $=359 / 360 \mathrm{~mm}$

Unterhautzenthal, Feature 101 (grave), NHM AA Inv. no.

24927

Sex: undetermined

Age: c. 12 years, dentition (upper and lower second molars partially erupted),

Body height: 135-139 cm

Bone surface preservation: moderately eroded

Green stains from bronze: right proximal radius and ulna, left distal radius, ribs

Pelvic features: no assessable characteristics

Stress/bone reactions: periosteal reactions visible at the surface of femora and tibiae

Trauma: none detected

Degenerative changes: none detected

Other: none detected

Anatomical variation: os incae laterale sinistra

Comment: measurement of diaphyseal length: radius = $173 \mathrm{~mm}$

Unterhautzenthal, Feature 102 (grave), NHM AA Inv. no. 24928

Sex: indifferent/female (?), sexing characteristics of skull and pelvic bones are inconsistent, tendency female

Age: 25-35 years, no cranial suture closure, dental wear (IIb), facies articularis sternalis (>III); TCA: $29.5 \pm 5$ years Body height: $162.2 \mathrm{~cm}$

Bone surface preservation: weakly eroded

Green stains from bronze: mentum mandibulae, right side of: humerus, radius, ulna and some carpals of the hand and some rib fragments

Pelvic features: no clear evidence of a preauricular groove at ilium (shape $r / 1: m-m-f$, stage $r / 1: 1 / 1$ ); left sacroiliac joint and left ventral symphysis exhibit some exostoses

Stress/bone reactions: none detected

Trauma: left patella shows a healed longitudinal fracture

Degenerative changes: slight osteophytes at some lumbar vertebra

Other: frontal sinus shows an osteom-like new bone formation (c. $5 \mathrm{~mm}$ ); lamina interna of os frontale is thickened 'hyperostosis frontalis'; LEH (enamel hypoplasia): severity stage $2 / 3$, two hypoplastic lines at maxillary canines corresponding to a formation age of 2.4 and 3.4 years, further two hypoplastic lines at mandibular left canine corresponding to a formation age of 3.1 and 4.2 years

Anatomical variation: proximal femoral joints exhibit 'facies poirier' (riding facet) 
Comment: measurements of long bones (right side/left side): humerus $=301 /-\mathrm{mm}$, radius $=232 /-\mathrm{mm}$, femur $=$ 441/- mm, tibia $=369 /-\mathrm{mm}$

Unterhautzenthal, Individual 103A, Feature 103 (grave), NHM AA Inv. no. 24929

Sex: female, sexing characteristics of cranium and mandible consistently female, no assessable characteristics at the pelvic fragments

Age: 16-20 years, no cranial suture closure, dental wear (Ia), facies articularis sternalis $(<\mathrm{I})$, epiphyseal fusion (open - proximal humerus, femur and tibia); TCA: $21.5 \pm 5$ years Body height: indeterminable

Bone surface preservation: strongly eroded

Green stains from bronze: cervical vertebra and right side of clavicle, scapula, rib fragments and foot

Pelvic features: no assessable characteristics

Stress/bone reactions: slight periosteal reactions at the bone surface of femora and tibiae

Trauma: none detected

Degenerative changes: none detected

Other: none detected

Anatomical variation: none detected

Comment: no measurements possible; humerus and scapula fragments of a young child were found with the skeleton $(2.5-3.5$ years, $103 \mathrm{~B})$

Unterhautzenthal, Individual 103B, Feature 103 (grave),

NHM AA Inv. no. 24929

Sex: undetermined

Age: 2.5-3.5 years, (size comparison of humerus and scapula with the child of Grave 87)

Body height: indeterminable

Bone surface preservation: well preserved

Green stains from bronze: thorough patination of left humerus and scapula fragment

Pelvic features: no assessable characteristics

Stress/bone reactions: none detected

Trauma: none detected

Degenerative changes: none detected

Other: none detected

Anatomical variation: none detected

Comment: no measurements possible; traces of prior sampling

Unterhautzenthal, Feature 104 (grave), NHM AA Inv. no.

24930

Sex: undetermined

Age: 7-8 years, dental development (only isolated teeth available)
Body height: indeterminable

Bone surface preservation: strongly eroded

Green stains from bronze: left side: os temporale, os parietale and mandibular ramus

Pelvic features: no assessable characteristics

Stress/bone reactions: left orbital roof covered by foramina

- cribra orbitalia

Trauma: none detected

Degenerative changes: none detected

Other: internal lamina of the frontal and temporal bone shows increased gyri imprints

Anatomical variation: none detected

Comment: no measurements possible

\section{Unterhautzenthal, Feature 105 (grave), NHM AA Inv. no.} 24942

Sex: undetermined

Age: 2-3 years, (measurements of diaphyseal length)

Body height: $85-89 \mathrm{~cm}$

Bone surface preservation: moderately eroded, cranium partially sintered

Green stains from bronze: right side: ulna, radius and phalanges of the hand, both femora, left side: tibia and fibula, some arches of thoracic and lumbar vertebrae

Pelvic features: no assessable characteristics

Stress/bone reactions: both femora show extensive new bone formation at the dorso-lateral side of their shafts - possible case of scurvy

Trauma: none detected

Degenerative changes: none detected

Other: none detected

Anatomical variation: none detected

Comment: measurements of diaphyseal length: ulna = $110 \mathrm{~mm}$, femur $=178 \mathrm{~mm}$;

$\mathrm{X}$-ray of left femur and tibia did not reveal growth arrest lines (no Harris lines); mislabelled as Feature 125B (AA 24942), corresponds to missing individual from Feature 105

Unterhautzenthal, Feature 106 (grave), NHM AA Inv. no.

\section{1}

Sex: undetermined

Age: 1-6 years

Body height: indeterminable

Bone surface preservation: strongly eroded

Green stains from bronze: some radius and ulna fragments

Pelvic features: no assessable characteristics

Stress/bone reactions: extensive new bone formation at femur and tibia fragments, also at radius and ulna fragments - possible case of scurvy

Trauma: none detected (erosion) 
Degenerative changes: none detected

Other: none detected

Anatomical variation: none detected

Comment: no measurements possible

\section{Unterhautzenthal, Feature 108 (grave), NHM AA Inv. no.}

\section{2}

Sex: male?, sexing characteristics of cranium predominantly male but those of mandible are mainly female, robustness (pelvis not preserved)

Age: 17-20 years, no cranial suture closure, dental wear (Ib), epiphyseal fusion (prox. humerus and femur - open)

Body height: indeterminable

Bone surface preservation: strongly eroded, partially sintered

Green stains from bronze: none detected

Pelvic features: no assessable characteristics

Stress/bone reactions: none detected

Trauma: none detected

Degenerative changes: none detected

Other: 1 carious lesion visible at right mandibular second molar

Anatomical variation: left maxillary first molar exhibits a foramen caecum

Comment: no measurements possible

Unterhautzenthal, Individual 109A, Feature 109 (grave), NHM AA Inv. no. 24933

Sex: female, sexing characteristics of cranium, mandible and pelvic bones are predominantly female

Age: 50-60 years, no cranial suture closure visible, dental wear (massive intravital tooth loss - traumata), facies articularis sternalis (>III), facies symphysialis (IX)

Body height: $161.7 \mathrm{~cm}$

Bone surface preservation: moderately eroded

Green stains from bronze: right os parietale (distinct round green stain, diameter $20 \mathrm{~mm}$ ), both processi mastoidei, left mandibular ramus, first and second cervical vertebrae, right processus acromialis, phalanges of the hand

Pelvic features: weakly developed left preauricular sulcus (surface smooth at the right side, shape $\mathrm{r} / \mathrm{l}: \mathrm{m}-\mathrm{m}-\mathrm{i} / \mathrm{f}-\mathrm{i}--$, stage $\mathrm{r} / \mathrm{l}: 2 / 2)$; large, tongue-like exostosis (c. $15 \times 20 \mathrm{~mm}$ ) at the anterior-superior margin of the right auricular facies with a corresponding facet at the os sacrum showing inflammatory changes; small extended pubic tubercle at the left pubic bone (stage 2) and a ridge-like elevation on the right side (located somewhat posterior at the pecten ossis pubis); exostoses and lesions at the left ventral symphysis (maybe there is a causal relationship to the large exostosis at the auricular facies) Stress/bone reactions: frontal bone/cranial base: local, re- active bone apposition (haematomas - maybe in causal relationship with depression fractures 'craniocerebral trauma') at the lamina interna of both fossae anteriores (c. $10 \times$ $10 \mathrm{~mm}$ ) and left fossa medialis (c. $10 \times 20 \mathrm{~mm}$ ); right orbital roof shows small, cyst-like lesions

Trauma: two healed depression fractures: one located in the left parietal/occipital bone (lambdoid suture) close to the mastoid (dimension c. $15 \times 10 \mathrm{~mm}$ ) showing round to oval shape and one at the left parietal/temporal bone with a dimension of c. $10 \times 20 \mathrm{~mm}$ and of rather rectangular shape with rounded edges, fracture line in extension of temporal line at mastoid visible (mastoid very prominent); possible greenstick fracture in the left distal ulnar shaft and one proximal hand phalanx ('thickening')

Degenerative changes: third and fourth lumbar vertebrae show osteophyte formation

Other: maxilla shows complete intravital tooth loss (possibly in causal relationship with cranial injuries?) except from upper right third molar as well as the left side of the mandible plus right first and second premolars; massive caries destroyed the buccal half of right second molar; left femur displays an osteom-like new bone formation at the dorso-medial part of the shaft

Anatomical variation: foramen trochlearis at both distal humeri

Comment: measurements of long bones (right side/left side): humerus = $-/ 306 \mathrm{~mm}$, femur $=-/ 439 \mathrm{~mm}$; left femur of a neonate $(109 \mathrm{~B})$ found with this individual

\section{Unterhautzenthal, Individual 109B, Feature 109 (grave), NHM AA Inv. no. 24933}

Sex: undetermined

Age: 0-0.2 years, neonate

Body height: c. $45 \mathrm{~cm}$

Bone surface preservation: weakly eroded (only left femur preserved)

Green stains from bronze: none detected

Pelvic features, Stress/bone reactions, Trauma, Degenerative changes, Anatomical variation: none detected Comment: diaphyseal length of left femur $=72 \mathrm{~mm}$; left femur of a neonate, found with the bones of Individual 109A

\section{Unterhautzenthal, Feature 111 (grave), NHM AA Inv. no. 24934}

Sex: male, sexing characteristics of cranium, mandible and pelvic bones are consistently male

Age: $30-40$ years, cranial suture closure (C1-3, S1-3 fused), dental wear (IIIa/b) - massive, habitual dental wear), facies articularis sternalis (>III), facies symphysialis (VI)

Body height: $161.2 \mathrm{~cm}$ 
Bone surface preservation: weakly eroded

Green stains from bronze: right processus acromialis, right ulna (distal)

Pelvic features: left os pubis exhibits slight changes at ventral symphyseal region

Stress/bone reactions: internal lamina of confluens sinuum and right sinus transversus shows remodelled bone apposition due to a healed perisinusitis; slight periosteal reactions at the bone surface of both tibiae

Trauma: possible compression trauma at a lumbar vertebra Degenerative changes: slight degenerative changes at the large joints; marked marginal rims at hand phalanges Other: habitual dental wear - massive uniform abrasion in the upper and lower jaw; maxillary left first molar exhibits an exposed lingual root; small carious lesion at lower left third molar

Anatomical variation: preinterparietal ossicle in sagittal suture and some ossiculae lambdoideae

Comment: measurements of long bones (right side/left side): humerus $=-/ 305 \mathrm{~mm}$, radius $=-/ 246 \mathrm{~mm}$, femur $=$ $435 /-\mathrm{mm}$, tibia $=386 / 386 \mathrm{~mm}$

\section{Unterhautzenthal, Feature 116A (grave), NHM AA Inv. no. 24935}

Sex: female, sexing characteristics of cranium and mandible consistently female as well as the preserved two pelvic characteristics

Age: 45-60 years, cranial suture closure (C2 and C3 fused), dental wear (>IIIc; distinct, uniform dental wear - habitual?), facies symphysialis (IX/X); TCA: $46.5 \pm 5$ years

Body height: $164.6 \mathrm{~cm}$

Bone surface preservation: moderately eroded

Green stains from bronze: right side of neuro- and viscerocranium, mandible, cervical vertebrae, clavicle, scapula and humerus

Pelvic features: small, weakly developed preauricular sulcus at the left side (stage 2), which was not assessable at the right side; massive lytic lesions that led to less density at the ventral symphyseal surface as well as slight dorsal pits at the left symphysis (osteitis pubis?)

Stress/bone reactions: lamina externa of parietal bones exhibits slight fine porous structure - porotic hyperostosis Trauma: right clavicle reveals a healed fracture in the middle of the shaft

Degenerative changes: strong arthritic changes at the right caput mandibulae; slight osteophyte growth visible at the bodies of the cervical vertebrae; degenerative changes visible at the right fossa glenoidalis

Other: several root tip granulomas at the position of the right maxillary canine, first premolar and first molar as well as the left mandibular first premolar; massive calculus at the right upper third molar; one tooth neck caries at right mandibular second molar

Anatomical variation: none detected

Comment: measurements of long bones (right side/left side): femur $=-/ 450 \mathrm{~mm} ; 3$ vertebral arches of a 4-6-yearold child (116B) were found with this skeleton

\section{Unterhautzenthal, Feature 116B (grave), NHM AA Inv. no. 24935}

Sex: undetermined

Age: 4-6 years, by size comparison with the children of features 87 and 105

Body height: indeterminable

Bone surface preservation: weakly eroded

Green stains from bronze: none detected

Pelvic features: none detected

Stress/bone reactions: none detected

Trauma: none detected

Degenerative changes: none detected

Anatomical variation: none detected

Comment: only 3 vertebral arches preserved, found with the skeleton 116A

Unterhautzenthal, Feature 120 (grave), NHM AA Inv. no.

24936

\section{Sex: undetermined}

Age: 6-7 years, dental development (maxilla only), diaphyseal length of humerus (168 mm)

Body height: c. 105-109 cm

Bone surface preservation: weakly eroded (still collagenous)

Green stains from bronze: none detected

Pelvic features: no assessable characteristics

Stress/bone reactions: cribra orbitalia - both orbital roof areas are covered by multiple foramina and thickening (stage 3)

Trauma: none detected

Degenerative changes: none detected

Other: none detected

Anatomical variation: none detected

Comment: measurements of diaphyseal length: humerus = $-/ 168 \mathrm{~mm}$

Unterhautzenthal, Individual 122A, Feature 122 (triple burial, grave), NHM AA Inv. no. 24937

Sex: male, sexing characteristics of cranium and mandible as well as the robustness of long bones are predominantly male Age: 35-40 years, cranial suture closure (S3, S4), dental wear (IIc/IIIa); TCA: $44.5 \pm 5$ years

Body height: $167.2 \mathrm{~cm}$ 
Bone surface preservation: strongly eroded and partially sintered

Green stains from bronze: right side - os temporale and mandibular ramus

Pelvic features: no information because of bad preservation status

Stress/bone reactions, Trauma, Degenerative changes, Other, Anatomical variation: none detected

Comment: measurements of long bones (right side/left side): humerus $=-/ 322 \mathrm{~mm}$, femur $=-/ 457 \mathrm{~mm}$; rodent gnawing marks at foramen magnum

\section{Unterhautzenthal, Individual 122B, Feature 122 (triple buri-} al, grave), NHM AA Inv. no. 24938

Sex: female, sexing characteristics of neurocranium, mandible and pelvic bones are consistently and distinctly female Age: 17-20 years, cranial suture closure (no fusion), dental wear (Ib), facies articularis sternalis (I), facies symphysialis (I/II); TCA: $20.8 \pm 5$ years

Body height: $156 \mathrm{~cm}$

Bone surface preservation: moderately eroded

Green stains from bronze: ossa temporalia, mandibular rami; pelvic bones are very well preserved showing plain green patination

Pelvic features: bilateral, weakly developed preauricular sulcus at the right side ( $\mathrm{f}-\mathrm{i}--$, $)$ plus distinct piriform tubercle at the left side ( $\mathrm{f}-\mathrm{i}-\mathrm{m})$; small extended pubic tubercle (stage 2) bilaterally developed; exostoses are present at the margin of the auricular surface bilaterally

Stress/bone reactions: gyri impressions visible at lamina interna of os frontale and ossa parietalia running parallel to the sagittal suture (cranial pressure symptomatology)

Trauma: left spina anterior inferior (os ilium) exhibits a round perforation (c. $15 \times 10 \mathrm{~mm}$ ) of supposedly perimortal origin (?)

Degenerative changes: none detected

Other: LEH (enamel hypoplasia): severity stage $2 / 3$, one hypoplastic line at mandibular first and second right incisors corresponding to a formation age of 2.7 years and two hypoplastic lines at mandibular canines corresponding to a formation age of 4.2 and 4.9 years

Anatomical variation: none detected

Comment: measurements of long bones (right side/left side): humerus $=287 / 287 \mathrm{~mm}$, femur $=418 / 421 \mathrm{~mm}$, tibia $=$ $-/ 353 \mathrm{~mm}$; cranial fragments of a neonatal to six months-old child (122C) found with the skeletons

Unterhautzenthal, Individual 122C, Feature 122 (triple burial, grave), NHM AA Inv. no. 24938

Sex: undetermined

Age: $0.25-0.5$ years, diaphyseal length of tibia $(75 / 80 \mathrm{~mm})$
Body height: c. 55-59 cm

Bone surface preservation: strongly eroded (small number of cranial remains, humerus fragments and tibia)

Green stains from bronze: none detected

Pelvic features, Stress/bone reactions, Trauma, Degenerative changes, Other, Anatomical variation: none detected Comment: measurements of diaphyseal length: tibia $=$ $75 / 80 \mathrm{~mm}$; cranial fragments of a neonatal to six monthsold child (122C) found with the individuals (122A, 122B)

\section{Unterhautzenthal, Feature 123 (grave), NHM AA Inv. no. 24939}

Sex: indifferent/female (?), sexing characteristics of cranium distinctly male, mandible inconsistent and pelvic bones predominantly of female expression

Age: 40-50 years, cranial suture closure (S3, C2, C3 fused), dental wear (>IIIc), facies articularis sternalis (>III); TCA: $43.5 \pm 5$ years

\section{Body height: $160.3 \mathrm{~cm}$}

Bone surface preservation: weakly eroded

Green stains from bronze: none detected

Pelvic features: moderately developed preauricular sulcus at the right side ) and a small, weakly developed sulcus at the left side (shape $\mathrm{r} / \mathrm{l}$ : $\mathrm{f}-\mathrm{f}--, \mathrm{f}-\mathrm{i}--$ ); the pecten ossis pubis shows a sharp-edged crista at the left side, with a pyramid-like small extended tubercle in its dorsal elongation (stage 2); arthritic changes are visible at the right auricular facies and corresponding sacral joint; exostoses and lytic lesions are developed at the ventral pubic surface;

Stress/bone reactions: maxilla shows intense spicule - stomatitis (correlated with dental wear?) and inflammatory new bone reaction at the right processus palatinus (palatal granuloma of third molar); finely porous new bone layer at the palatinal part of the left maxillary sinus (sinusitis)

Trauma: right clavicle is considerably less robust than the left one (traumatically?)

Degenerative changes: degenerative changes at the intervertebral joints of the second to the third cervical vertebra and fourth to fifth lumbar vertebra; as well as at the left shoulder joint - humerus and scapula affected, slight eburnation at humeral head, marginal exostoses; additional changes at the basic thumb joints and marginal exostoses at the phalanges Other: the teeth show massive, uniform abrasion, especially maxillary teeth affected (first molars worn down to the root - use of teeth as tools?) with several resulting root tip abscesses

Anatomical variation: none detected

Comment: measurements of long bones (right side/left side): humerus $=-/ 301 \mathrm{~mm}$, radius $=238 / 237 \mathrm{~mm}$, femur $=$ $434 / 436 \mathrm{~mm}$, tibia $=353 / 359 \mathrm{~mm}$ 
Unterhautzenthal, Feature 124 (grave), NHM AA Inv. no.

\section{0}

Sex: male, sexing characteristics of cranium, mandible and pelvic bones are predominantly male

Age: 35-50 years, cranial suture closure (C3 fused), dental wear (IIc), facies articularis sternalis (>III), facies symphysialis (VIII/IX); TCA: $60.5 \pm 5$ years

Body height: $163.9 \mathrm{~cm}$

Bone surface preservation: strongly eroded

Green stains from bronze: distal part of right humerus, left radius and ulna

Pelvic features: weakly developed preauricular sulcus at the left side (shape r/l: m-m--/i-m-i, stage r/l: 1/2)

Stress/bone reactions: none detected

Trauma: none detected

Degenerative changes: slight, age related changes at shoulder and hip joint

Other: internal lamina of os frontale and left os parietale shows large foveolae granulares; massive, uniform abrasion, especially in the maxilla (use of teeth as tools?), intravital tooth loss visible at maxillary first and second molars; LEH (enamel hypoplasia): severity stage 3, one hypoplastic line at mandibular canines corresponding to a formation age of 3.1 years

Anatomical variation: none detected

Comment: measurements of long bones (right side/left side): humerus $=-/ 318 \mathrm{~mm}$, femur $=445 / 447 \mathrm{~mm}$

\section{Unterhautzenthal, Feature 125 (grave), NHM AA Inv. no. \\ 24941}

Sex: female, sexing characteristics of cranium, mandible and pelvic bones are consistently female

Age: 45-60 years, cranial suture closure (C2 and C3 fused), dental wear (>IIIc), facies articularis sternalis (>III), facies symphysialis (IX)

\section{Body height: $149.6 \mathrm{~cm}$}

Bone surface preservation: moderately eroded

Green stains from bronze: none detected

Pelvic features: moderately developed preauricular sulci at both sides (shape r/l: f-i-f/f-i-f, stage r/l: 3/3); exostoses visible at the auricular facies of the sacroiliac joints

Stress/bone reactions: none detected

Trauma: possible greenstick fracture at the left ulnar shaft and a cracked fracture visible at one rib fragment

Degenerative changes: bilaterally occurring, small rounded lytic defect at the glenoid cavity (congenital origin?); cervical spine shows arthritic changes; osteophytic lipping visible at the lumbar spine (L3-L5)

Other: massive intravital tooth loss, lower jaw entirely without teeth, remaining teeth strongly abraded

Anatomical variation: none detected
Comment: measurements of long bones (right side/left side): humerus $=281 /-\mathrm{mm}$

\section{Unterhautzenthal, Feature 127 (grave), NHM AA Inv. no.} 24943

\section{Sex: undetermined}

Age: 8-9 years, dental development, diaphyseal length of humerus, radius and femur

Body height: $\mathbf{1 1 5}-119 \mathrm{~cm}$

Bone surface preservation: weakly eroded

Green stains from bronze: right side of os temporale, mandibular ramus, cervical vertebrae, scapula, humerus (shaft) and two metacarpals

Pelvic features: no assessable characteristics

Stress/bone reactions: fine foramina covering small area of both orbital roofs - cribra orbitalia (stage 2); two ribs show a partially remodelled bone apposition at the inner side healed pleuritis

Trauma: one rib reveals a $10 \times 5 \mathrm{~mm}$ large circumscribed lacuna plus swelling, possibly due to a traumatically caused reactive osteomyelitis (?)

Degenerative changes: massive changes at the articular facies of the dens axis (congenital or wear?); both tibiae exhibit distinct sulcus-like insertions of the soleus and popliteus muscles

Other: no LEHs, first incisors show vertical striations (erosion, mutilation?)

Anatomical variation: none detected

Comment: measurements of diaphyseal length: humerus = $188 /-\mathrm{mm}$, radius $=-/ 146 \mathrm{~mm}$, femur $=270 / 271 \mathrm{~mm}$

\section{Unterhautzenthal, Feature 128 (grave), NHM AA Inv. no. 24944}

Sex: female, sexing characteristics of cranium, mandible and pelvic bones are consistently female; gracile skeleton

Age: 40-50 years, cranial suture closure (C1, C3, S1 fused), dental wear (IIc/IIIa), facies symphysialis (VII/VIII); TCA: $58.2 \pm 5$ years

Body height: $154.9 \mathrm{~cm}$

Bone surface preservation: moderately eroded

Green stains from bronze: cervical vertebrae (2-7)

Pelvic features: preauricular sulcus (shape r/l: i-i-f/i-i-f, stage $r / 1: 2 / 2$ ), extended pubic tubercle and dorsal pitting all show stage 2; exostoses are present at the margin of the auricular facies of the sacroiliac joints and ventral symphysis, the latter possible inflammatory changes due to osteitis pubis; a sharp edged ridge was found at pecten ossis pubis, even more marked at the right side; dorsal side of the ilium reveal distinct, ridge like changes at the insertion of the gluteal muscles (joint function is abduction) 
Stress/bone reactions: right maxillary and frontal sinus show net-like layers, indicating active sinusitis; skeletal elements reveal generally strong osteoporosis

Trauma: probably humeral subluxation of the right shoulder indicated from massive destructive lesions at the right scapular joint corresponding to the humerus with secondary joint facets, potentially causal association with the healed fracture of the left clavicle and healed rib fractures Degenerative changes: very gracile skeleton but with distinct muscle marks (e.g. deltoid muscle); several degenerative joint changes: fovea dentis (first cervical vertebra) with massive formation of exostoses and eburnation, lumbar spine reveals strong marginal lipping ventrally; carpal and tarsal bones show strong arthroses; formation of massive marginal ridges at the knee joints (especially at right side)

Other: one carious lesion visible at the upper right first molar

Anatomical variation: sutura metopica at os frontale

Comment: measurements of long bones (right side/left side): radius $=225 /-\mathrm{mm}$, femur $=414 / 418 \mathrm{~mm}$, tibia $=$ $344 / 342 \mathrm{~mm}$

Unterhautzenthal, Feature 129 (grave), NHM AA Inv. no. 24945

\section{Sex: undetermined}

Age: 3-5 years, dental development (only molars present), diaphyseal length of ulna

Body height: c. 95-104 cm

Bone surface preservation: strongly eroded, partially sintered

Green stains from bronze: right ulna (distal), two ribs (pleural side of the dorsal arch) and vertebral fragments

Pelvic features: no assessable characteristics

Stress/bone reactions: finely porous new bone formation at medial side of one rib - pleuritis (?)

Trauma, Degenerative changes, Other, Anatomical variation: none detected

Comment: measurements of diaphyseal length: ulna = c. $110 \mathrm{~mm}$

Unterhautzenthal, Feature 130 (grave), NHM AA Inv. no.

24946

\section{Sex: undetermined}

Age: c. 1 year, dental mineralisation (deciduous first molar), diaphyseal length of femur fragment (?)

Body height: indeterminable

Bone surface preservation: strongly eroded (cranial fragments, right pars petrosal, long bone fragments)

Green stains from bronze: none detected
Pelvic features: no assessable characteristics

Stress/bone reactions: none detected (strong erosion)

Trauma: local hematoma (fine porous new bone formation) at lateral side of a rib fragment;

Degenerative changes, Other, Anatomical variation: none detected

Comment: measurements of diaphyseal length: femur = c. $115-120 \mathrm{~mm}$

\section{Unterhautzenthal, Feature 131 (grave), NHM AA Inv. no.}

24947

Sex: undetermined

Age: 1.5-2 years, dental development (mandible only), diaphyseal length of tibia

Body height: indeterminable

Bone surface preservation: strongly eroded

Green stains from bronze: right clavicle and two cervical vertebrae

Pelvic features: no assessable characteristics

Stress/bone reactions: internal lamina of parietal bones reveals several dendritic vessel imprints (haemorrhagic?)

Trauma, Degenerative changes, Other, Anatomical variation: none detected

Comment: measurements of diaphyseal length: tibia $=$ c. $95-100 \mathrm{~mm}$

\section{Unterhautzenthal, Feature 132 (grave?), NHM AA Inv. no. 24948}

Sex: male, sexing characteristics of cranium and mandible are predominantly male (no pelvic remains)

Age: 35-50 years, cranial suture closure (C3 fused), dental wear (no teeth, but alveolar position present)

Body height: indeterminable

Bone surface preservation: moderately eroded, partially sintered (collagenous)

Green stains from bronze: none detected

Pelvic features: no assessable characteristics

Stress/bone reactions: porous changes at the right maxillary sinus - sinusitis maxillaris

Trauma: none detected

Degenerative changes: osteophyte growth at lumbar vertebrae; marked muscle insertions of intercostal muscles Other: os frontale appears to be thickened - hyperostosis frontalis; internal lamina of os frontale shows age-related foveolae granulares

Anatomical variation: none detected

Comment: measurements of long bones (right side/left side): $u$ lna $=-/ 278 \mathrm{~mm}$ 
Unterhautzenthal, Feature 133 (grave), NHM AA Inv. no.

\section{9}

Sex: undetermined

Age: 3-4 years, dental development (full deciduous dentition)

Body height: indeterminable

Bone surface preservation: weakly eroded

Green stains from bronze: right side of: mandibular ramus, clavicle, scapula, humerus (whole surface) and femur (distal); left humerus (distal), both radii and ulnae, manubrium and sternum, some phalanges of the hand

Pelvic features: no assessable characteristics

Stress/bone reactions: internal lamina of os frontale and ossa parietalia exhibits haemorrhagic structures in and around the sinus sagittalis possibly indicative for perisinusitis; the confluens sinuum shows remodelled bone apposition due to healed perisinusitis; possible meningeal reaction present in terms of fine porous new bone structures in the gyri impressions of the right parietal bone; fine porous foramina visible at orbital roofs - cribra orbitalia (stage 2); porous new bone formation at both ulnae (proximal/lateral) and at the right femur (proximal/lateral) - signs of scurvy

Trauma: in malposition, fracture ends shifted, partially healed fracture of the right distal humeral shaft

Degenerative changes: none detected

Other: none detected

Anatomical variation: none detected

Comment: no measurements possible; X-ray: no Harris lines visible

\section{Unterhautzenthal, Feature 134 (grave), NHM AA Inv. no. \\ 24950}

Sex: female, sexing characteristics of cranium, mandible and pelvic bones are consistently female

Age: 30-40 years, cranial suture closure (C3 S3 fused), dental wear (IIc), facies sternalis (>III), facies symphysialis (VI); TCA: $20.2 \pm 5$ years

Body height: $152 \mathrm{~cm}$

Bone surface preservation: moderately eroded

Green stains from bronze: ossa temporalia of both sides left mandibular ramus

Pelvic features: small, weakly developed preauricular sulcus at both sides (shape $r / 1: \mathrm{m}-\mathrm{i}-\mathrm{f} / \mathrm{m}-\mathrm{i}-\mathrm{f}$, stage $\mathrm{r} / \mathrm{l}$ : $2 / 2$ ), sharp ridge at the pecten ossis pubis with small extended pubic tubercles at both sides (stage r/1: 2/2), dorsal pubic changes (pits) and exostoses at the facies auricularis at the sacroiliac joints and at the ventral pubic surface

Stress/bone reactions: fine porous structure in the left orbital roof - cribra orbitalia

Trauma: none detected
Degenerative changes: only slight degenerative changes in the shoulder girdle and the elbow

Other: upper third molars are developed as pivot teeth; carious lesions at six molar teeth

Anatomical variation: sacralisation of the fifth lumbar vertebra, first sacral vertebra reveals a fissure formation

Comment: measurements of long bones (right side/left side): humerus $=298 / 298 \mathrm{~mm}$, radius $=222 / 222 \mathrm{~mm}$, femur $=-/ 403 \mathrm{~mm}$

\section{Unterhautzenthal, Feature 136 (grave), NHM AA Inv. no. 24951}

Sex: undetermined

Age: 9-11 years, dental development (mixed dentition), measurements of diaphyseal length

Body height: 115-119 cm

Bone surface preservation: moderately eroded

Green stains from bronze: slightly at the left os ilium

Pelvic features: no assessable characteristics

Stress/bone reactions: internal lamina of os frontale shows finely porous new bone formation - meningeal nests - in the pronounced imprints of the gyri due to an intracranial pressure (ICP) symptomatology (?); stomatitis visible in form of moderately porous structure of the palatine and strongly developed cribra orbitalia as substantial area of orbital roofs are covered by large foramina and pleuritis in terms of massive, partially remodelled new bone formation on the left dorsal rib arch

Trauma: none detected

Degenerative changes: none detected

Other: prognathism visible as protruding maxillary portion and teeth

Anatomical variation: none detected

Comment: measurements of diaphyseal length: femur = $287 / 287 \mathrm{~mm}$, tibia $=236 / 236 \mathrm{~mm}$

$\mathrm{X}$-ray: one weak Harris line in the left distal femur and proximal tibia

Unterhautzenthal, Feature 138 (grave), NHM AA Inv. no.

24952

Sex: female (?), sexing characteristics of cranium and mandible are inconsistent, most likely female

Age: 55-65 years, cranial suture closure (S1-4, C1, L1 and L2 fused), dental wear (>IIIc, intravital tooth loss), facies sternalis (>III)

Body height: $153 \mathrm{~cm}$

Bone surface preservation: moderately eroded

Green stains from bronze: ossa temporalia and mandibular ramus of both sides, cervical vertebra 1-3 and left radius (distal) 
Pelvic features: rare pelvic elements mostly show no changes except for lesions at the left ventral pubic surface Stress/bone reactions: periostitis visible as slight striations at the surface of right tibia

Trauma: none detected

Degenerative changes: age related massive degenerative changes at the glenoid fossa and elbow corresponding to strong muscle insertions on the humeri and ulnae (pectoralis major muscle and teres major muscle)

Other: massive, uniform abrasion of maxillary teeth and massive calculus on maxillary molars

Anatomical variation: none detected

Comment: measurements of long bones (right side/left side): radius $=-/ 226 \mathrm{~mm}$, femur $=405 /-\mathrm{mm}$

\section{Acknowledgements}

We would like to thank Karin Wiltschke-Schrotta and Margit Berner from the Department of Anthropology at the Natural History Museum in Vienna for granting us access to the skeletal collection as well as their continued support and advice, as well as them and Maria Marschler for plenty of collegial exchange. Wolfgang Reichmann took the excellent photographs of the skeletal material. Matthias Kucera helped with statistical graphs and provided feedback. Erich Pucher shared his expertise on juvenile pigs. Astrid Haase and Bernhard Weinzinger prepared the histological thin sections for the tooth cementum annulation analysis at the Unit of Forensic Anthropology of the Medical University of Vienna. We further thank Ernst Lauermann for access to the skeletons on display in the Museum MAMUZ Schloss Asparn during the winter months, as well as for providing the photographs of features 95 and 122 . We would like to acknowledge Peter Brugger for discussions on anatomy and suggestions of helpful literature, as well as Edeltraud Aspöck and Estella Weiss-Krejci for discussions on burial taphonomy. Last-minute reassurance on the interpretation of the ${ }^{14} \mathrm{C}$ dates came from Ken Massy. Michaela Fritzl and Lukas Waltenberger provided research support. This study was undertaken within the framework of the pilot project The social status of motherhood in Bronze Age Europe funded by the Austrian Science Fund FWF (P 26820). Patrik Galeta was supported by the University of West Bohemia Project SGS-2016-028. Future work will be funded by the European Research Council (ERC) under the European Union's Horizon 2020 research and innovation programme (grant agreement No 676828).

\section{Author Contributions}

Katharina Rebay-Salisbury: concept, archaeological analysis, methodology, funding acquisition, writing

Doris Pany-Kucera: skeletal analysis, osteological methodology, writing

Michaela Spannagl-Steiner: skeletal analysis

Fabian Kanz: tooth cementum annulation analysis

Patrik Galeta: demographic data, simulations, statistics

Maria Teschler-Nicola: population characteristics

Roderick B. Salisbury: GIS, data management, ${ }^{14} \mathrm{C}$ data modelling, editing

\section{References}

ACSÁdi, NemesKÉRI 1970

G. AcsÁdi, J. Nemeskéri, History of Human Life Span and Mortality. Budapest 1970.

AlQahtani, Hector, Liversidge 2010

S. J. AlQAhtani, M. P. Hector, H. M. Liversidge, Brief communication: the London atlas of human tooth development and eruption, American Journal of Physical Anthropology 142/3, 2010, 481-490.

ВАСН 1965

H. BACH, Zur Berechnung der Körperhöhe aus den langen Gliedmaßenknochen weiblicher Skelette, Anthropologischer Anzeiger $29,1965,12-21$

BAs 2017

M. BAs, Exploratory study of microwear signatures in human deciduous molars from the Tooth Fairy collection: methodological, biomechanical and archaeological considerations. Unpublished MSc thesis, University of Bordeaux 2017.

BASS 1971

W. M. BAss, Human Osteology: A Laboratory and Field Manual of the Human Skeleton. Columbia 1971.

BEAUMONT et al. 2015

J. BeAumont, J. Montgomery, J. Buckberry, M. Jay, Infant mortality and isotopic complexity: new approaches to stress, maternal health, and weaning, American Journal of Physical Anthropology 157/3, 2015, 441-457.

Bertemes 1989

F. Bertemes, Das frühbronzezeitliche Gräberfeld von Gemeinlebarn: Kulturhistorische und paläometallurgische Studien. Saarbrücker Beiträge zur Altertumskunde 45, Bonn 1989.

BERTRAND et al. 2016

B. Bertrand, G. Robbins Schug, C. Polet, S. Naji, T. Colard, Age-at-death estimation of pathological individuals: a complementary approach using teeth cementum annulations, International Journal of Paleopathology, 2016, 120-127.

Bickle, Fibiger 2014

P. Bickle, L. Fibiger, Ageing, childhood and social identity in the Early Neolithic of central Europe, European Journal of Archaeology 17/2, 2014, 208-228.

BLESL 2006

C. BLEsL, Das frühbronzezeitliche Gräberfeld von Pottenbrunn. Fundberichte aus Österreich, Materialheft A15, Vienna 2006.

BLIDDAL et al. 2016

M. Bliddal, A. Pottegard, H. Kirk\&EgaArd, J. Olsen, J. S. Jorgensen, T. I. Sorensen, L. Dreyer, E. A. Nohr, Association of pre-pregnancy body mass index, pregnancy-related weight changes, and parity with the risk of developing degenerative musculoskeletal conditions, Arthritis \& Rheumatology 68/5, 2016, 1156-1164.

BLONDiAux et al. 2016

J. Blondiaux, S. Naji, E. Audureau, T. Colard, Cementochronology and sex: a reappraisal of sex-associated differences in survival in past French societies, International Journal of Paleopathology $15,2016,152-163$.

BocqueT-APPEL 2002

J.-P. Bocquet-Appel, Paleoanthropological traces of a Neolithic demographic transition, Current Anthropology 43/4, 2002, 637-650. 
Bourbou et al. 2013

C. Bourbou, B. T. Fuller, S. J. Garvie-Lok, M. P. Richards, Nursing mothers and feeding bottles: reconstructing breastfeeding and weaning patterns in Greek Byzantine populations $\left(6^{\text {th }}-15^{\text {th }}\right.$ centuries AD) using carbon and nitrogen stable isotope ratios, Journal of Archaeological Science 40/11, 2013, 3903-3913.

BRANDON et al. 2012

C. Brandon, J. A. Jacobson, L. K. Low, L. Park, J. DeLancey, J. Miller, Pubic bone injuries after first childbirth: utility of MR in detection and differential diagnosis of structural injury, Ultrasound in Obstetrics \& Gynecology 39/4, 2012, 444-451.

BREITINGER 1937

E. Breitinger, Zur Berechnung der Körperhöhe aus den langen Gliedmaßenknochen, Anthropologischer Anzeiger 14, 1937, 149-274.

BROOKS, SUCHEY 1990

S. BRooKs, J. SuCHEY, Skeletal age determination based on the os pubis: a comparison of the Acsárdi-Nemeskéri and Suchey-Brooks methods, Journal of Human Evolution 5/3, 1990, 227-238.

BRŮŽEK 2002

J. BRUீŽEK, A method for visual determination of sex, using the human hip bone, American Journal of Physical Anthropology 117, 2002, 157-168.

BUiKSTRA, UBELAKER 1994

J. E. Buikstra, D. H. Ubelaker, Standards for data collection from human skeletal remains. Arkansas Archeological Survey Research Series 44, Fayetteville 1994.

BURMEISTER 2000

S. Burmeister, Geschlecht, Alter und Herrschaft in der Späthallstattzeit Württembergs. Tübinger Schriften zur Ur- und Frühgeschichtlichen Archäologie 4, Münster 2000.

Chamberlain 2006

A. Chamberlain, Demography in Archaeology. Cambridge Manuals in Archaeology, Cambridge 2006.

Cox 2000

M. Cox, Assessment of parturition. In: M. Cox, S. MAys (Eds.), Human Osteology in Archaeology and Forensic Science. London 2000, 131-144.

Cunningham, Scheuer, Black 2016

C. Cunningham, L. Scheuer, S. Black, Developmental Juvenile Osteology. London 2016.

Decrausaz 2014

S.-L. Decrausaz, A morphometric analysis of parturition scarring on the human pelvic bone. Unpublished MA thesis, University of Victoria 2014.

Dihlmann 1987

W. Dihlmann, Gelenke-Wirbelverbindungen: Klinische Radiologie einschließlich Computertomographie - Diagnose, Differentialdiagnose. Stuttgart/New York 1987.

Duan, Wang, Jiang 2017

X. DuAn, J. WAng, X. JiAng, A meta-analysis of breastfeeding and osteoporotic fracture risk in the females, Osteoporosis International 28/2, 2017, 495-503.

DUDAY 2006

H. DUDAY, L'archéothanatologie ou l'archéologie de la mort (Archaeothanatology or the Archaeology of Death). In: R. L. GowLAND, C. J. KNÜSEL (Eds.), Social Archaeology of Funerary Remains. Oxford 2006, 30-56.
DUdAY 2009

H. DudAY, The Archaeology of the Dead: Lectures in Archaeothanatology. Oxford 2009.

Dursun et al. 2006

N. Dursun, S. Akin, E. Dursun, I. Sade, F. Korkusuz, Influence of duration of total breast-feeding on bone mineral density in a Turkish population: does the priority of risk factors differ from society to society?, Osteoporosis International 17/5, 2006, 651-655.

ENGELHARDT 1973

K. Engelhardt, Fels am Wagram, p. B. Tulln, N.Ö: Monographie einer bonzezeitlichen Fundstelle. Unpublished PhD Dissertation, University of Vienna 1973.

ERIKSSON 2013

G. ERIKsson, Stable isotope analysis of humans. In: S. TARLOw, L. Nilsson Stutz (Eds.), The Oxford Handbook of the Archaeology of Death and Burial. Oxford 2013, 123-146.

EsPARZA et al. 2017

Á. Esparza, S. Palomo-Díez, J. Velasco-Vázquez, G. Delibes, E. Arroyo-Pardo, D. C. Salazar-García, Familiar kinship? Palaeogenetic and isotopic evidence from a triple burial of the Cogotas I archaeological culture (Bronze Age, Iberian Peninsula), Oxford Journal of Archaeology 36/3, 2017, 223-242.

FAFLia et al. 1998

C. P. Faflia, P. K. Prassopoulos, M. E. Daskalogiannaki, N. C. Gourtsoyiannis, Variation in the appearance of the normal sacroiliac joint on pelvic CT, Clinical Radiology 53/10, 1998, 742-746.

FAHY et al. 2017

G. E. Fahy, C. Deter, R. Pitfield, J. J. Miszkiewicz, P. Mahoney, Bone deep: variation in stable isotope ratios and histomorphometric measurements of bone remodelling within adult humans, Journal of Archaeological Science 87, 2017, 10-16.

FAZEKas, Kósa 1978

I. G. FazeKas, F. Kósa, Forensic Fetal Osteology. Budapest 1978.

Ferembach, Schwidetzky, StLoukal 1979

D. Ferembach, I. Schwidetzky, M. Stloukal, Empfehlungen für die Alters- und Geschlechtsdiagnose am Skelett, Homo 30, 1979, $1-32$.

Fischer, MitTeroecker 2015

B. Fischer, P. Mitteroecker, Covariation between human pelvis shape, stature, and head size alleviates the obstetric dilemma, Proceedings of the National Academy of Sciences 112/18, 2015, $5655-5660$.

FULLER et al. 2006

B. T. Fuller, T. I. Molleson, D. A. Harris, L. T. Gilmour, R. E. M. Hedges, Isotopic evidence for breastfeeding and possible adult dietary differences from late/sub-Roman Britain, American Journal of Physical Anthropology 129/1, 2006, 45-54.

FulminANTE 2015

F. Fulminante, Infant feeding practices in Europe and the Mediterranean from prehistory to the Middle Ages: a comparison between the historical sources and bioarchaeology, Childhood in the Past 8/1, 2015, 24-47.

Galeta 2010

P. GALETA, Odhady ukazatelů porodnosti a přirozeného přírůstku $\mathrm{v}$ paleodemografii (Estimation of fertility and growth rates in palaeodemography), Demografie 52, 2010, 77-89. 
GALLOWAY 1995

A. Galloway, Determination of parity from the maternal skeleton: an appraisal, Rivista di Antropologia 73, 1995, 83-98.

Goodman, Rose 1990

A. H. Goodman, J. C. Rose, Assessment of systemic physiological perturbations from dental enamel hypoplasias and associated histological structures, American Journal of Physical Anthropology 33/S11, 1990, 59-110.

GRESKY, SCHULTZ 2011

J. Gresky, M. Schultz, Einflüsse von Klima- und Wohnbedingungen auf Erkrankungen der Nasennebenhöhlen am Beispiel der population des bajuwarischen Gräberfeldes von Hartig (Oberpfalz). In: N. Benecke, S. Flohr (Eds.), Beiträge zur Archäozoologie und Prähistorischen Anthropologie 8, Langenweißbach 2011, 83-94.

Grupe, Harbeck, McGlynn 2015

G. Grupe, M. Harbeck, G. C. McGlynn, Prähistorische Anthropologie. Berlin - Heidelberg 2015

Guglielmi, Muscarella, Bazzocchi 2011

G. Guglielmi, S. Muscarella, A. Bazzocchi, Integrated imaging approach to osteoporosis: state-of-the-art review and update, Radiographics 31/5, 2011, 1343-1364.

Hamilton et al. 2013

J. Hamilton, R. A. Bentley, P. Bickle, L. Fibiger, R. Hedges, L. Reynard, C. Wright, P. Cullen, C. Dale, G. Nowell, A. Whittle, Seeking diversity: methodology. In: P. Bickle, A. Whittle (Eds.), The First Farmers of Central Europe: Diversity in LBK lifeways. Oxford 2013, 29-41.

Hodson 1990

F. R. Hodson, Hallstatt: The Ramsauer Graves: Quantification and Analysis. Monographien des Römisch-Germanischen Zentralmuseums 16, Mainz 1990.

Holman, Wood, Campbell 2000

D. J. Holman, J. W. Wood, K. L. Campbell, Age-dependent decline of female fecundity is caused by early fetal loss. In: E. R. VELDE, F. Broekmans, P. Pearson (Eds.), Female Reproductive Ageing. Studies in Profertility 9, Carnforth 2000, 123-136.

HOWCROFT 2013

R. Howcroft, Weaned Upon A Time: Studies of the Infant Diet in Prehistory. Stockholm 2013.

Jackes, Roksandić, Meiklejohn 2008

M. Jackes, M. Roksandić, C. Meiklejohn, Demography of the Đerdap Mesolithic-Neolithic transition. In: C. Bonsall, V. BoRONEANT, I. Radovanović (Eds.), The Iron Gates in Prehistory: New Perspectives. Oxford 2008, 77-88.

JAY et al. 2008

M. Jay, B. T. Fuller, M. P. Richards, C. J. Knusel, S. S. King, Iron Age breastfeeding practices in Britain: isotopic evidence from Wetwang Slack, East Yorkshire, American Journal of Physical Anthropology 136/3, 2008, 327-37.

\section{JUDD 2008}

M. A. JuDD, The parry problem, Journal of Archaeological Science $35,2008,1658-66$

Kagerer, Grupe 2001

P. Kagerer, G. Grupe, Age-at-death diagnosis and determination of life-history parameters by incremental lines in human dental cementum as an identification aid, Forensic Science International 118/1, 2001, 75-82.

KELLEY 1979

M. A. Kelley, Parturition and Pelvic Changes, American Journal of Physical Anthropology 51, 1979, 541-546.
KIENLIN 2008

T. L. KiEnlin, Der „Fürst“ von Leubingen: Herausragende Bestattungen der Frühbronzezeit als Bezugspunkt gesellschaftlicher Kohärenz und kultureller Identität. In: C. KümmeL, B. SchweIZER, U. VEIT (Eds.), Körperinszenierung - Objektsammlung - Monumentalisierung: Totenritual und Grabkult in frühen Gesellschaften. Tübinger Archäologische Taschenbücher 6, Münster 2008, 181-206.

King, Humphrey, Hillson 2005

T. King, L. T. Humphrey, S. Hillson, Linear enamel hypoplasias as indicators of systemic physiological stress: evidence from two known age-at-death and sex populations from postmedieval London, American Journal of Physical Anthropology 128/3, 2005, 547-59.

KLINGNER 2016

S. Klingner, Ätiologie und Epidemiologie der Erkrankungen des Respirationstraktes im Frühneolithikum Mitteleuropas am Beispiel der linearbandkeramischen Population von Wandersleben. Unpublished PhD Dissertation, University of Leipzig 2016.

KNEISSEL et al. 1994

M. Kneissel, A. Boyde, M. Hahn, M. Teschler-Nicola, G. Kalchhauser, H. Plenk, Age- and sex-dependent cancellous bone changes in a 4000y BP population, Bone 15/5, 1994, 539-545.

KNOTHE, KÜNZIE 2009

D. Knothe, M. KünZIE, Stress markers in tooth cementum: methodical possibilities and problems, Bulletin der Schweizerischen Gesellschaft für Anthropologie 14/1-2, 2009, 37.

Kósa 1989

F. KósA, Age estimation from the fetal skeleton. In: M. Y. IşCAN (Ed.), Age Markers in the Human Skeleton. Springfield 1989, 21-54.

KREMER et al. 2008

C. Kremer, S. Racette, C.-A. Dionne, A. Sauvageau, Discrimination of falls and blows in blunt head trauma: systematic study of the hat brim line rule in relation to skull fractures, Journal of Forensic Sciences 53/3, 2008, 716-719.

Kremer, Sauvageau 2009

C. Kremer, A. Sauvageau, Discrimination of falls and blows in blunt head trauma: assessment of predictability through combined criteria, Journal of Forensic Sciences 54/4, 2009, 923-926.

LARSEN 1997

C. S. LARSEN, Bioarchaeology: Interpreting Behavior from the $\mathrm{Hu}$ man Skeleton. Cambridge 1997.

LAUERMANN 1991a

E. Lauermann (Ed.); Bronzezeit im Raum Stockerau. Stockerau 1991.

LAUERMANN 1991b

E. LAUERMANN, Frühbronzezeitliche Bestattungen im Bereich einer bronzezeitlichen Siedlung in Unterhautzenthal, Gem. Sierndorf, Niederösterreich, Archaeologia Austriaca 75, 1991, 63-78.

LAUERMANN 1992

E. Lauermann, Sonderbestattungen der frühen Bronzezeit, Praehistorische Zeitschrift 67/2, 1992, 183-200.

LAUERMANN 1993

E. LAUERmann, KG Unterhautzenthal, Fundberichte aus Österreich 31/1992, 1993, 430.

LAUERMANN 1995

E. Lauermann, Ein frühbronzezeitliches Gräberfeld aus Unterhautzenthal, NÖ. Stockerau 1995. 


\section{LAUERMANN 1996}

E. Lauermann, „Frage nach den Pfaden der Vorzeit...“ Archäologische Forschungsergebnisse aus der Großgemeinde Sierndorf, Bezirk Korneuburg. Stockerau 1996.

LAUERMANN 1997

E. Lauermann, Sonderbestattungen im Bereich einer frühbronzezeitlichen Siedlung in Unterhautzental, Niederösterreich. In: K.-F. RitTershofer (Ed.) Sonderbestattungen in der Bronzezeit im östlichen Mitteleuropa. Internationale Archäologie 37, Espelkamp 1997, 42-46.

LAUERMANN 2003

E. Lauermann, Studien zur Aunjetitz-Kultur im nördlichen Niederösterreich. Universitätsforschungen zur prähistorischen Archäologie 99, Bonn 2003.

Lauermann, Pucher, Schmitzberger 2001

E. Lauermann, E. Pucher, M. Schmitzberger, Unterhautzenthal und Michelberg: Beiträge zum Siedlungswesen der frühbronzezeitlichen Aunjetitz-Kultur im nördlichen Niederösterreich. Archäologische Forschungen in Niederösterreich 1, St. Pölten 2001.

LEE 1972

R. B. LEe, Population growth and the beginnings of sedentary life among the !Kung bushmen. In: B. SPooner (Ed.) Population Growth: Anthropological Implications. Cambridge, Mass. 1972, 329-342.

LEWIS 2004

M. E. LEWIs, Endocranial lesions in non-adult skeletons: understanding their aetiology, International Journal of Osteoarchaeology 14/2, 2004, 82-97.

LEWIS 2007

M. E. Lewis, The Bioarchaeology of Children: Perspectives from Biological and Forensic Anthropology. Cambridge 2007.

LOVEJOY et al. 1985a

C. O. Lovejoy, R. S. Meinde, R. P. Mensforth, T. J. Barton, Multifactorial determination of skeletal age at death: a method and blind tests of its accuracy, American Journal of Physical Anthropology 68/1, 1985, 1-14.

LOVEJOY et al. $1985 \mathrm{~b}$

C. O. Lovejoy, R. S. Meinde, T. R. Pryzbeck, R. P. Mensforth, Chronological metamorphosis of the auricular surface of the ilium: a new method for the determination of adult skeletal age at death, American Journal of Physical Anthropology 68/1, 1985, 15-28.

Löw 2010

C. Löw, Als die Kunst der weisen Frauen versagte: $\mathrm{Zu}$ den „Wöchnerinnen“-Bestattungen im Alten Brühl. In: J. ConRAD (Ed.) Wiege einer Stadt: Forschungen zur Martinskirche im Alten Brühl von Völklingen. Saarbrücken 2010, 211-222.

MaAss 2012

P. MAAss, The bony pelvis: scars of parturition and factors influencing their manifestation. Unpublished $\mathrm{PhD}$ thesis, University of Cape Town 2012.

MaAss, Friedling 2016

P. MaAss, L. J. Friedling, Scars of parturition? Influences beyond parity, International Journal of Osteoarchaeology 26/1, 2016, 121-131.

Martin, Harrod, PÉrez 2013

D. L. Martin, R. P. Harrod, V. R. Pérez (Eds.), Bioarchaeology: An Integrated Approach to Working with Human Remains. Manuals in Archaeological Method, Theory and Technique, New York 2013.
Martin, Saller 1957

R. Martin, K. Saller, Lehrbuch der Anthropologie in systematischer Darstellung. Stuttgart 1957.

MaYs 2014

S. MAYs, The palaeopathology of scurvy in Europe, International Journal of Paleopathology 5, 2014, 55-62.

MeindL, Lovejoy 1985

R. S. MeindL, C. O. Lovejoy, Ectocranial suture closure: a revised method for the determination of skeletal age at death based on the lateral-anterior sutures, American Journal of Physical Anthropology 68/1, 1985, 57-66.

Naji et al. 2016

S. Naji, T. Colard, J. Blondiaux, B. Bertrand, E. D'Incau, J.-P. Bocquet-Appel, Cementochronology, to cut or not to cut?, International Journal of Paleopathology, 2016, 113-119.

Neugebauer 1991

J.-W. Neugebauer, Die Nekropole F von Gemeinlebarn, Niederösterreich: Untersuchungen zu den Bestattungssitten und zum Grabraub in der ausgehenden Frühbronzezeit in Niederösterreich südlich der Donau zwischen Enns und Wienerwald. Römisch-Germanische Forschungen 49, Mainz 1991.

Neugebauer 1994

J.-W. Neugebauer, Bronzezeit in Ostösterreich. Wissenschaftliche Schriftenreihe Niederösterreich 98-101, Vienna - St. Pölten 1994.

Neugebauer, Neugebauer 1997

C. Neugebauer, J.-W. Neugebauer, Franzhausen: Das frühbronzezeitliche Gräberfeld I. Fundberichte aus Österreich, Materialhefte A5/1-2, Horn 1997.

Newell 1988

C. Newell, Methods and Models in Demography. London 1988.

OrtNer 2003

D. J. ORTner, Identification of Pathological Conditions in Human Skeletal Remains. San Diego 2003.

Özaltin, Hill, Subramanian 2010

E. Özaltin, K. Hill, S. V. Subramanian, Association of maternal stature with offspring mortality, underweight, and stunting in low- to middle-income countries, Journal of the American Medical Association 303/15, 2010, 1507-1516.

Pany-KuCERA 2015

D. PANY-KuCERA, “Warriors versus working men?" - An entheses and joint study on the early medieval skeletal remains of Thunau/ Kamp. Unpublished PhD Thesis, University of Vienna 2015.

Pany-Kucera, Spannagl-Steiner, Rebay-Salisbury 2017

D. Pany-Kucera, M. Spannagl-Steiner, K. Rebay-Salisbury, 'Parity features' and social status at prehistoric sites in Austria. Poster presented at the $44^{\text {th }}$ North American Meeting of the Paleopathology Association 15 $5^{\text {th }}-19^{\text {th }}$ April, 2017, New Orleans 2017.

Papageorgopoulou et al. 2011

C. Papageorgopoulou, S. K. Suter, F. J. Rühli, F. Siegmund, Harris lines revisited: prevalence, comorbidities, and possible etiologies, American Journal of Human Biology 23/3, 2011, 381-391.

Parker Pearson 1999

M. Parker Pearson, The Archaeology of Death and Burial. Stroud 1999.

Pellegrini et al. 2011

A. Pellegrini, M. Teschler-Nicola, F. Bookstein, P. MitterOECKER, Craniofacial morphology in Austrian Early Bronze Age populations reflects sex-specific migration patterns, Journal of Anthropological Sciences 89, 2011, 139-151. 
Perréard Lopreno, Bruzek 2010

G. Perréard Lopreno, J. Bruzek, A well evaluated preauricular groove on the coxal bone is a very reliable sexual trait but not an indicator of parity: test in the SIMON collection of identified skeletons (Switzerland), American Journal of Physical Anthropology 141, 2010, 188.

Proisy et al. 2014

M. Proisy, A. Rouil, H. Raoult, C. Rozel, P. Guggenbuhl, D. Jaсов, R. GuilLin, Imaging of musculoskeletal disorders related to pregnancy, American Journal of Roentgenology 202/4, 2014, $828-838$.

Putschar 1931

W. G. J. Putschar, Entwicklung. Wachstum und Pathologie der Beckenverbindungen des Menschen: Mit besonderer Berücksichtigung von Schwangerschaft, Geburt, und ihren Folgen. Jena 1931.

ReBAy 2006

K. C. Rebay, Das hallstattzeitliche Gräberfeld von Statzendorf, Niederösterreich. Universitätsforschungen zur prähistorischen Archäologie 135, Bonn 2006.

Rebay-SAlisbury 2017a

K. Rebay-SAlisbury, Breast is best - and are there alternatives? Feeding babies and young children in prehistoric Europe, Mitteilungen der Anthropologischen Gesellschaft in Wien 147, 2017, $13-29$.

Rebay-Salisbury 2017b

K. Rebay-Salisbury, Bronze Age beginnings: the conceptualisation of motherhood in prehistoric Europe. In: D. CoOper, C. PHELAN (Eds.), Motherhood in Antiquity. New York 2017, 169-196.

Rebay-Salisbury in press

K. Rebay-Salisbury, Personal relationships between co-buried individuals in the central European early Bronze Age. In: E. Murphy, G. Lillehammer (Eds.), Giving New Meaning to Cultural Heritage: The Old and the Young in Past Societies. Stavanger: in press.

Reid, Dean 2006

D. J. ReID, M. C. DeAn, Variation in modern human enamel formation times, Journal of Human Evolution 50, 2006, 329-346.

Reimer et al. 2013

P.J. Reimer, E. Bard, A. Bayliss, J. W. Beck, IntCal13 and Marine13 radiocarbon age calibration curves $0-50,000$ years cal BP, Radiocarbon 55/4, 2013, 1869-1887.

Reynard, Tuross 2015

L. M. Reynard, N. Tuross, The known, the unknown and the unknowable: weaning times from archaeological bones using nitrogen isotope ratios, Journal of Archaeological Science 53, 2015, 618-625.

Resnick, Niwayama 1995

D. Resnick, G. Niwayama, Metabolic diseases: osteoporosis. In: D. Resnick (Ed.), Diagnosis of Bone and Joint Disorders: With Emphasis on Articular Abnormalities, Vol. 4. Philadelphia 1995, 1781-1923.

RetTenbacher 2004

M. Rettenbacher, Die Siedlung und die Gräberfelder von Schleinbach: Eine Studie zur Aunjetitz-Kultur im südlichen Weinviertel. Archäologische Forschungen in Niederösterreich 2, St. Pölten 2004.

ROBERTS, MANCHESTER 2005

C. Roberts, K. Manchester, The Archaeology of Disease. Stroud 2005.

RuCKDESCHEL 1978

W. Ruckdeschel, Die frühbronzezeitlichen Gräber Südbayerns. Antiquitas 11, Bonn 1978.
RufF et al. 2012

C. B. Ruff, B. M. Holt, M. Niskanen, V. Sladék, M. Berner, E. Garofalo, H. M. Garvin, M. Hora, H. Maijanen, S. Niinimäki, K. SAlo, E. Schuplerová, D. Tompkins, Stature and body mass estimation from skeletal remains in the European Holocene, American Journal of Physical Anthropology 148/4, 2012, 601-617.

SCHAMALl 2008

D. Schamall, Qualitative und quantitative Differentialdiagnose von Individuen mit und ohne Mineralisationsstörungen am Beispiel spätantiker, neuzeitlicher und rezenter menschlicher Skelettreste - unter Verwendung des radiologischen, histologischen und histomorphometrischen Analysespektrums. Unpublished $\mathrm{PhD}$ Dissertation, University of Vienna 2008.

Scheuer, Black, Christie 2004

L. Scheuer, S. Black, A. Christie, The Juvenile Skeleton. London 2004.

SCHULTZ 1988

M. Schultz, Paläopathologische Diagnostik. In: R. Knussmann (Ed.), Anthropologie: Handbuch der vergleichenden Biologie des Menschen, Vol. 1/1. Stuttgart 1988, 480-496.

Schultz 1993

M. Schultz, Spuren unspezifischer Entzündungen an prähistorischen und historischen Schädeln: Ein Beitrag zur Paläopathologie. Anthropologische Beiträge 4A-B, Aesch 1993.

SCOTt, Halcrow 2017

R. M. Sсотт, S. E. Halcrow, Investigating weaning using dental microwear analysis: a review, Journal of Archaeological Science: Reports 11, 2017, 1-11.

Shibata, Shirai, Miyamoto 2002

Y. Shibata, Y. Shirai, M. Miyamoto, The aging process in the sacroiliac joint: helical computed tomography analysis, Journal of Orthopaedic Science 7/1, 2002, 12-18.

SJøVOLD 1990

T. SJøvold, Estimation of stature from long bones utilizing the line of organic correlation, Human Evolution 5/5, 1990, 431-447.

SLÁDEK et al. 2015

V. Sládek, J. Macháček, C. B. Ruff, E. Schuplerová, R. PřichySTAlová, M. Hora, Population-specific stature estimation from long bones in the early medieval Pohansko (Czech Republic), American Journal of Physical Anthropology 158/2, 2015, 312324.

SNOdgrass, Galloway 2003

J. J. Snodgrass, A. Galloway, Utility of dorsal pits and pubic tubercle height in Parity Assessment, Journal of Forensic Science 48/6, 2003, 1226-1230.

SPANNAGL-STEINER et al. 2016

U. M. Spannagl-Steiner, F. Novotny, D. Pany-Kucera, K. Rebay-Salisbury, M. Teschler-Nicola, Accidental versus intentional head injuries: a comparative pilot-study of cranial depressed fractures. Poster presented at the $21^{\text {st }}$ European Meeting of the Paleopathology Association, $15^{\text {th }}-19^{\text {th }}$ August, 2016, Research Institute and Museum of Anthropology, Moscow 2016.

SPRENGER 1999

S. SPREnger, Zur Bedeutung des Grabraubes für sozioarchäologische Gräberfeldanalysen: Eine Untersuchung am frühbronzezeitlichen Gräberfeld Franzhausen I, Niederösterreich. Fundberichte aus Österreich, Materialheft A7 Vienna 1999.

STECKel et al. 2006

R. H. Steckel, P. W. Sciulli, C. S. Larsen, P. L. Walker, The Global History of Health: Data Collection Codebook. Ohio 2006. 
STEWART 1970

T. D. STEWART, Identification of the scars of parturition in the skeletal remains of females. In: T. D. STEWART (Ed.), Personal Identification in Mass Disasters. Washington 1970, 127-135.

Stlounkal, Hanáková 1978

M. STlounkal, H. HanÁková, Die Länge der Längsknochen altslawischer Bevölkerungen unter besonderer Berücksichtigung von Wachstumsfragen, Homo 29, 1978, 53-69.

STOCKHAMmer et al. 2015

P. W. Stockhammer, K. Massy, C. Knipper, R. Friedrich, B. Kromer, S. Lindauer, J. Radosavljević, F. Wittenborn, J. Krause, Rewriting the central European Early Bronze Age chronology: evidence from large-scale radiocarbon dating, PLoS ONE 10/10, 2015, e0139705. doi: 10.1371/journal.pone.0139705

Strott, Grupe 2003

N. Strott, G. Grupe, Strukturauffälligkeiten des Zahnzements von Bestattungen des ersten katholischen Friedhofs in Berlin (St. Hedwigs-Friedhof, Berlin-Mitte, 1777-1834), Anthropologischer Anzeiger 61/2, 2003, 203-213.

STUCHLí́ 1990

S. STUснці́к, Die sekundären Eingriffe in den Gräbern der Úněticer Kultur, Anthropologie 28/2-3, 1990, 159-167.

SZILVÁssY 1978

J. SzILVÁssy, Eine Methode zur Altersbestimmung mit Hilfe der sternalen Gelenksflächen der Schlüsselbeine, Mitteilungen der Anthropologischen Gesellschaft in Wien 108, 1978, 166-168.

SZILVÁsSY 1988

J. Szilvássy, Altersdiagnose am Skelett. In: R. Knussmann (Ed.), Anthropologie: Handbuch der vergleichenden Biologie des Menschen, Vol. 1/1: Wesen und Methoden der Anthropologie, Stuttgart 1988, 421-443.

TAgue 2000

R. G. TAGUE, Do big females have big pelves?, American Journal of Physical Anthropology 112/3, 2000, 377-393.

Teschler-Nicola 1989

M. Teschler-Nicola, Soziale und biologische Differenzierung in der fühen Bronzezeit am Beispiel des Gräberfeldes F von Gemeinlebarn, Niederösterreich, Annalen des Naturhistorischen Museums Wien 90 A, 1989, 134-145.

Teschler-Nicola 1992

M. Teschler-Nicola, Untersuchungen zur Bevölkerungsbiologie der Bronzezeit in Ostösterreich: Phänetische Analyse kontinuierlicher und nichtkontinuierlicher Skelettmerkmale. Thesis of Habilitation, University of Vienna 1992.

Teschler-Nicola 1994

M. Teschler-Nicola, Bevölkerungsbiologische Aspekte der frühen und mittleren Bronzezeit. In: J.-W. Neugebauer (Ed.), Bronzezeit in Ostösterreich. Wissenschaftliche Schriftenreihe Niederösterreich 98-101, St. Pölten - Vienna 1994, 167-183.

Teschler-Nicola, Berner 1991

M. Teschler-Nicola, M. Berner, Anthropologischer Befund der frühbronzezeitlichen Skelettreste aus Unterhautzenthal, Niederösterreich. In: E. LAUERMAnN (Ed.) Die Bronzezeit im Raum Stockerau. Stockerau 1991, 44-56.

Teschler-Nicola, Winter 2013

M. Teschler-Nicola, E. Winter, Bedeutungsvolle Steine: Beispiele aus der Körpersteinkollektion der Pathologisch-anatomischen Sammlung im „Narrenturm“ - Naturhistorisches Museum Wien (PASiN - NHM), Archäologie Österreichs 24/1, 2013, 43-48.
Thompson 2013

M. E. Thompson, Comparative reproductive energetics of human and nonhuman primates, Annual Review of Anthropology 42/1, 2013, 287-304.

ToDD 1920

T. W. TodD, Age changes in the pubic bone: I. The male white pubis, American Journal of Physical Anthropology 3/3, 1920, 285-334.

Tsutaya, YonedA 2013

T. TsuTAYA, M. YonEDA, Quantitative reconstruction of weaning ages in archaeological human populations using bone collagen nitrogen isotope ratios and approximate Bayesian computation, PLoS ONE 8/8, 2013, e72327. doi: 10.1371/journal.pone.0072327

UBELAKER 1978

D. H. Ubelaker, Human Skeletal Remains: Excavation, Analysis, Interpretation. Chicago 1978.

Ubelaker, De la Paz 2012

D. H. Ubelaker, J. S. De La Paz, Skeletal indicators of pregnancy and parturition: a historical review, Journal of Forensic Science 57/4, 2012, 866-872.

ULLRICH 1975

H. UllRICH, Estimation of fertility by means of pregnancy and childbirth alterations at the pubis, the ilium and the sacrum, Ossa 2, 1975, 23-39.

WALDRON 2009

T. WALDron, Palaeopathology. Cambridge Manuals in Archaeology, Cambridge 2009.

WALKer et al. 2009

P. L. Walker, R. R. Bathurst, R. Richman, T. GJerdrum, V. A. Andrushro, The causes of porotic hyperostosis and cribra orbitalia: a reappraisal of the iron-deficiency-anemia hypothesis, American Journal of Physical Anthropology 139/2, 2009, 109-125.

WEWERKA 1982

B. WeWERKA, Ein frühbronzezeitliches Gräberfeld aus Zwingendorf, Niederösterreich, Archaeologia Austriaca 66, 1982, 21-47.

White, Black, FolKens 2012

T. D. White, M. T. Black, P. A. Folkens, Human Osteology. Amsterdam 2012.

Williams 1995

P. L. Williams, Pelvic Mechanism. In: H. Gray, P. L. Williams, L. H. Bannister (Eds.), Gray's Anatomy: The Anatomical Basis of Medicine and Surgery. New York 1995, 678.

WitTwer-Backofen, Gampe, Vaupel 2004

U. Wittwer-Backofen, J. Gampe, J. W. Vaupel, Tooth cementum annulation for age estimation: results from a large known-age validation study, American Journal of Physical Anthropology $123 / 2,2004,119-129$.

WOLFF-HeIDEGGER 1954

G. Wolff-Heidegger, Atlas der systematischen Anatomie des Menschen, Vol. 1, Basel - New York 1954.

WOOD 1992

S. R. Wood, Tooth Wear and the Sexual Division of Labour in an Inuit Population. MA Thesis, Simon Fraser University 1992.

WURDINGER et al. 2002

S. Wurdinger, K. Humbsch, J. R. Reichenbach, G. Peiker, H. J. SEEwALD, W. A. KaISER, MRI of the pelvic ring joints postpartum: normal and pathological findings, Journal of Magnetic Resonance Imaging 15/3, 2002, 324-329. 
Katharina Rebay-Salisbury

Institute for Oriental and European Archaeology Austrian Academy of Sciences Hollandstraße 11-13 1020 Vienna Austria katharina.rebay-salisbury@oeaw.ac.at (D) orcid.org/0000-0003-0126-8693

Doris Pany-Kucera Institute for Oriental and European Archaeology Austrian Academy of Sciences Hollandstraße 11-13 1020 Vienna Austria doris.pany-kucera@oeaw.ac.at (iD) orcid.org/0000-0003-4140-3220

Michaela Spannagl-Steiner Institute for Oriental and European Archaeology Austrian Academy of Sciences Hollandstraße 11-13 1020 Vienna Austria michaela.spannagl@oeaw.ac.at iD orcid.org/0000-0002-6927-8284

Fabian Kanz Unit of Forensic Anthropology Medical University of Vienna Center for Forensic Medicine Sensengasse 2 1090 Vienna Austria fabian.kanz@meduniwien.ac.at D orcid.org/0000-0001-6720-6781
Patrik Galeta

Department of Anthropology University of West Bohemia in Pilsen Sedláčkova 15 30125 Plzeñ Czech Republic galeta@ksa.zcu.cz orcid.org/0000-0002-4937-1369

Maria Teschler-Nicola Department of Antbropology Natural History Museum Vienna Burgring 7 1010 Vienna Austria maria.teschler-nicola@nhm-wien.ac.at (D) orcid.org/0000-0003-3080-3085

Roderick B. Salisbury Institute for Oriental and European Archaeology Austrian Academy of Sciences Hollandstraße 11-13 1020 Vienna Austria roderick.salisbury@oeaw.ac.at iD orcid.org/0000-0003-3773-5337 